\title{
The Kenya rift revisited: insights into lithospheric strength through data-driven 3-D gravity and thermal modelling
}

\author{
Judith Sippel $^{1}$, Christian Meeßen ${ }^{1,2}$, Mauro Cacace ${ }^{1}$, James Mechie $^{1}$, Stewart Fishwick ${ }^{3}$, Christian Heine ${ }^{4}$, \\ Magdalena Scheck-Wenderoth ${ }^{1}$, and Manfred R. Strecker ${ }^{2}$ \\ ${ }^{1}$ GFZ German Research Centre for Geosciences, Sections $6.1 \& 2.2$, Telegrafenberg, 14473 Potsdam, Germany \\ ${ }^{2}$ Institute of Earth and Environmental Science, University of Potsdam, 14476 Potsdam, Germany \\ ${ }^{3}$ Department of Geology, University of Leicester, Leicester, LE1 7RH, UK \\ ${ }^{4}$ New Ventures, Upstream International, Shell International Exploration \& Production B.V., 2596 HR, The Hague, \\ the Netherlands
}

Correspondence to: Judith Sippel (sippel@gfz-potsdam.de)

Received: 27 September 2016 - Published in Solid Earth Discuss.: 4 October 2016

Revised: 14 December 2016 - Accepted: 15 December 2016 - Published: 16 January 2017

\begin{abstract}
We present three-dimensional (3-D) models that describe the present-day thermal and rheological state of the lithosphere of the greater Kenya rift region aiming at a better understanding of the rift evolution, with a particular focus on plume-lithosphere interactions. The key methodology applied is the 3-D integration of diverse geological and geophysical observations using gravity modelling. Accordingly, the resulting lithospheric-scale 3-D density model is consistent with (i) reviewed descriptions of lithological variations in the sedimentary and volcanic cover, (ii) known trends in crust and mantle seismic velocities as revealed by seismic and seismological data and (iii) the observed gravity field. This data-based model is the first to image a 3D density configuration of the crystalline crust for the entire region of Kenya and northern Tanzania. An upper and a basal crustal layer are differentiated, each composed of several domains of different average densities. We interpret these domains to trace back to the Precambrian terrane amalgamation associated with the East African Orogeny and to magmatic processes during Mesozoic and Cenozoic rifting phases. In combination with seismic velocities, the densities of these crustal domains indicate compositional differences. The derived lithological trends have been used to parameterise steady-state thermal and rheological models. These models indicate that crustal and mantle temperatures decrease from the Kenya rift in the west to eastern Kenya, while the integrated strength of the lithosphere increases. Thereby, the detailed strength configuration appears strongly
\end{abstract}

controlled by the complex inherited crustal structure, which may have been decisive for the onset, localisation and propagation of rifting.

\section{Introduction}

Continental rifting involves lithospheric stresses imparted by thermally driven mantle upwelling (as featured by the active rift model) or far-field stresses generated by plate-boundary forces (as highlighted by the passive rift model; e.g. Turcotte and Emerman, 1983). Beside these extrinsic factors, localised stretching of lithospheric plates is controlled by the rheology of rocks and thus by intrinsic factors such as the composition as well as the pressure and temperature configuration of the lithosphere (as demonstrated by forward numerical experiments, e.g. Watts and Burov, 2003; Huismans et al., 2005). Hence, to improve our understanding of how deformation localises in continental rifts, site-specific lithological heterogeneities have to be taken into account. To assess the compositional configuration of rifted lithosphere is challenging given that the continental crust is generally the product of a complex structural, magmatic and metamorphic history, leading to pronounced anisotropies prone to guide extensional deformation processes. This is an important problem in the East African Rift System (EARS; Fig. 1a) and particularly the Kenya rift, because this region has a long history of continental collision, subsequent orogeny-parallel 


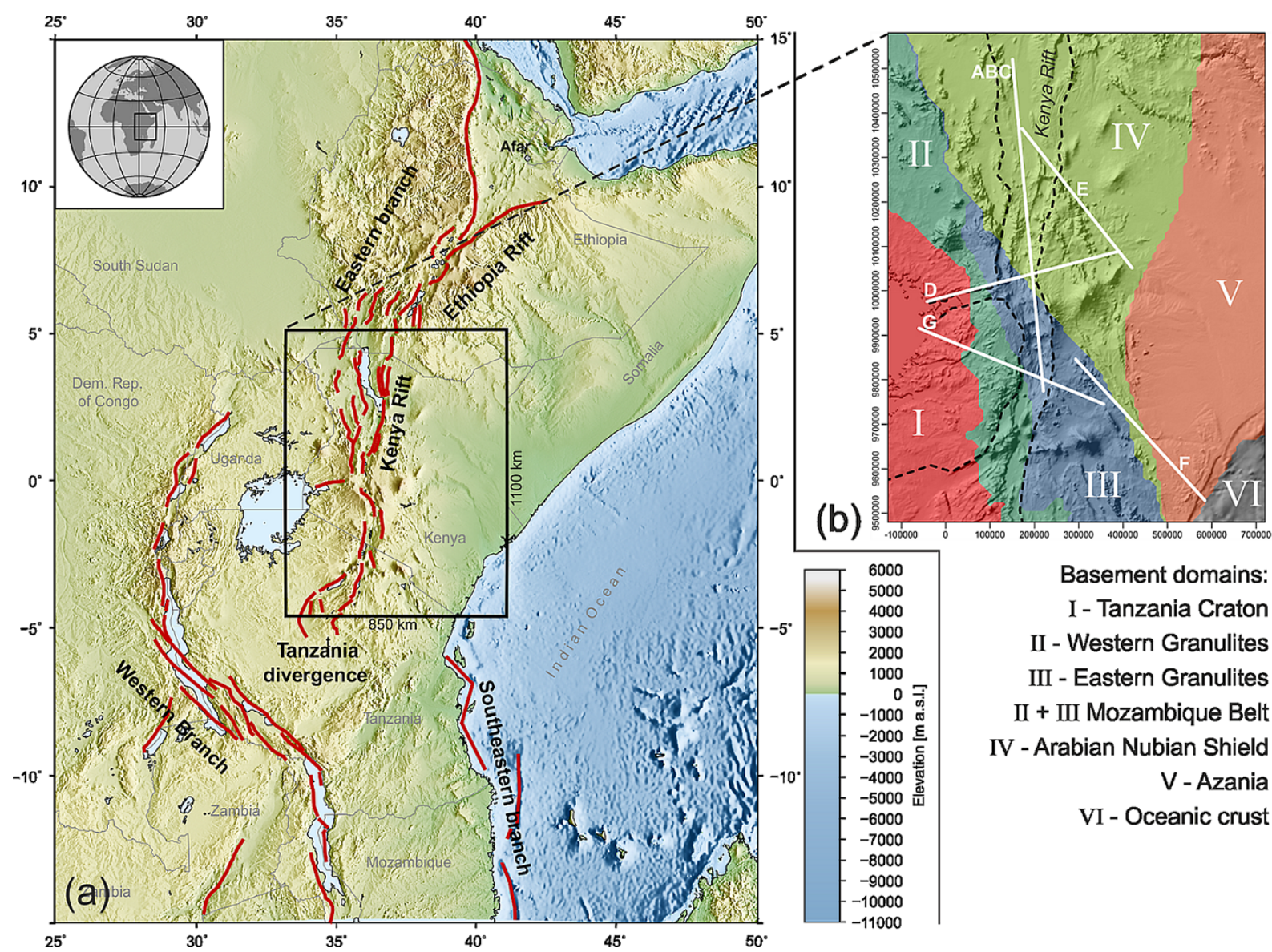

Figure 1. (a) Topography and bathymetry of the East African Rift System (EARS; from ETOPO1; Amante and Eakins, 2009); major faults of rift branches are from Chorowicz (2005); black frame marks the modelled study area. (b) Precambrian basement domains modified from Fritz et al. (2013); note that over wide parts of the region, these proposed basement domains are covered by Mesozoic-Cenozoic sediments and volcanics so that their spatial distributions are locally subjected to interpolation uncertainties; solid white lines represent the KRISP refraction seismic profiles (Khan et al., 1999); distribution of oceanic crust derived from Müller et al. (2008); surface expressions of the Kenya and Nyanza rifts (dashed lines) have been derived from Beicip (1987) and Milesi et al. (2010).

shearing and extensional faulting prior to the formation of the Cenozoic Kenya rift (Burke, 1996). The key to a holistic lithological and physical description of the lithosphere lies in the three-dimensional (3-D) integration of different geological and geophysical observations. Here, we present data and lithology-driven numerical 3-D models describing the present-day thermal and rheological state of the lithosphere for the greater Kenya rift region (Fig. 1a) to uncover major strength anomalies that are prone to localise deformation.

The Kenya rift is regarded as the classical example of an active rift, whose initiation and protracted evolution have been fundamentally controlled by mantle dynamics until the present-day. A continental-scale plate kinematic model (i.e. Stamps et al., 2008) reveals that East Africa is dominated by extensional processes that control the separation of the Somalia and Nubia plates with an approximate rate of $4.7 \mathrm{~mm} \mathrm{yr}^{-1}$ determined for the Ethiopia-Kenya border area. Seismological studies in East Africa have imaged an upper- mantle low-velocity zone below the EARS that is commonly interpreted as a high-temperature anomaly (e.g. Mulibo and Nyblade, 2013), inferred to be connected to the lower-mantle sectors of the southern African superplume (e.g. Bagley and Nyblade, 2013). During the past 35-45 Ma, the African tectonic plate has been moving northward relative to the East African plume as underscored by the volcanic and topographic evolution of the EARS (e.g. Ebinger and Sleep, 1998; Moucha and Forte, 2011; Wichura et al., 2015). Subsequent to regional doming, but possibly also during updoming, extensional tectonics and volcanism have affected the region from the Turkana area in northern Kenya to the Tanzania divergence (Fig. 1a; e.g. Morley, 1999).

There is consensus that crustal extension and magmatism in the Kenya rift are related to plume-lithosphere interactions (e.g. Mechie et al., 1997). Halldórsson et al. (2014) suggested that regionally overlapping amagmatic and magmatic sectors of rift initiation in East Africa follow the asym- 
metric impingement of a single mantle plume at the base of the lithosphere in the transition between the Tanzania Craton (Fig. 1b) and areas to the east. Koptev et al. (2015) presented a thermo-mechanical numerical model that simulates how (under tensional far-field stress) the proposed mantle plume is deflected by the lithospheric keel of the Tanzania Craton to cause the initiation of a rift system east of it. In this rheologically consistent model, strain localisation is due to lithospheric thinning and channelised flow of the plume material. Furthermore, many authors (e.g. McConnell, 1972; Smith and Mosley, 1993; Tesha et al., 1997) have put forward structural and compositional differences between different Precambrian basement domains, mainly the Tanzania Craton and the weaker Mozambique Belt (Holmes, 1951), as controlling factors for the localisation of the Cenozoic Kenya rift. However, detailed regional-scale assessments on the interaction between mantle dynamics and the overlying compositionally heterogeneous lithosphere in order to explain rift localisation and the mechanical predisposition of fault propagation have not been attempted yet for the region. To improve our understanding of where and how the observed extensional deformation patterns have evolved, we develop a lithospheric-scale 3-D structural model covering the larger Kenya rift region (Fig. 1a; black rectangle) and providing the basis for modelling the rheological configuration of the lithosphere as a key to decipher its Cenozoic tectonic evolution.

In general, predictions on the strength of the lithosphere require knowledge about its compositional and thermal configuration (e.g. Goetze and Evans, 1979; Burov, 2011). For the study area, it is particularly challenging to assess how the complex Precambrian basement geology continues into the deeper crust. The results of the Kenya Rift International Seismic Project (KRISP; 1985-1994) provide important constraints on the nature of the crust along five regional sections extending along and across the rift (Fig. 1b). We have integrated the processed and interpreted KRISP refraction seismic profiles (Khan et al., 1999) with various other geological and geophysical observations (from sedimentary fills, crustal and mantle characteristics) to perform 3-D gravity modelling and develop a lithospheric-scale 3-D density model. In this 3-D data integration process, $P$ and $S$ wave velocity models of the mantle (e.g. Achauer and Masson, 2002) play an important role, especially as mantle anomalies significantly affect the regional gravity field (e.g. Achauer, 1992; Ravat et al., 1999; Mariita and Keller, 2007). The spatially continuous gravity signal facilitates a 3-D investigation of the crust and thus guides extrapolations of crustal properties beyond the KRISP profiles. Finally, we have derived lithological variations within the crust and discussed them with respect to their potential origin.

The interdisciplinary integration of data thus allows us to assign thermal and rheological properties to lithological model units to assess the present-day thermal and yieldstrength configuration of the lithosphere in a forward modelling manner. The resulting 3-D rheological models ulti- mately reflect the interplay between the observed mantle thermal anomaly and compositionally different crustal domains. The models allow for a straightforward spatial correlation between modelled strength heterogeneities and regional deformation structures of the rift, seismicity patterns and major locations of volcanic activity, which we briefly discuss in terms of causal relationships. To improve upon these aspects, future studies are planned, which will integrate the presented 3-D models into numerical forward geodynamics experiments in order to test hypotheses on the entire Cenozoic deformation history of the study area. In any case, the model as it now stands already shows how far a compositionally heterogeneous crust has controlled lithospheric deformation and thus rift localisation and propagation processes.

\section{Geological setting}

The formation of the continental crust in East Africa dates back to the Neoproterozoic when the East African Orogeny (at $\approx 650-620 \mathrm{Ma}$ ) led to the amalgamation of numerous terranes to form central Gondwana (e.g. Fritz et al., 2013). This orogeny resulted from collisions of the Arabian-Nubian Shield and its southward continuation, the Mozambique Belt (Holmes, 1951), with the Tanzania (Nyanzian) Craton to the west and the Azania microcontinent to the east. According to Fritz et al. (2013), five major tectono-thermal domains of different Precambrian ages and lithologies are juxtaposed against each other in the study area (Fig. 1b). From west (W) to east (E), these are (i) the Nyanzian System (Clifford, 1970) of the Archean Tanzania Craton, (ii) the Western Granulites representing reworked pre-Neoproterozoic crust of the Mozambique Belt (Maboko, 1995; Möller et al., 1998), (iii) the Eastern Granulites representing Neoproterozoic juvenile crust of the Mozambique Belt (Möller et al., 1998; Maboko and Nakamura, 2002; Tenczer et al., 2006), (iv) the Neoproterozoic Arabian-Nubian Shield and (v) the microcontinent Azania representing reworked pre-Neoproterozoic crust (Fritz et al., 2013). Near-surface observations indicate that rocks of the Mozambique Belt and the Arabian-Nubian Shield structurally overlie both the craton in the west and the microcontinent in the east (Fritz et al., 2013).

The top of the crystalline basement in the study area (Fig. 2a) is overlain by sedimentary and volcanic rocks of Permo-Carboniferous to Holocene ages (Beicip, 1987), while its geometry reflects different phases of sedimentary basin formation and localised subsidence. For instance, the Mandera and Lamu basins in eastern Kenya (Fig. 2a) are regarded as the north-easternmost extension of the Karoo rift system, the initiation of which was related to the Late Carboniferous-Early Permian assembly and subsequent breakup of Pangea (Catuneanu et al., 2005). After an early phase of eastward rifting of Madagascar (and India) away from the conjugate block of Kenya and northern Tanzania (e.g. Reeves et al., 2002), from $\approx 185-180$ Ma Madagascar 

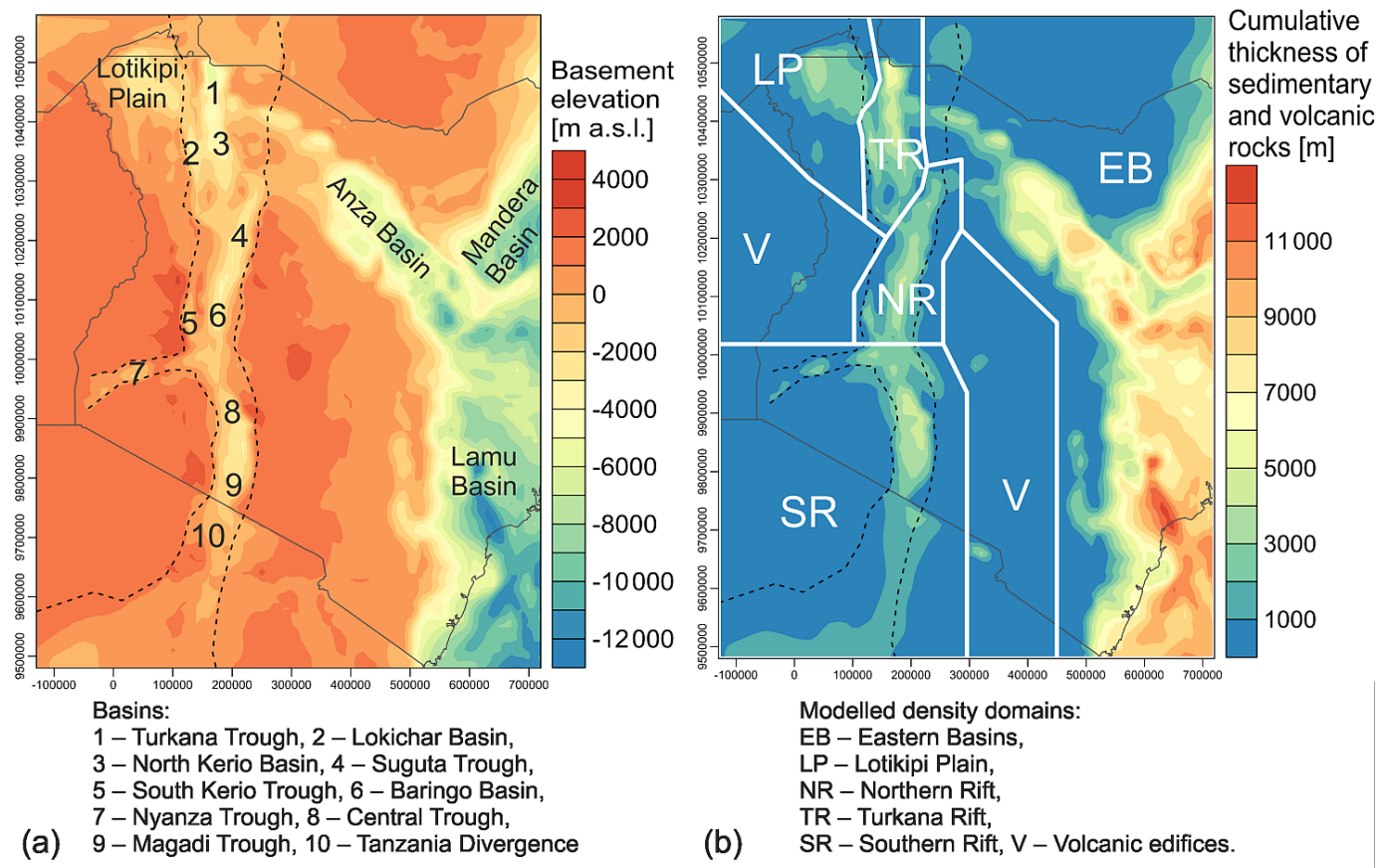

Figure 2. Structure of the sedimentary and volcanic basin infill; all interpolations in this study have been performed using the convergent interpolation algorithm implemented in Petrel (Schlumberger ${ }^{\odot}$ ) and the coordinates are in UTM Zone $37 \mathrm{~S}$; (a) elevation of the base of the sedimentary and volcanic rocks (i.e. top of the Precambrian basement) constructed by combining data from Kenya (Beicip, 1987) with a global sediment thickness map (Exxon, 1985; USGS, 2012; for details see main text); (b) cumulative thickness of sedimentary and volcanic rocks as derived from (a) and from the topography (ETOPO1, Amante and Eakins, 2009; Fig. 1).

moved southwards (e.g. Cox, 1992) leading to the formation of oceanic crust in the Indian Ocean (at < 166-152 Ma; Seton et al., 2012) and transforming the Lamu Basin area into a passive margin setting.

Farther west, the oldest structural elements of the northwest-south-east (NW-SE)-oriented Anza Basin (Fig. 2a; Bosworth and Morley, 1994) and the N-S-oriented Lotikipi Plain, Turkana, Lokichar and North Kerio basins (e.g. Morley, 1999) began forming during the Cretaceous and continued subsiding into the Cenozoic (Foster and Gleadow, 1996; Morley, 1999; Tiercelin et al., 2012). The Anza Basin has been regarded as part of the E-W-striking central African rift system (Guiraud et al., 2005; Heine et al., 2013), which formed under the influence of (i) the northeastward movement of the Arabian-Nubian block, (ii) ongoing seafloor spreading between Madagascar and East Africa (which ceased at around $120 \mathrm{Ma}$; Seton et al., 2012) and (iii) the opening of the South Atlantic (since $132 \mathrm{Ma}$ ).

During the past 35-45 Ma, East Africa was moving northward relative to the East African plume (e.g. Ebinger and Sleep, 1998; Wichura et al., 2015), which resulted in regional doming, extensional tectonics and volcanism from the Turkana divergence in northern Kenya to the north Tanzania divergence (Fig. 2a; e.g. Morley, 1999). In the northern Kenya rift, the earliest extension began during the Paleocene-Eocene (Morley et al., 1992; Ebinger and
Scholz, 2012). New thermo-chronological data from the Elgeyo Escarpment in Kenya's central rift segment also reveal Paleocene-Eocene rift initiation, subsequent subsidence and heating, which was followed by renewed cooling and formation of major rift-bounding faults after $15 \mathrm{Ma}$ (Torres Acosta et al., 2015). Along the Nguruman Escarpment of the southern Kenya rift, extensional faulting is shown to have started at approximately $7 \mathrm{Ma}$ (Crossley, 1979). In contrast, farther south within the Tanzania divergence, thermo-chronological data suggest that extensional faulting and cooling began during the Cretaceous and continued into the Paleocene-Eocene (Noble et al., 1997; Mbede, 2001).

Rifting is generally thought to have followed shortly after volcanism started in the different rift segments (e.g. Morley et al., 1992). The oldest volcanics in northernmost Kenya are as old as $\approx 39-45 \mathrm{Ma}$ (e.g. Ebinger et al., 2000), while volcanism reached the intersection between the northern/central Kenya rift and the Nyanza rift (Fig. $2 \mathrm{a}$ ) at $\approx 20 \mathrm{Ma}$ (Pickford, 1982; Fitch et al., 1985) and the oldest volcanics in the southern Kenya rift are between 20 and $16 \mathrm{Ma}$ (Baker et al., 1972; Chapman et al., 1978; Smith, 1994; Hay et al., 1995). A recent synopsis on the onset of volcanic activity in East Africa by Michon (2015) suggests that earlier interpretations of a N-S migration of volcanism and tectonic activity (Nyblade and Brazier, 2002) may not apply to the Kenya rift and that these processes were rather highly disparate in space and 
time in the EARS, as also suggested previously by Zeyen et al. (1997).

To summarise, western Kenya has strongly been affected by Cenozoic mantle dynamics as is evident from the high topography (as a result of doming; Fig. 1a) and the narrow basement lows (graben structures; Fig. 2a). In contrast, eastern Kenya shows low topographies (Fig. 1a) and considerably broader and deeper basins (Fig. 2a) that largely trace back to Mesozoic times. For western Kenya, the KRISP seismic experiments provide distributed information on deep crustal structures, while for eastern Kenya such information is confined to the south-easternmost parts of the proposed microcontinent Azania (Fig. 1b).

\section{Modelling approach: 3-D data integration and gravity modelling}

The key methodology of this study is 3-D gravity modelling. This involves determining a 3-D density configuration of the subsurface, for which the calculated gravity response reproduces the observed gravity field. As the potential field modelling techniques are inherently non-unique, our goal has been to minimise the number of free parameters in advance. We have followed a strategy to (1) take into account various geological and geophysical data to constrain a starting density model with defined interfaces and densities for the sedimentary and volcanic cover, the crystalline crust and the mantle, and (2) modify the density configuration of the crust within the data constraints to fit the observed gravity. We have used the 3-D potential field modelling software IGMAS+ (Transinsight $\mathrm{GmbH}^{\odot}$ ), which allows for interactively changing 3-D density configurations while simultaneously maintaining visual control over the calculated gravity response (Schmidt et al., 2011).

\subsection{Constraints on the density configuration of the sedimentary and volcanic rocks}

Information on the depth of the base of sedimentary and volcanic rocks is combined from two sources in the study area: within the political boundaries of Kenya and offshore; the Geological Map of Kenya provides contour lines for the depth to the crystalline basement (spaced at $1 \mathrm{~km}$ depth intervals; Beicip, 1987). For the modelled areas outside of Kenya, basement depth constraints have been derived from a global map of total sediment thickness. This sediment thickness estimate is based on isopachs derived from the Exxon Tectonic Map of the World (Exxon, 1985). For the global model, the digitised isopachs were gridded using a spherical splines-intension algorithm (Wessel et al., 2013) onto a 6 arcmin raster, taking into account outcropping basement rocks as determined by the USGS World Energy Project regional geological map data (USGS, 2012). The scattered data from inside and outside Kenya have been jointly interpolated to obtain a continuous regular grid (of originally $5 \mathrm{~km} \times 5 \mathrm{~km}$ horizontal resolution) of basement depths covering the entire study area (Fig. 2a).

The difference in elevation between the topography/bathymetry (Fig. 1a) and the base of the sedimentary and volcanic rocks (Fig. 2a) defines the thickness of the rift-basin fill (Fig. 2b). The largest cumulative thicknesses of locally $>10 \mathrm{~km}$ are found in the Mandera, Lamu and Anza basins in eastern Kenya, whereas in the Kenya rift, deposits may locally attain thicknesses of up to $8 \mathrm{~km}$ (Mugisha et al., 1997; Hautot et al., 2000).

In general, the density of sedimentary and volcanic rocks depends on their mineralogical composition and porosity, the latter in turn being related to the local degree of compaction. According to differences in the prevailing lithological compositions as described in numerous studies (Table 1; Appendix A), we have subdivided the sedimentary and volcanic cover of the study area into seven domains of distinct density configurations (Fig. 2b; Table 2). The Mandera, Lamu and Anza basins, for example, have been grouped into the eastern basins domain. Some of these domains are additionally separated into vertical sequences of sub-units with different densities, thus reflecting further lithological and/or porosity variations (Table 2; Appendix A).

\subsection{Constraints on the density configuration of the crystalline crust}

\subsubsection{Geological constraints}

Table 3 provides an overview of the lithological variation across the five Precambrian tectono-thermal domains (Fig. 1b; Fritz et al., 2013). The Nyanzian System of the Archean Tanzania Craton is a typical low-grade metamorphic greenstone belt assembly of metamorphosed volcanics, sediments and granites (e.g. Clifford, 1970). Since the Western Granulites mainly consist of low-grade metamorphic rocks of sedimentary and magmatic origin (Mosley, 1993), the name "granulites" is misleading although widely established (Fritz et al., 2005, 2013; Cutten et al., 2006). The Eastern Granulites largely consist of a basal unit of metaigneous rocks (Tenczer et al., 2006) and an upper unit of meta-sedimentary sequences (Fritz et al., 2005, 2009). According to Mosley (1993), the lithostratigraphic groups of the Eastern Granulites and the Arabian-Nubian Shield are very similar. The metamorphic volcano-sedimentary sequences of the Arabian-Nubian Shield, however, largely belong to several arc-magmatic terranes and include numerous ophiolites (Fritz et al., 2013).

Due to the thick cover of Mesozoic sedimentary rocks in the eastern parts of the study area (Fig. 2b), the crustal composition of Azania has largely been inferred from other parts of this microcontinent, exposed in Madagascar (e.g. Randriamamonjy, 2006) and Somalia. Accordingly, the crust of Azania mainly consists of orthogneisses (Collins and Pis- 
Table 1. Devised lithological domains for modelling the sedimentary and volcanic infill of the basins.

\begin{tabular}{|c|c|c|c|}
\hline & Domains and subdomains & Prevailing lithologies & Key references \\
\hline $\mathrm{V}$ & $\begin{array}{l}\text { Mt. Elgon volcano } \\
\text { Mt. Kenya volcano } \\
\text { Kilimanjaro volcano }\end{array}$ & $\begin{array}{l}\text { Melanephelinites, carbonatites } \\
\text { Phonolites, trachytes, basalts } \\
\text { Alkali olivine basalts, } \\
\text { trachybasalts/trachyandesites, trachytes, } \\
\text { rhomb porphyries and phonolites }\end{array}$ & $\begin{array}{l}\text { Baker (1987) } \\
\text { Price et al. (1985) } \\
\text { Williams (1969) }\end{array}$ \\
\hline SR & $\begin{array}{l}\text { Southern rift (Nyanza } \\
\text { trough, central } \\
\text { trough, Magadi trough, Tanza- } \\
\text { nia } \\
\text { divergence) }\end{array}$ & $\begin{array}{l}\text { Nephelinites, carbonatites, trachytes, } \\
\text { basalts (all mainly formed as tuff), } \\
\text { volcanic-derived sediments, shales }\end{array}$ & $\begin{array}{l}\text { Nyanza: Baker et al. (1971), Jones and } \\
\text { Lippard (1979), Pickford (1982); central } \\
\text { and Magadi: Baker and } \\
\text { Mitchell (1976), Crossley (1979), Simiyu } \\
\text { and Keller (2001); North Tanzania } \\
\text { divergence: Ring et al. (2005) }\end{array}$ \\
\hline NR & $\begin{array}{l}\text { Northern rift (Suguta trough, } \\
\text { South Kerio trough, Baringo } \\
\text { Basin) }\end{array}$ & $\begin{array}{l}\text { Siliciclastic sediments (mainly sand- } \\
\text { stones), basalts, phonolites, trachytes }\end{array}$ & $\begin{array}{l}\text { Suguta trough: Bosworth and Mau- } \\
\text { rin (1993); South Kerio Basin: Mugisha } \\
\text { et al. (1997); Baringo Basin: Swain et } \\
\text { al. (1981), Maguire et al. (1994), Tiercelin } \\
\text { et al. (2012) }\end{array}$ \\
\hline TR & $\begin{array}{l}\text { Turkana rift (Turkana, Lo- } \\
\text { kichar and North Kerio basins) }\end{array}$ & $\begin{array}{l}\text { Depth level B-D: Sandstones (partly } \\
\text { arkosic), shales, conglomerates }\end{array}$ & $\begin{array}{l}\text { Turkana: Morley et al. (1992), Ebinger } \\
\text { and Ibrahim (1994), Feibel (2011); Lo- } \\
\text { kichar: Morley et al. (1992), Talbot } \\
\text { et al. (2004), Tiercelin et al. (2004, } \\
\text { 2012); North Kerio: Morley et al. (1992), } \\
\text { Tiercelin et al. (2012) }\end{array}$ \\
\hline LP & Lotikipi Plain & $\begin{array}{l}\text { Depth level A: Volcanic-derived } \\
\text { sediments } \\
\text { Depth level B: Basalts, rhyolites, tuffa- } \\
\text { ceous sediments, sandstones (grits) }\end{array}$ & $\begin{array}{l}\text { Morley (1999), Wescott et al. (1995), } \\
\text { Feibel (2011), Tiercelin et al. (2012) }\end{array}$ \\
\hline EB & $\begin{array}{l}\text { Eastern basins (Mandera, } \\
\text { Lamu, and Anza basins) }\end{array}$ & $\begin{array}{l}\text { Sandstones, shales, limestones, silts, } \\
\text { evaporites, volcanics }\end{array}$ & $\begin{array}{l}\text { Mandera: Ali Kassim et al. (2002), Kerr } \\
\text { et al. (1997); Lamu: Nyagah (1995), Yuan } \\
\text { et al. (2012); Anza: Winn et al. (1993), } \\
\text { Class et al. (1994), Bosworth and Mor- } \\
\text { ley (1994) }\end{array}$ \\
\hline
\end{tabular}

arevsky, 2005, and references therein) that are described as granites north of the Anza Basin (Mosley, 1993) or granite gneisses and granites overlain by meta-sedimentary sequences in western Madagascar (Collins and Pisarevsky, 2005; Randriamamonjy, 2006).

\subsubsection{Geophysical constraints}

For the starting density model, we generated a Moho-depth configuration by interpolation between data derived from diverse sources and scattered widely across the study area (Fig. 3a): most importantly the Moho derived from the KRISP refraction seismic profiles (e.g. Khan et al., 1999) and receiver function data (Tugume et al., 2012, 2013); but also crust-mantle boundaries as imaged by a regional, seismically and gravity-constrained 3-D density model (Woldetinsae,
2005) as well as by the global model LITHO1.0 (Pasyanos et al., 2014). The obtained Moho reveals two major highs with depths of $<25 \mathrm{~km}$ (Fig. 3a): one extending N-S underneath the surface expression of the Turkana Basin domain (cf. Fig. 2a) and a second one delineating the oceanic crustal domain of the Indian Ocean. The largest Moho depths of $>40 \mathrm{~km}$ are observed in the north-western parts of the study area, and locally on the eastern flanks of the rift (KRISP line F; Fig. 3a).

The difference in depth between the top of the basement (Fig. 2a) and the Moho (Fig. 3a) defines the thickness of the crystalline crust underlying the sedimentary and volcanic deposits (Fig. 3b). In the oceanic domain, crustal thicknesses are as low as $5-12 \mathrm{~km}$ while for $60 \%$ of the continental domain crustal thicknesses are larger than $35 \mathrm{~km}$. The Turkana and northern rift domains have thicknesses of the crystalline 
Table 2. Properties of the modelled sedimentary and volcanic basin domains.

\begin{tabular}{llrrrr}
\hline Domain & $\begin{array}{l}\text { Depth } \\
\text { level }\end{array}$ & $\begin{array}{r}\text { Maximum } \\
\text { thickness } \\
{[\mathrm{m}]}\end{array}$ & $\begin{array}{r}\text { Modelled } \\
\text { density } \\
{\left[\mathrm{kg} \mathrm{m}^{-3}\right]}\end{array}$ & $\begin{array}{r}\text { Thermal } \\
\text { conductivity } \\
{\left[\mathrm{W} \mathrm{m}^{-1} \mathrm{~K}^{-1}\right]}\end{array}$ & $\begin{array}{r}\text { Radiogenic heat } \\
\text { production } \\
{\left[\mu \mathrm{W} \mathrm{m}^{-3}\right]}\end{array}$ \\
\hline V & A & 3391 & $(\text { not relevant })^{1}$ & $2.00^{2}$ & 1.00 \\
\hline SR & A & 4614 & 2400 & $2.00^{2}$ & 1.20 \\
\hline NR & A & 4199 & 2550 & $2.30^{2}$ & 0.90 \\
\hline TR & A & 2000 & 2400 & $2.00^{2}$ & 0.90 \\
& B & 2000 & 2520 & $2.20^{2}$ & 1.20 \\
& C & 2000 & 2630 & $2.40^{2}$ & 1.20 \\
& D & 502 & 2660 & $2.50^{2}$ & 1.20 \\
\hline LP & A & 1000 & 2350 & $1.90^{2}$ & 0.90 \\
\hline EB & B & 2562 & 2550 & $2.30^{2}$ & 1.10 \\
& A & 2000 & 2270 & $3.00^{3}$ & \\
& B & 2000 & 2520 & & \\
& C & 2000 & 2630 & & \\
& D & 2000 & 2680 & & \\
& E & 2000 & 2700 & & \\
\hline & F & 2225 & 2710 & & \\
\hline
\end{tabular}

${ }^{1}$ Not considered for calculations of the gravity response of the 3-D density model (see main text). ${ }^{2}$ Bulk (combined matrix and fluid) thermal conductivity, derived from Cermak and Rybach (1982). ${ }^{3}$ Matrix thermal conductivity, derived from Midtømme and Roaldset (1999). ${ }^{4}$ Geometric mean equation used to calculate bulk thermal conductivity (e.g. Fuchs et al., 2013). ${ }^{5}$ Derived from Vilà et al. (2010).

Table 3. Precambrian basement domains of the study area.

\begin{tabular}{|c|c|c|c|}
\hline & Description (Fritz et al., 2013) & Prevailing rock types & Key references \\
\hline $\begin{array}{l}\text { Nyanzian } \\
\text { System of } \\
\text { the Tanzania } \\
\text { Craton }\end{array}$ & $\begin{array}{l}\text { craton; low-grade metamorphic } \\
\text { Archean greenstone belt assembly }\end{array}$ & $\begin{array}{l}\text { metamorphic volcanics (rhyolites, } \\
\text { andesites, basalts), metamorphic } \\
\text { sediments (graywackes, mud- } \\
\text { stones), meta-granites }\end{array}$ & Clifford (1970) \\
\hline $\begin{array}{l}\text { Western } \\
\text { Granulites }\end{array}$ & $\begin{array}{l}\text { reworked pre-Neoproterozoic } \\
\text { crust; low-grade metamorphic } \\
\text { assemblage }\end{array}$ & $\begin{array}{l}\text { paragneisses, meta- } \\
\text { volcanosediments, quartzites, } \\
\text { amphibolites }\end{array}$ & $\begin{array}{l}\text { Mosley (1993), Maboko (1995), } \\
\text { Möller et al. (1998) } \\
\text {, Fritz et al. (2005, 2013), Cutten et } \\
\text { al. (2006) }\end{array}$ \\
\hline $\begin{array}{l}\text { Eastern Gran- } \\
\text { ulites }\end{array}$ & $\begin{array}{l}\text { part of the eastern granulite } \\
\text { Cabo Delgado Nappe Complex; } \\
\text { meta-igneous assemblage of Neo- } \\
\text { proterozoic juvenile crust }\end{array}$ & $\begin{array}{l}\text { meta-igneous rocks (including } \\
\text { anorthosites), meta-sedimentary } \\
\text { rocks (including marbles) }\end{array}$ & $\begin{array}{l}\text { Möller et al. (1998), Maboko and } \\
\text { Nakamura (2002), Fritz et al. (2005, } \\
\text { 2009), Tenczer et al. (2006) }\end{array}$ \\
\hline $\begin{array}{l}\text { Arabian- } \\
\text { Nubian } \\
\text { Shield }\end{array}$ & $\begin{array}{l}\text { juvenile oceanic crust including nu- } \\
\text { merous ophiolites, magmatic ter- } \\
\text { rains }\end{array}$ & $\begin{array}{l}\text { meta-volcanosedimentary } \\
\text { sequences (mainly gneisses), } \\
\text { ophiolites (basalts, gabbros) }\end{array}$ & $\begin{array}{l}\text { Fritz et al. (2013) and references } \\
\text { therein }\end{array}$ \\
\hline Azania & $\begin{array}{l}\text { reworked pre-Neoproterozoic } \\
\text { crust; microcontinent exposed, e.g., } \\
\text { in Madagascar, Somalia }\end{array}$ & $\begin{array}{l}\text { orthogneisses (granite gneisses), } \\
\text { granites, meta-sedimentary rocks }\end{array}$ & $\begin{array}{l}\text { Collins and Pisarevsky (2005), Ran- } \\
\text { driamamonjy (2006) }\end{array}$ \\
\hline
\end{tabular}

crust reduced to less than $16 \mathrm{~km}$. Thinned crystalline crust also characterises the eastern basins domain, such as along the Anza Basin axis (with thicknesses of around $30 \mathrm{~km}$; cf.
Figs. 3b, 2a) and the Lamu Basin, close to the continentocean boundary, where values decrease to $<15 \mathrm{~km}$. 

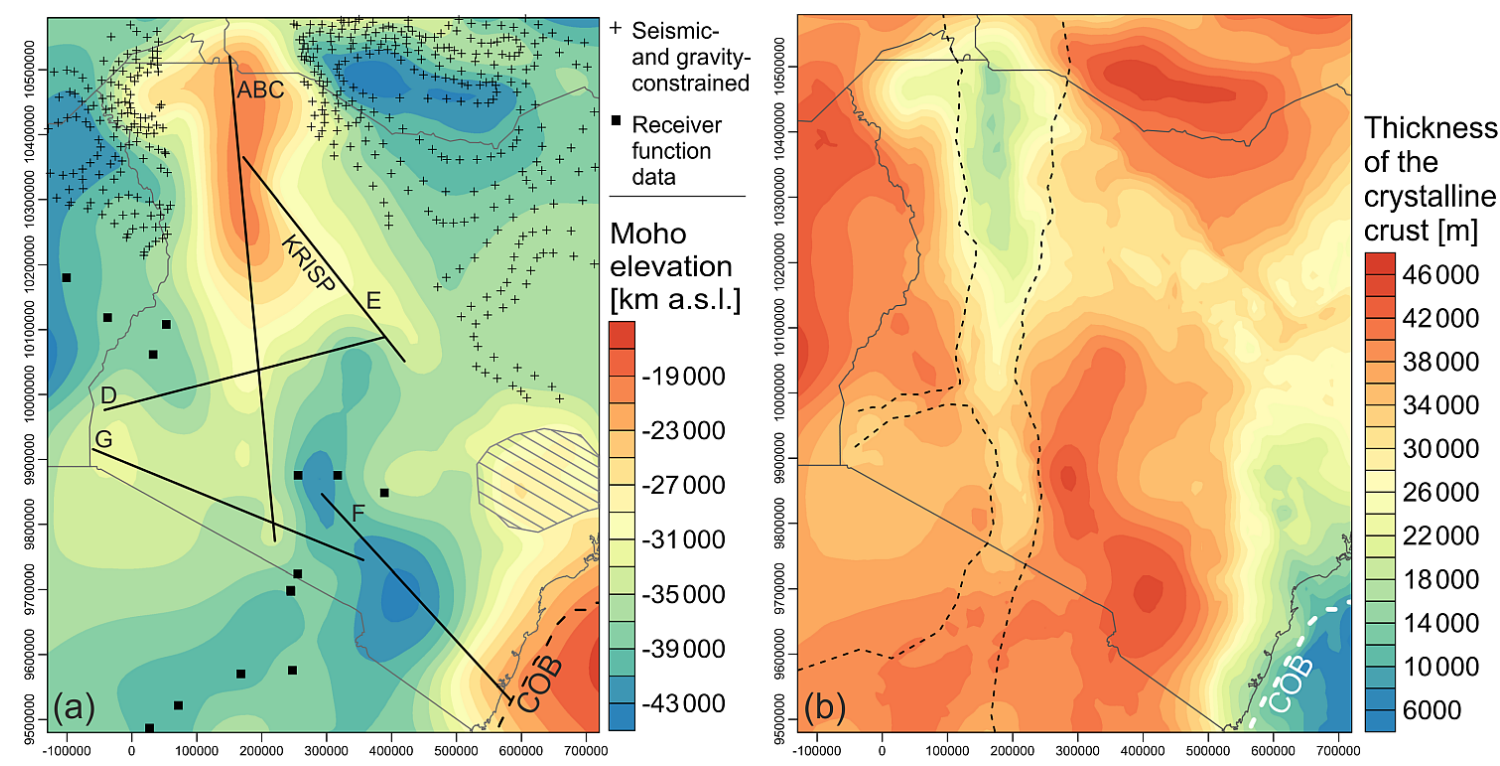

Figure 3. (a) Crust-mantle boundary (Moho); constraining data comprise the KRISP refraction seismic profiles (A-G; Khan et al., 1999), receiver function data (squares; Tugume et al., 2012, 2013), and a 3-D gravity-constrained model (crosses; Woldetinsae, 2005); the interpolation also integrated Moho depths in the oceanic crustal domain outside the study area as derived from LITHO1.0 (Pasyanos et al., 2014); the hatched area indicates where the Moho depth was interactively modified (moved upwards) according to the gravity response of the 3-D density model. (b) Thickness of the crystalline crust underlying the sedimentary and volcanic deposits as obtained by subtracting the depth to basement (Fig. 2a) from the Moho in (a). COB - continent-ocean boundary.

The KRISP refraction seismic profiles further provide information on intracrustal discontinuities (e.g. Khan et al., 1999; Fig. 4a; Appendix B). For each profile, seismic velocity information is available at grid points laterally spaced at $10 \mathrm{~km}$ intervals. Vertically, from the top of the basement down to the Moho, velocity is defined at 3-8 depth levels, depending on the $X-Y$ position and the complexity of the velocity models. According to these seismic profiles, the crust is widely structured into three sub-horizontal layers, such as on lines ABC, E and F (Khan et al., 1999; Appendix B). However, locally a four-layered crust (line G) or smallerscale velocity discontinuities within the shallower crust do occur as well (line D; Fig. 4a).

A structural element that can be traced continuously over all profiles inside and outside the rift is what previous authors have referred to as the basal crustal layer (Fig. 4a). While the Moho is depicted by a sudden increase in $P$ wave velocities to values of $v_{p}>7.5 \mathrm{~km} \mathrm{~s}^{-1}$, the top of the basal crustal layer is identified as the depth at which velocities rise to values of $v_{p} \geq 6.7 \mathrm{~km} \mathrm{~s}^{-1}$ (up to $v_{p} \leq 7.1 \mathrm{~km} \mathrm{~s}^{-1}$; Mechie et al., 1997; Khan et al., 1999). In contrast, crustal domains located between the basal crustal layer and the sedimentary cover show an overall velocity range of $v_{p}=5.9-6.65 \mathrm{~km} \mathrm{~s}^{-1}$ and are, in the following sections, collectively referred to as the upper crustal layer (locally comprised of upper, middle and lower crust).

Together with the top of the basement (Fig. 2a), the depth configurations of these velocity contrasts outline the thick- nesses of the upper crustal layer (Fig. 4b) and the basal crustal layer (Fig. 4c). The upper crustal layer thins from the rift flanks toward the rift; although less distinctly expressed, this trend is also observed for the basal crustal layer (lines ABC, D, E, G). Furthermore, both crustal layers continuously thin from $\mathrm{S}$ to $\mathrm{N}$ along the rift (line $\mathrm{ABC}$ ). Finally, while the upper crustal layer significantly thins towards the continent-ocean boundary (COB), the basal crustal layer reveals its largest thicknesses in the south-eastern parts of the study area.

To uncover lateral trends from the complex velocity structure of the upper crustal layer, we have vertically averaged over the observed interval velocities to obtain a mean velocity for each $X-Y$ position along the KRISP profiles. The resulting average velocities show an overall range of $v_{p}=6.10-6.46 \mathrm{~km} \mathrm{~s}^{-1}$ (Fig. 4d). In western Kenya (west of the stippled line in Fig. 4d), velocities of $v_{p, c}<6.35 \mathrm{~km} \mathrm{~s}^{-1}$ are abundant, whereas in eastern Kenya larger velocities of $v_{p, c} \geq 6.40 \mathrm{~km} \mathrm{~s}^{-1}$ prevail. Representative means for western and eastern Kenya would be $v_{p, c} \approx 6.33$ and $v_{p, c} \approx 6.43 \mathrm{~km} \mathrm{~s}^{-1}$, respectively. The relationship between crustal density $\left(\rho_{\mathrm{c}}\left[\mathrm{kg} \mathrm{m}^{-3}\right]\right)$ and velocity $\left(v_{p, c}\left[\mathrm{~km} \mathrm{~s}^{-1}\right]\right)$ reading as

$\rho_{\mathrm{c}}=378.8 \times v_{p, c}+350$

is a modification of Birch's $(1961,1964)$ law (Appendix C). According to Eq. (1), the mean velocities of the upper crustal layer in western and eastern Kenya translate into densities of 

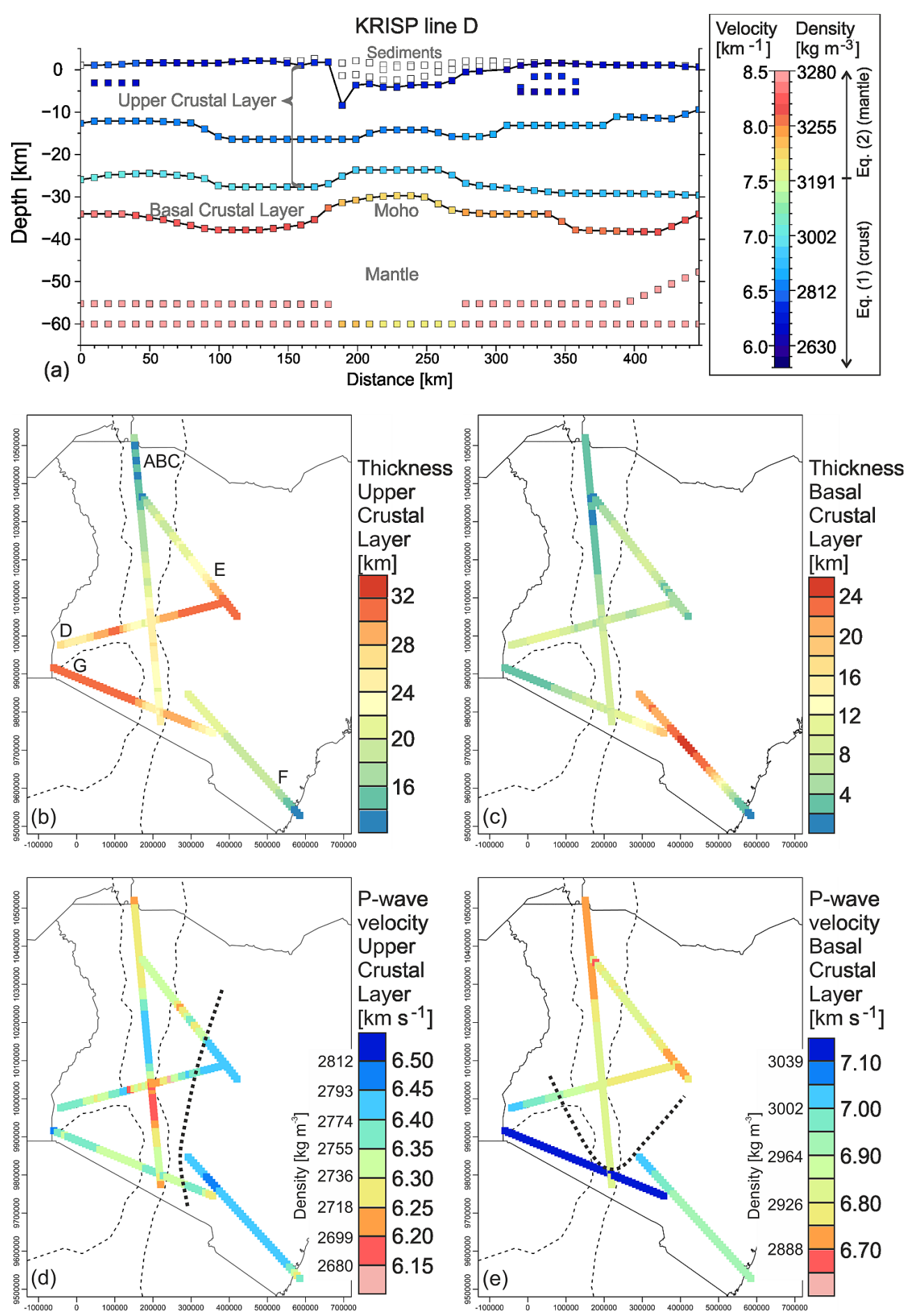

Figure 4. Configuration of the crust and mantle derived from the KRISP refraction seismic survey (Khan et al., 1999). (a) $P$ wave velocity structure across KRISP profile D; the plotted velocities represent mean values for the depth interval below the respective vertex; for details on the velocity-density conversions see main text. (b) Cumulative thickness of the upper crustal layer. (c) Thickness of the basal crustal layer. (d) Lateral variations in $P$ wave velocity of the upper crustal layer. Each velocity represents a thickness-weighted vertical average of all subsedimentary crustal layers showing $v_{p} \leq 6.65 \mathrm{~km} \mathrm{~s}^{-1}$. Stippled line separates western Kenya with prevailing velocities of $v_{p, c}<6.35 \mathrm{~km} \mathrm{~s}$ $\left(\rho_{\mathrm{c}}<2760 \mathrm{~kg} \mathrm{~m}^{-3}\right)$ from eastern Kenya showing mainly velocities of $v_{p, c} \geq 6.40 \mathrm{~km} \mathrm{~s}^{-1}\left(\rho_{\mathrm{c}} \geq 2770 \mathrm{~kg} \mathrm{~m}^{-3}\right)$. Densities have been converted using Eq. (1). (e) Velocity distribution of the basal crustal layer. Stippled line separates converted densities of mainly $\rho_{\mathrm{c}}<3000 \mathrm{~kg} \mathrm{~m}^{-3}$ in the rifted region from prevailing densities of $\rho_{\mathrm{c}} \geq 3000 \mathrm{~kg} \mathrm{~m}^{-3}$ in the surroundings. Densities have been converted using Eq. (1). 
$\rho_{\mathrm{c}} \approx 2750$ and $\rho_{\mathrm{c}} \approx 2780 \mathrm{~kg} \mathrm{~m}^{-3}$, respectively. One goal of performing the 3-D gravity modelling is to test whether this general W-E velocity increase effectively corresponds with a respective density increase in the upper crustal layer.

We have applied the same density conversion function, Eq. (1), to the velocities of the basal crustal layer (Fig. 4e). Accordingly, the deepest crust shows the largest velocities and densities $\left(\rho_{\mathrm{c}} \geq 3000 \mathrm{~kg} \mathrm{~m}^{-3}\right)$ in the south (lines $\mathrm{F}, \mathrm{G}$ ) and the smallest values $\left(\rho_{\mathrm{c}}<3000 \mathrm{~kg} \mathrm{~m}^{-3}\right)$ along the rift and farther to the NE (lines ABC, E).

\subsection{Constraints on the density configuration of the mantle}

To assess the 3-D density configuration of the mantle, in particular the geometry of the low-velocity anomaly (LVA) underneath the rift, we have analysed published models of seismic $P$ and $S$ wave velocities.

\subsubsection{Analysis of $P$ wave velocity data}

Ravat et al. (1999) have proposed a linear $P$ wave velocitydensity relationship for the mantle underlying the Kenya rift and its shoulders:

$\rho_{\mathrm{m}}=2855+50 \times v_{p, m}$,

where $\rho_{\mathrm{m}}\left[\mathrm{kg} \mathrm{m}^{-3}\right]$ is the mantle density and $v_{p, m}\left[\mathrm{~km} \mathrm{~s}^{-1}\right]$ its $P$ wave velocity. To assess this formulation (that is valid for depths down to $\approx 200 \mathrm{~km}$ ), those authors integrated diverse data from southern Kenya, such as (i) crustal velocities from the KRISP refraction line D (Fig. 4a; Braile et al., 1994; Maguire et al., 1994), (ii) upper-mantle velocities from the KRISP 1985 teleseismic experiment (Slack et al., 1994; Fig. 5a) and (iii) gravity data (Maguire et al., 1994).

We have made use of this relationship to convert mantle $P$ wave velocity data to density. The KRISP refraction seismic profiles image mantle $P$ wave velocity from the Moho down to a maximum depth of $70 \mathrm{~km}$ (e.g. Khan et al., 1999). After performing a point-by-point velocity-to-density conversion of the data using Eq. (2), we have vertically averaged over the resulting mantle densities for each $X-Y$ location. In this way, the gravity-relevant lateral density contrasts across the region were revealed (Fig. 5a).

One main finding of the KRISP survey is that mantle domains underlying the rift proper (e.g. KRISP line ABC) are characterised by lower velocities than mantle domains outside the rift (off-rift parts of KRISP lines D, E, F, G; e.g. Mechie et al., 1994). Accordingly, line D in KRISP (Fig. 4a) shows average mantle densities of $\rho_{\mathrm{m}} \approx 3270 \mathrm{~kg} \mathrm{~m}^{-3}$ west and east of the rift, whereas densities are as low as $\rho_{\mathrm{m}} \approx 3250 \mathrm{~kg} \mathrm{~m}^{-3}$ right beneath the surface expression of the rift. This across-rift density difference of $\Delta \rho_{\mathrm{m}} \approx 20 \mathrm{~kg} \mathrm{~m}^{-3}$ derives from a velocity difference of about $\Delta v_{p} \approx 0.4 \mathrm{~km} \mathrm{~s}^{-1}$ and is also observed along the across-rift line $\mathrm{G}$ further south (Fig. 5a). Along the strike of the rift, i.e. along line $\mathrm{ABC}$ in KRISP, the mantle shows densities increasing from about 3240 in the south to $3250 \mathrm{~kg} \mathrm{~m}^{-3}$ in the north. A similar $\mathrm{S}-\mathrm{N}$ increase in mantle density $(\approx 15-$ $20 \mathrm{~kg} \mathrm{~m}^{-3}$ ) is observed outside the rift as revealed by the density difference between (i) lines D and E in KRISP in the north compared to (ii) lines F and $\mathrm{G}$ further in the south.

Besides the KRISP refraction data, we have also analysed the teleseismic data of Slack et al. (1994) and Achauer and Masson (2002), both covering depths greater than $150 \mathrm{~km}$. For the analysis of these teleseismic models, images from publications of the tomographic models have been georeferenced and the resulting scattered velocities converted to densities using Eq. (2). The tomographic $P$ wave velocity model presented by Achauer and Masson (2002; grey square in Fig. 5a) reveals a pronounced LVA under the rift, with amplitudes as large as $-10 \%$ relative to the Preliminary Reference Earth Model (PREM; Dziewonski and Anderson, 1981). Slack et al. (1994) described a more gradual change from a $12 \%$-velocity anomaly confined to the rift to a $6 \%$-velocity anomaly below its flanks. In both cases, the velocity perturbations delineate a LVA that is essentially confined to the surface expression of the rift down to about $100 \mathrm{~km}$ depth. With increasing depths down to $300 \mathrm{~km}$, the LVA widens while becoming more diffuse so that it cannot be delineated from the surrounding unperturbed mantle anymore in the tomography model of Achauer and Masson (2002).

According to Eq. (2), the $P$ wave velocity perturbation with respect to PREM as revealed by the model of Achauer and Masson (2002) records an across-rift density variation of $\approx 7 \mathrm{~kg} \mathrm{~m}^{-3}\left(3251-3258 \mathrm{~kg} \mathrm{~m}^{-3}\right)$ at depths of $35-70 \mathrm{~km}$ and $\approx 4 \mathrm{~kg} \mathrm{~m}^{-3}\left(3251-3255 \mathrm{~kg} \mathrm{~m}^{-3}\right)$ at depths of $70-110 \mathrm{~km}$. Thus, the density contrast of the mantle anomaly indicated by the tomography study is smaller than the contrast revealed by the KRISP refraction seismic profiles $\left(\approx 20-25 \mathrm{~kg} \mathrm{~m}^{-3}\right)$. However, the two datasets are consistent in terms of the location and spatial extent of the mantle-density anomaly.

Overall, $P$ wave velocities are indicative of a LVA that (i) is essentially confined to the surface expression of the rift, i.e. only slightly widening down to depths of about $100 \mathrm{~km}$, and (ii) differs in density from its surroundings by $\leq 25 \mathrm{~kg} \mathrm{~m}^{-3}$. Considering these observations, we have constructed a starting density model of the shallow mantle (between the Moho and $100 \mathrm{~km}$ b.s.l.) that differentiates six density domains (Fig. 5a). The LVA is represented by a southern domain of 3240 and a northern domain of $3250 \mathrm{~kg} \mathrm{~m}^{-3}$. Thereby, the modelled western and eastern boundaries of the LVA are inclined (Fig. 5a) reflecting the observed downward widening of the LVA, which is more pronounced in the north (e.g. Simiyu and Keller, 1997) than in the south (Slack et al., 1994; Achauer and Masson, 2002). Outside the rift, this starting density model differentiates four domains for the shallow mantle with densities that are larger by $15-25 \mathrm{~kg} \mathrm{~m}^{-3}$ compared to the two rift-mantle domains (Fig. 5a). These four off-rift mantle regions also reveal a general increase in density from the south to the north. Hence, we have chosen the 

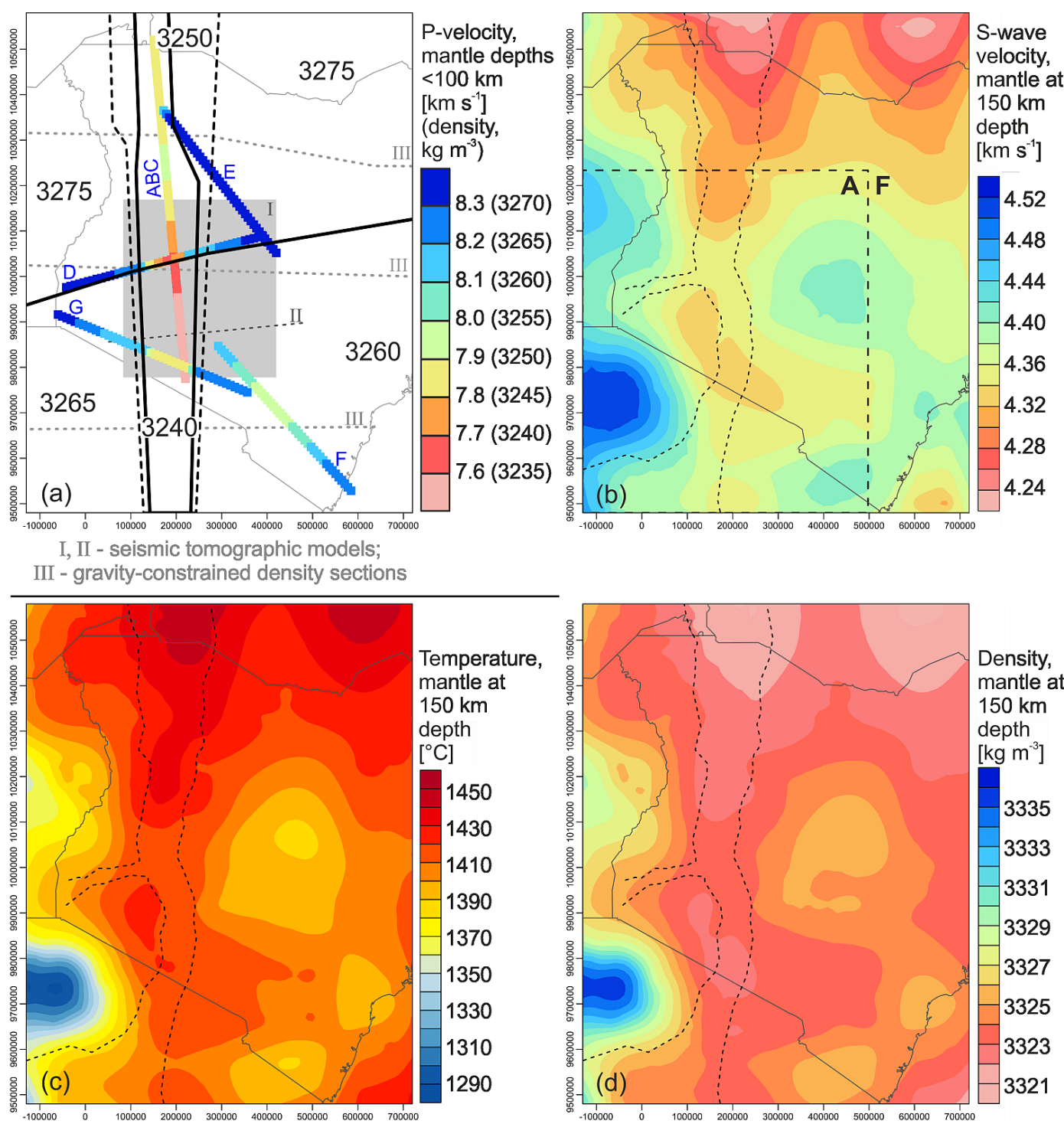

Figure 5. Analysis of mantle seismic velocities. (a) Six density domains (separated by black lines; numbers in $\mathrm{kg} \mathrm{m}^{-3}$ ) have been derived from $P$ wave velocities for depths between the Moho and $100 \mathrm{~km}$; the low-density domains underneath the rift are slightly narrower at the Moho (solid lines) than at $100 \mathrm{~km}$ depth (dashed lines). KRISP refraction seismic profiles A-G shown with vertically averaged mantle velocity and density (converted according to Eq. 2); I (grey square) - tomographic $P$ wave velocity model of Achauer and Masson (2002); II - tomographic model of Slack et al. (1994); III - gravity-constrained density profiles of Simiyu and Keller (1997). (b) Combined $S$ wave velocity datasets of "A" - Adams et al. (2012) and "F" - Fishwick (2010; separated by the dashed line) at a depth of $150 \mathrm{~km}$. (c) Temperature at $150 \mathrm{~km}$ depth as derived from $S$ wave velocity data according to the approach of Priestley and McKenzie (2006). (d) Density at $150 \mathrm{~km}$ depth derived from temperature according to Eq. ( $\mathrm{C} 1$; for details see main text).

overall larger density contrasts as indicated by the velocity profiles derived from the KRISP refraction data for the starting density model to be tested against the gravity field.

\subsubsection{Analysis of $S$ wave velocity data}

Adams et al. (2012) presented a quasi-3-D $S$ wave velocity model of the upper mantle that is inverted from Rayleigh wave phase velocities as derived from teleseismic recordings on broadband stations located in Uganda, Tanzania and
Kenya. The derived $S$ wave velocity model provides information on the mantle configuration for depths of $50-400 \mathrm{~km}$ and covers the Tanzania Craton and its adjacent western and eastern branches of the EARS, thereby also extending into the south-western parts of Kenya. For a 3-D analysis of this particular region, we have digitised and georeferenced four depth slices (at 100, 150, 200 and $250 \mathrm{~km}$ depth) and six profiles presented in the paper of Adams et al. (2012). 
Since the model of Adams et al. (2012) only covers the south-western parts of the study area, we have also utilised the results of an updated surface-wave tomography study based on Fishwick (2010). This study is likewise based on Rayleigh wave velocities, but using source-to-receiver paths that cover the entire African continent and surrounding oceans. Accordingly, the nodal points of the model of Fishwick (2010) are set at $1.5^{\circ}$ intervals, i.e. at a larger distance compared to the phase velocity inversion of Adams et al. (2012), which was performed on a grid with $0.5^{\circ}$ node spacing. Vertically, the tomographic models by Fishwick (2010) of $S$ wave velocity are defined at $25 \mathrm{~km}$ depth intervals from 50 to $350 \mathrm{~km}$ depth.

Despite the differences between the two surface-wave tomography models in terms of utilised data and inversion procedures, they are consistent with respect to the main trends in absolute $S$ wave velocities across the south-western parts of Kenya. Thus, we have merged the two $S$ wave velocity models for subsequent modelling steps. In more detail, we have complemented the model of Adams et al. (2012) towards the $\mathrm{N}$ and $\mathrm{E}$ by the model of Fishwick (2010) and 3-D interpolated the scattered point information to obtain a voxel grid of regular spacing of $50 \mathrm{~km}$ horizontally and $20 \mathrm{~km}$ vertically.

At a depth of $150 \mathrm{~km}$ (Fig. 5b), the combined model shows the lowest velocities of around $4.3 \mathrm{~km} \mathrm{~s}^{-1}$ below the Kenya rift, increasing to $4.4 \mathrm{~km} \mathrm{~s}^{-1}$ in the eastern basins domain and to $>4.5 \mathrm{~km} \mathrm{~s}^{-1}$ in the Tanzania Craton domain. Furthermore, the LVA underneath the Kenya rift widens significantly from $\mathrm{S}$ to $\mathrm{N}$. The difference between the LVA and higher velocities in the surroundings decreases with depth; at $100 \mathrm{~km}$ depth, the lateral variability amounts to $0.5 \mathrm{~km} \mathrm{~s}^{-1}$, while at $200 \mathrm{~km}$ depth $S$ wave velocities differ maximally by $0.2 \mathrm{~km} \mathrm{~s}^{-1}$. Below $200 \mathrm{~km}$ depth, the LVA widens significantly transforming into a continuous low-velocity layer that extends from the Kenya rift across the Tanzania Craton to the western branch of the EARS (e.g. Adams et al., 2012). Consequently, there are no gravity-relevant, lateral density contrasts to be expected from depths of $>200 \mathrm{~km}$.

To convert the observed mantle $S$ wave velocities into densities we have followed a two-stage approach. In a first step, we used the set of empirical equations and constants proposed by Priestley and McKenzie (2006) to convert mantle $S$ wave velocity to temperature. This non-linear relationship is assumed to be valid for any mantle composition, while being most accurate for temperatures that exceed $1100{ }^{\circ} \mathrm{C}$ and depths of $>100 \mathrm{~km}$. In a second step (Appendix D), we used a mantle composition proposed for the region (Mechie et al., 1994) and converted the calculated mantle temperatures to densities. Because of (i) the depth restriction of the velocitydensity conversion, (ii) the good coverage of $P$ wave velocity data down to $100 \mathrm{~km}$ and (iii) the very small variability in $S$ wave velocities at depths of $>200 \mathrm{~km}$, we have performed these conversions for each point of the $S$ wave velocity voxel grid between depths of 100 and $200 \mathrm{~km}$.
Figure 5b-d show depth slices at $150 \mathrm{~km}$ b.s.l. extracted from the calculated 3-D grids. According to the low $S$ wave velocities underneath the Kenya rift and in the northern parts of the study area (Fig. 5b), the mantle shows the highest temperatures (Fig. 5c) and the lowest densities (Fig. 5d) there. This high-temperature, low-density anomaly widens from the Kenya rift towards the north (i.e. the Ethiopian and Afar rift systems). East of the Kenya rift, density increases to moderate values under the eastern basins domain while decreasing again towards the Indian oceanic domain in the southeast. The largest densities are found in the Tanzania Craton domain (Fig. 5d; cf. Fig. 1b). Overall, the absolute densities at a depth of $150 \mathrm{~km}$ scatter around a mean of $3324 \mathrm{~kg} \mathrm{~m}^{-3}$ with a total lateral variance of about $15 \mathrm{~kg} \mathrm{~m}^{-3}$. At $110 \mathrm{~km}$ depth, densities show a larger variance of $55 \mathrm{~kg} \mathrm{~m}^{-3}$ around a lower mean of $3299 \mathrm{~kg} \mathrm{~m}^{-3}$ while at $190 \mathrm{~km}$ depth the scatter reduces to $5 \mathrm{~kg} \mathrm{~m}^{-3}$ for a mean of $3353 \mathrm{~kg} \mathrm{~m}^{-3}$.

\subsection{3-D gravity modelling}

We have used the above constraints on the structure and density of the sedimentary and volcanic cover (Fig. 2, Tables 1,2), the crystalline crust (Figs. 3, 4) and the mantle (Fig. 5) to set up a starting 3-D density model. This model spans $850 \mathrm{~km}$ in E-W direction and $1100 \mathrm{~km}$ in N-S direction (black rectangle in Fig. 1a). To model discrete density bodies, the corresponding scattered information on delineating structural interfaces has been interpolated to regular grids of $50 \mathrm{~km} \times 50 \mathrm{~km}$ horizontal resolution. For example, the initial depth to the top of the basal crustal layer has been obtained through interpolation (and extrapolation) of the corresponding KRISP refraction seismic information (Fig. 4a; Appendix B) to cover the entire continental crustal domain of the study area. In the same way, we have generated regular $50 \mathrm{~km} \times 50 \mathrm{~km}$ grids for all first-order model layers, i.e. gridded tops for all sedimentary and volcanic units (Tables 1,2), the upper crustal layer (Fig. 2a) and the mantle (Moho; Fig. 3a). Accordingly, the vertical resolution of the crustal parts of the generated 3-D density model is variable as it is determined by the thicknesses of the different units. This also applies to the upper-mantle domain between the Moho and $100 \mathrm{~km}$, modelled by six units, each showing a constant density as derived from $P$ wave velocities (Fig. 5a). The $S$ wave-derived density configuration of the lower-mantle domain reaching from 100 to $200 \mathrm{~km}$ depth, on the other hand, is represented by pointwise density information, i.e. by the generated voxel grid with a regular spacing of $50 \mathrm{~km}$ horizontally and $20 \mathrm{~km}$ vertically.

The constant densities assigned to the modelled sedimentary and volcanic units are presented in Table 2 and those of the shallowest mantle in Fig. 5a. For the starting density model, we have further chosen $\rho=2750 \mathrm{~kg} \mathrm{~m}^{-3}$ for the upper crustal layer (cf. Fig. 4d) and $\rho=3000 \mathrm{~kg} \mathrm{~m}^{-3}$ for the basal crustal layer (cf. Fig. 4e), whereas the oceanic crust has been assigned a value of $\rho=2900 \mathrm{~kg} \mathrm{~m}^{-3}$. 

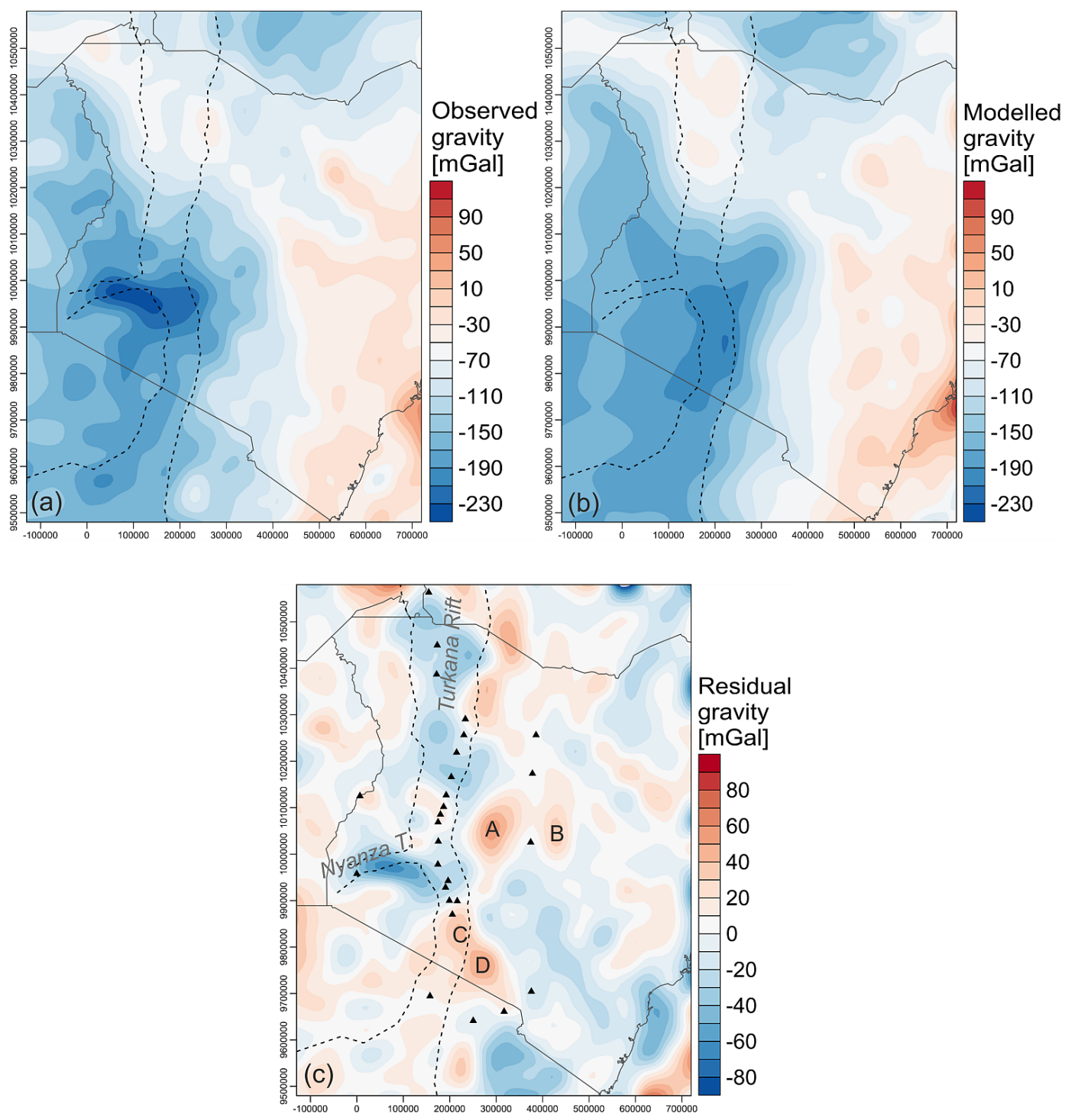

Figure 6. Gravity anomalies. (a) Observed Bouguer (onshore) and free-air (offshore) anomalies (Eigen-6C4; Förste et al., 2015). This dataset and corresponding reductions are available from http://icgem.gfz-potsdam.de/ICGEM/Service.html. (b) Calculated anomalies of the final model. (c) Residual gravity (observed minus calculated anomalies) of the final model; black triangles mark volcanoes (from the Global Volcanism Program, Department of Mineral Sciences, Smithsonian Institution, http://volcano.si.edu/). For comments on residual anomalies A-D, refer to main text.

The gravity field data that we have chosen to utilise are EIGEN-6C4, a combined surface and satellite data-based global gravity model released by GFZ German Research Centre for Geoscience and GRGS Toulouse (Förste et al., 2015). As we are mainly interested in the density configuration of the deeper crust, we have used the corresponding Bouguer gravity anomaly in the onshore parts of the study area, complemented by free-air gravity anomalies in the offshore domain (Fig. 6a). Details on the reduction of the original gravity data to obtain free-air and Bouguer anomalies (e.g. assuming a constant density of $2670 \mathrm{~kg} \mathrm{~m}^{-3}$ for the Bouguer plate) are presented on the GFZ-hosted website
(http://icgem.gfz-potsdam.de/ICGEM/). To warrant comparability between the Bouguer anomalies and the calculated response of the 3-D density models, all masses located above sea level have been removed from the model (thus referring to the Bouguer plate above the geoid).

Based on originally constructed $X-Y-Z$ grids, the gravity modelling software IGMAS + geometrically approximates 3-D density bodies by multiple polyhedra that are spanned through triangulation between 2-D vertical slices (working planes). Given the $\mathrm{N}-\mathrm{S}$ extension of the model area of $1100 \mathrm{~km}$ (Fig. 1a) and the horizontal grid resolution of $50 \mathrm{~km}, 23 \mathrm{E}-\mathrm{W}$-striking working planes have been created 
for this study. IGMAS+ calculates the gravity field as the sum of the effects of all triangulated polyhedra (and voxel cuboids), whereas in our case stepwise and interactive modifications of geometries and/or densities have been performed along the 23 working planes to obtain the desired fit between modelled and observed gravity. Furthermore, IGMAS+ calculates gravity anomalies by considering densities of the 3-D model as density anomalies with respect to an overall reference density. For this study, this background density has been chosen as $3250 \mathrm{~kg} \mathrm{~m}^{-3}$, a value that represents an approximate overall average density of the starting model.

It is important to note that the main focus of our study is to assess the density configuration of the continental crystalline crust across the whole study area. Therefore, we have only modified the starting 3-D density model by varying this particular structural domain. Indeed, we have found that a reasonable fit between calculated and observed gravity can be obtained when keeping the density configurations of the sedimentary and volcanic cover as well as the mantle domains fixed (Fig. 6; Sect. 4).

In order to reproduce the observed long-wavelength variations in the gravity field, we have systematically modified the crustal 3-D density configuration in our model. For this purpose, we have followed a "stepwise approach" relying on the IGMAS + software capabilities. First, we have modified the topology of the top basal crustal layer at locations not constrained by the KRISP refraction lines in an attempt to arrive at a better agreement between calculated and observed gravity anomalies. We have followed a procedure in which we have varied (i.e. increased or decreased) the thickness of the basal crustal layer along the selected 2-D working sections while keeping track of the calculated gravity response of the model. It is worth mentioning that with these first imposed changes to the starting density model, we did not alter the thickness of the whole crustal layer; instead, any imposed variation in the basal layer thickness was complemented by respective variations in the thickness of the upper crustal layer.

In a second stage, we have checked and confirmed (see Sect. 4) that a further improvement of the model fit on firstorder gravity anomalies can be obtained through the implementation of the trends observed in the $P$ wave velocity configurations of the upper and basal crustal layers (Fig. 4d, e). This integration of lateral variations of density within both crustal layers was systematically done while interactively quantifying the gravity response of the whole model to each modification step. In a final step, the Moho topology has been adjusted in order to improve the fit between modelled and observed gravity anomalies, though limited to an area of small lateral extent where no gravity-independent constraints were available (hatched area; Fig. 3a).

\section{Results: 3-D density configuration of the continental crust}

By adjusting the density configuration of the subsedimentary continental crust within the geometrical constraints of the KRISP refraction seismic profiles, it is possible to reproduce the main observed gravity anomalies (Fig. 6a, b). Almost $90 \%$ of the residual gravity is within the range of $\pm 30 \mathrm{mGal}$ (Fig. 6c). Thereby, the half-wavelengths of local residual anomalies exceeding $\pm 30 \mathrm{mGal}$ are smaller than $100 \mathrm{~km}$. Hence, the 3-D density model best reproduces gravity anomalies of larger wavelengths.

The final density model is characterised by a continental upper crustal layer that is denser in the east $\left(\rho=2800 \mathrm{~kg} \mathrm{~m}^{-3}\right)$ than in the west $\left(\rho=2750 \mathrm{~kg} \mathrm{~m}^{-3}\right.$; Fig. 7a, d). This density difference corresponds well with higher $P$ wave velocities observed on line F in KRISP as well as in the easternmost parts of lines D and E (Fig. 4c). Furthermore, we find that the modelled boundary between the high- and low-density domains is almost consistent with Azania's western margin (cf. Fig. 1b; Fritz et al., 2013).

Combining the gravity-constrained density and mean $P$ wave velocity $\left(6.33 \mathrm{~km} \mathrm{~s}^{-1}\right)$ of the upper crustal layer in western Kenya with the laboratory-derived property compilations of Christensen and Mooney (1995), this unit might represent granite/granodiorites, phyllites and/or paragranulites. This is fairly consistent with the lithologies of the Precambrian basement domains of western Kenya as observed at the Earth's surface (Tanzania Craton, Western and Eastern Granulites, Arabian-Nubian Shield; Fig. 1b, Table 3). Both geophysical and geological data are thus indicative of a mixture of meta-sedimentary and meta-igneous rocks (Table 4). In contrast, the physical properties of the upper crustal layer in eastern Kenya $\left(2800 \mathrm{~kg} \mathrm{~m}^{-3} ; 6.43 \mathrm{~km} \mathrm{~s}^{-1}\right)$ are indicative of diorites (according to the property tables of Christensen and Mooney, 1995), whereas the spatially corresponding microcontinent Azania is dominated by meta-igneous rocks (Table 3).

The thickness of the upper crustal layer (Fig. 7a) varies between $0 \mathrm{~km}$ (at the COB) and $>30 \mathrm{~km}$ in western Kenya where it is constrained by the KRISP refraction seismic lines. Based on these data, domains of reduced thickness spatially correlate with domains characterised by large depths to basement (Fig. 2a), large sedimentary thickness (Fig. 2b) and reduced total crustal thicknesses (Fig. 3b). These domains are known to have been affected by Mesozoic and/or Cenozoic rifting.

The basal crustal layer is subdivided into four domains of distinct densities (Fig. 7b). The lowest density of $2920 \mathrm{~kg} \mathrm{~m}^{-3}$ is found underneath the Turkana and northern rifts (cf. Fig. 2), while the highest density of $3050 \mathrm{~kg} \mathrm{~m}^{-3}$ has been modelled for the south-eastern parts of the study area. In the western and north-eastern parts of the study area, the modelled basal crustal layer shows a density of $3000 \mathrm{~kg} \mathrm{~m}^{-3}$. Again, these density differences correspond 
Table 4. Physical properties and lithologies of the model units.

\begin{tabular}{|c|c|c|c|c|c|c|c|c|c|}
\hline Model unit & $\begin{array}{r}\text { Bulk } \\
\text { density, } \\
\rho \\
{\left[\mathrm{kg} \mathrm{m}^{-3}\right]}\end{array}$ & $\begin{array}{r}\text { KRISP } \\
\text { mean } \\
\text { velocity, } \\
v_{p} \\
{\left[\mathrm{~m} \mathrm{~s}^{-1}\right]}\end{array}$ & $\begin{array}{l}\text { Prevailing } \\
\text { lithology }\end{array}$ & $\begin{array}{r}\text { Thermal } \\
\text { conductivity, } \\
\lambda \\
{\left[\mathrm{W} \mathrm{m}^{-1} \mathrm{~K}^{-1}\right]}\end{array}$ & $\begin{array}{r}\text { Radiogenic } \\
\text { heat } \\
\text { production, } \\
A^{8} \\
{\left[\mu \mathrm{W} \mathrm{m}^{-3}\right]}\end{array}$ & $\begin{array}{l}\text { Type } \\
\text { rheology } \\
\text { [reference] }\end{array}$ & $\begin{array}{r}\text { Power- } \\
\text { law activation } \\
\text { energy, } \\
Q_{P} \\
{\left[\mathrm{~kJ} \mathrm{~mol}^{-1}\right]}\end{array}$ & $\begin{array}{r}\text { Power- } \\
\text { law strain } \\
\text { rate } \\
A_{P} \\
{\left[\mathrm{~Pa}^{-n} \mathrm{~s}^{-1}\right]}\end{array}$ & $\begin{array}{r}\text { Power- } \\
\text { law exponent } \\
n\end{array}$ \\
\hline Sediments, volcanics & (Table 2) & & (Table 2) & (Table 2) & (Table 2) & Quartzite, dry ${ }^{1,2}$ & 190 & $5.00 \mathrm{E}-12$ & 3.00 \\
\hline Upper crustal layer, W & 2750 & 6330 & $\begin{array}{l}\text { Meta-sedimentary and } \\
\text { meta-igneous rocks }\end{array}$ & $3.0^{5}$ & 1.70 & Granite, dry ${ }^{1}$ & 186.00 & $3.16 \mathrm{E}-26$ & 3.30 \\
\hline Upper crustal layer, E & 2800 & 6430 & Meta-igneous rocks & $2.9^{6}$ & 2.10 & Diorite, dry ${ }^{2}$ & 219.00 & $5.20 \mathrm{E}-18$ & 2.40 \\
\hline Basal crustal layer, $N$ rift & 2920 & 6800 & Gabbroid rocks & $2.0^{6}$ & 0.35 & Diabase, dry ${ }^{1}$ & 276.00 & $6.31 \mathrm{E}-20$ & 3.05 \\
\hline Basal crustal layer, W \& NE & 3000 & 7000 & Gabbroid rocks & $2.0^{6}$ & 0.35 & Diabase, dry ${ }^{1}$ & 276.00 & $6.31 \mathrm{E}-20$ & 3.05 \\
\hline Basal crustal layer, $\mathrm{SE}$ & 3050 & 7000 & Mafic granulites & $2.0^{5}$ & 0.15 & Mafic granulite ${ }^{3}$ & 445.00 & 8.83E-22 & 4.20 \\
\hline Oceanic crust & 2900 & NA & Gabbroid rocks & $2.6^{6}$ & 0.35 & Diabase, dry ${ }^{1}$ & 276.00 & $6.31 \mathrm{E}-20$ & 3.05 \\
\hline Mantle & (variable) & (variable) & Peridotite & $3.0^{7}$ & 0.01 & Olivine, dry 4 & 510 & $7.00 \mathrm{E}-14$ & 3.00 \\
\hline
\end{tabular}

${ }^{4}$ Goetze and Evans (1979). Thermal properties from ${ }^{5}$ Seipold (1992), ${ }^{6}$ Cermak and Rybach (1982), ${ }^{7}$ McKenzie et al (2005) and references therein, ${ }^{8}$ Vilà et al (2010).

well with the trends in $P$ wave velocity variation along the KRISP refraction seismic profiles (Fig. 4e). A comparison of the densities and mean $P$ wave velocity values of the basal crustal layer with the property compilations of Christensen and Mooney (1995) points to an overall dominance of rocks with gabbroid composition (Table 4). Only the south-eastern parts of the basal crustal layer would consist of mafic granulites accordingly.

The basal crustal layer is thinnest $(<10 \mathrm{~km}$ thick; Fig. 7b) underneath the Turkana and northern rifts as well as the Nyanza trough (cf. Fig. 2a). The greatest thicknesses $(>20 \mathrm{~km})$ are reached east of the southern rift (KRISP line F) and in north-eastern Kenya below the Anza Basin (cf. Fig. 2b). The modelled thickness anomalies of the basal crustal layer differ significantly in wavelength $(<150 \mathrm{~km})$ and spatial distribution from both its internal segmentation into four regional density domains (Fig. 7b) and the Moho geometry (Fig. 3a). This demonstrates that it was possible to differentiate between thickness and density characteristics of this layer since they correspond to different components of the observed gravity field. Interestingly, large thicknesses of the basal crustal layer locally correlate with reduced thicknesses of the upper crustal layer and the prevailing strike direction of these equivalent structures is WNW-ESE (Fig. 7a, b), such as beneath the axis of the Anza Basin (cf. Fig. 2a).

\section{Implications for the strength of the lithosphere}

\subsection{Thermal and rheological modelling approach}

We use the 3-D density model (e.g. Fig. 7d) as a basis for assessing the thermo-mechanical configuration of the lithosphere. Based on the assumption that heat is transported predominantly by conduction within the Earth's lithosphere, we numerically solve the 3-D equation of heat conduction using the Finite Element Method as implemented in the software package GMS (e.g. Cacace et al., 2010). For a thermally equilibrated system (steady-state conditions) the mathemati- cal formulation of the relevant equation reads as

$\nabla \cdot\left(\lambda_{\mathrm{b}} \nabla T\right)=-S$,

where $\nabla$ is the Nabla operator $\left[\mathrm{m}^{-1}\right], \lambda_{\mathrm{b}}$ is the bulk thermal conductivity [ $\mathrm{W} \mathrm{m}^{-1} \mathrm{~K}^{-1}$ ], $T$ is the temperature $[\mathrm{K}]$ and $S$ is the radiogenic heat production $\left[\mathrm{W} \mathrm{m}^{-3}\right]$.

For the calculation of the 3-D conductive thermal field, each model unit is assigned a constant value of radiogenic heat production and bulk thermal conductivity (Tables 2, 4). Thereby, the thermal property values are chosen from published compilations of laboratory measurements according to the prevailing lithologies of the model units (Table 4). To account for the depth-variable porosities of the sedimentary and volcanic rocks in the eastern basins domain (Appendix A), the average bulk (solid plus fluid) thermal conductivity, $\lambda_{\mathrm{b}}$, is calculated for the defined depth levels (Table 2) using the geometric mean equation:

$\lambda_{\mathrm{b}}=\lambda_{\mathrm{w}}^{\phi_{z}} \times \lambda_{\mathrm{s}}^{\left(1-\phi_{z}\right)}$,

where $\lambda_{\mathrm{w}}$ is the thermal conductivity of liquid water assumed to fill the pore space $\left(\lambda_{\mathrm{W}}=0.6 \mathrm{Wm}^{-1} \mathrm{~K}^{-1}\right), \phi_{z}$ is the depthdependent porosity (Appendix A) and $\lambda_{\mathrm{s}}$ is the thermal conductivity of the solid rock components

The model set-up is finalised by setting thermal boundary conditions. While the lateral boundaries of the model are closed to heat flow, the upper thermal boundary condition is set to a constant value of $20^{\circ} \mathrm{C}$ at the topography (respectively bathymetry), which represents the annual mean surface temperature of Kenya as derived from a global climatological model (Jones et al., 1999). Finally, we define the lower thermal boundary condition by the depth of the $1350^{\circ} \mathrm{C}$ isotherm (Fig. 8a) as derived from the combined $S$ wave velocity models (Fishwick, 2010; Adams et al., 2012) using the approach of Priestley and McKenzie (2006).

To predict spatial variations in the strength of the lithosphere of Kenya, we follow a similar approach as previous regional (e.g. Gac et al., 2016) or global studies (e.g. Tesauro et al., 2012, 2013) while using the code of Cacace and ScheckWenderoth (2016). In general, the strength of the lithosphere 

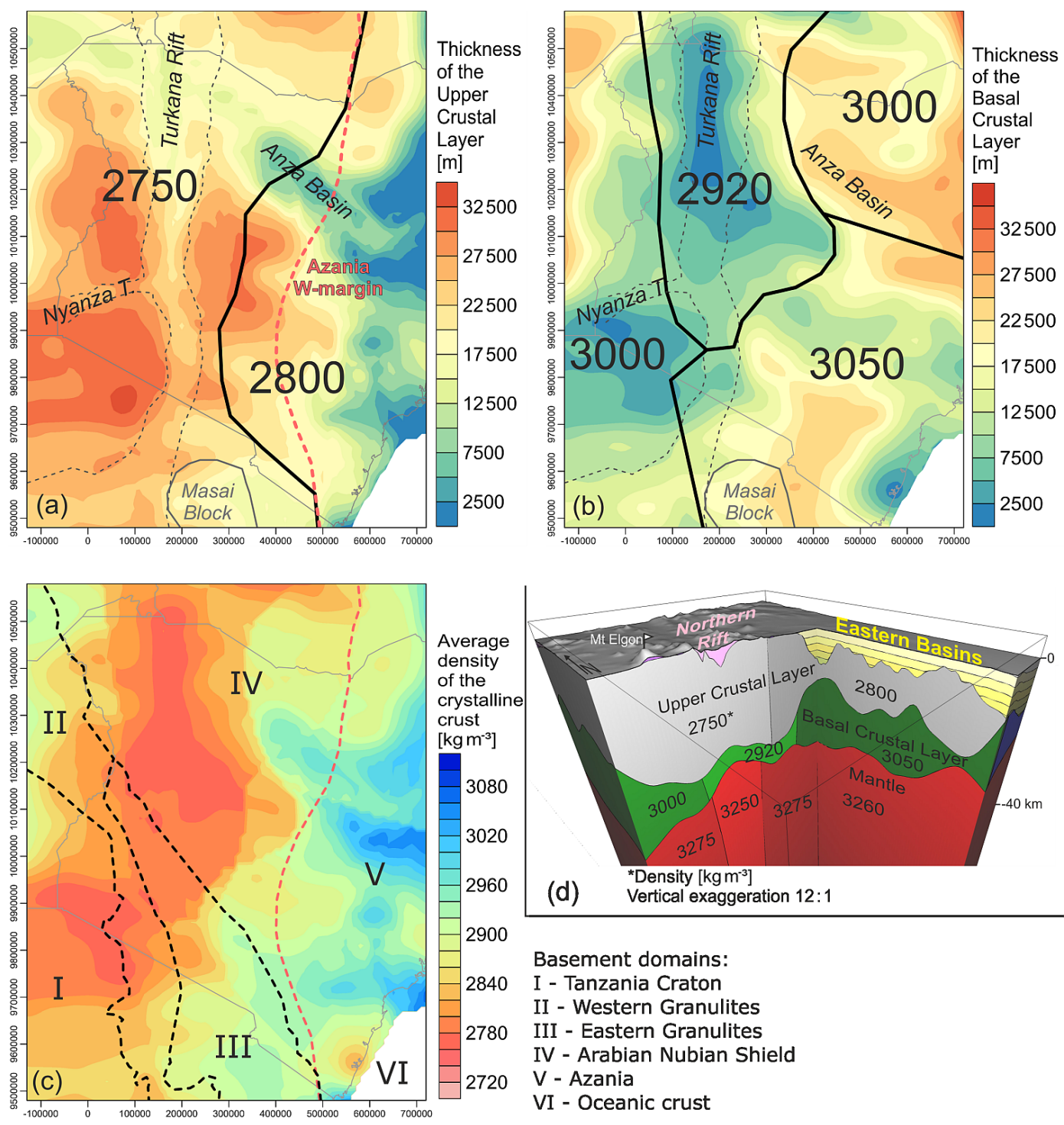

$-2900$

Basement domains:

I - Tanzania Craton

II - Western Granulites

2780 III - Eastern Granulites

IV - Arabian Nubian Shield

2720 V - Azania

VI - Oceanic crust

Figure 7. Gravity-constrained 3-D density configuration of the sub-sedimentary continental crust. (a) Thickness of the continental upper crustal layer; solid black line separates domains of different average density $\left[\mathrm{kg} \mathrm{m}^{-3}\right]$; dashed red line denotes the western margin of the microcontinent Azania after Fritz et al. (2013); grey line denotes spatial extension of the Masai block as derived from Le Gall et al. (2008). (b) Thickness of the continental basal crustal layer; black lines separate domains of different average density [kg $\left.\mathrm{m}^{-3}\right]$. (c) Average density of the crystalline continental crust calculated by vertically averaging the densities of the upper and basal crustal layers according to their share in the total thickness of the crust; dashed lines delineate basement domains of Fritz et al. (2013). (d) Perspective view into the 3-D density model; for densities of units also refer to Table 2 (sedimentary and volcanic), Table 4 (crystalline crust) and Fig. 5 (shallow mantle).

can be described as the maximum differential stress $\left(\Delta \sigma_{\max }\right)$ that rocks under certain pressure and temperature conditions are able to resist without experiencing brittle or ductile deformation:

$\Delta \sigma_{\max }=\sigma_{1}-\sigma_{3}$,

where $\sigma_{1}$ and $\sigma_{3}$ are the maximum and minimum principal stresses, respectively. Furthermore, a certain rock type will deform according to the mechanism that requires least differential stress at a given depth. At shallow depths, rocks predominantly deform by brittle behaviour, which is empirically described with the temperature-independent law by Byerlee (1978):

$$
\Delta \sigma_{\mathrm{b}}=f_{\mathrm{f}} \rho_{\text {bulk }} g z\left(1-f_{\mathrm{p}}\right)
$$

where $\Delta \sigma_{\mathrm{b}}$ is the brittle yield strength $[\mathrm{Pa}], f_{\mathrm{f}}$ is the friction coefficient, $\rho_{\text {bulk }}$ is the bulk density $\left[\mathrm{kg} \mathrm{m}^{-3}\right], g$ is the acceleration due to gravity $\left[g=9.81 \mathrm{~m} \mathrm{~s}^{-2}\right.$ ], $z$ is the depth below topography $[\mathrm{m}]$ and $f_{\mathrm{p}}[-]$ is the pore fluid factor $\left(f_{\mathrm{p}}=0.36\right)$. Since strain is overall extensional within the EARS (e.g. 
Bosworth and Strecker, 1997; Stamps et al., 2014), the friction coefficient is chosen to represent extensional deformation $\left(f_{\mathrm{f}}=0.75\right)$.

At larger depths, if temperature is sufficiently high, rocks experience ductile deformation associated with solid-state creep (dislocation or glide). The dominant creep mechanism for the crust and upper mantle is dislocation creep, which represents temperature-dependent non-linear viscous flow (Karato and Wu, 1993). For differential stresses of $\Delta \sigma_{\mathrm{b}}>200 \mathrm{MPa}$ within the mantle, Dorn's law describing solid-state creep behaviour of olivine is a better approximation of the mode of mantle rock deformation (Goetze and Poirier, 1978; Goetze and Evans, 1979).

The corresponding ductile yield-stress equations read as power-law rheology functions:

$$
\begin{aligned}
& \Delta \sigma_{d,<200 \mathrm{MPa}}=\left(\frac{\dot{\varepsilon}}{A_{\mathrm{p}}}\right)^{\frac{1}{n}} \exp \left(\frac{Q}{\mathrm{nRT}}\right), \\
& \Delta \sigma_{d,>200 \mathrm{MPa}}=\sigma_{\mathrm{D}}\left(1-\left[-\frac{\mathrm{RT}}{Q_{\mathrm{D}}} \ln \frac{\dot{\varepsilon}}{A_{\mathrm{D}}}\right]^{\frac{1}{2}}\right),
\end{aligned}
$$

where $\dot{\varepsilon}$ is the reference strain rate $\left(\dot{\varepsilon}=10^{-15} \mathrm{~s}^{-1}\right.$; e.g. Sonder and England, 198), $A_{\mathrm{p}}$ is a pre-exponential scaling factor $\left[\mathrm{Pa}^{-n}\right], n$ is the power-law exponent, $Q$ is the activation energy [J], $\sigma_{\mathrm{D}}$ is the Dorn's law stress [Pa], $Q_{\mathrm{D}}$ is the Dorn's law activation energy $[\mathrm{J}]$ and $A_{\mathrm{D}}$ is the Dorn's law strain rate $\left[\mathrm{s}^{-1}\right.$ ], while $R$ and $T$ are the universal gas constant $\left[R=8.314 \mathrm{~J} \mathrm{~K}^{-1} \mathrm{~mol}^{-1}\right]$ and the absolute temperature $[\mathrm{K}]$, respectively.

The variation of maximum yield strength with depth for a certain $X-Y$ position is expressed by a yield-strength envelope (YSE; Goetze and Evans, 1979):

$\mathrm{YSE}=\min \left(\Delta \sigma_{\mathrm{b}}, \Delta \sigma_{\mathrm{d}}\right)$.

Based on this vertical variation in strength, we finally compute the depth $(z)$-integrated strength of the entire lithosphere (respectively crust):

$\sigma_{\mathrm{L}}=\int_{0}^{z}\left(\sigma_{1}-\sigma_{3}\right) \times \mathrm{d} z$.

To calculate the ductile strength of the lithosphere using Eq. $(7 a, b)$, temperatures are derived from the 3-D conductive thermal model. The rheological parameters assigned to the model units (type rheologies) are consistent with the physical properties (i.e. seismic velocity, density) and derived lithologies of the units (Table 4). For example, considering the demonstrated differences between the western and eastern domains of the upper crustal layer (Fig. 7a; Sect. 3), we have chosen "granite (dry)" and "diorite (dry)" as their rheological type compositions, respectively. In a similar way, the rheological parameterisation of the basal crustal layer is also guided by prevailing lithologies as inferred from available geophysical observations (Table 4). The overall reasoning for the parameterisation is that we assume that the larger the seismic velocity and density, the stiffer the crustal rheology.

\subsection{Results}

Figure $8 \mathrm{~b}$ shows the surface heat-flux density derived from the 3-D thermal model. The spatial correlation of high heatflux density in western Kenya $\left(>70 \mathrm{~mW} \mathrm{~m}^{-2}\right)$ with shallower depths of the $1350{ }^{\circ} \mathrm{C}$ isotherm (Fig. 8a) is obvious. In contrast, low heat-flux values $\left(<60 \mathrm{~mW} \mathrm{~m}^{-2}\right)$ occur in the eastern basins domain where the $1350^{\circ} \mathrm{C}$ isotherm is located at larger depths and the sediment thickness is high (Fig. 2b). The effect of the lower thermal boundary condition is superimposed by the influence of radiogenic heat produced in the crust as becomes obvious from the correlation of high surface heat flux (Fig. 8a) and large thickness of the upper crustal layer (Fig. 7a) that is assumed to produce more heat on average than the basal crustal layer (Table 4).

To validate the 3-D thermal model, we have analysed temperatures measured over variable depth ranges in shallow boreholes (with minimum and maximum depths below topography of 19 and $280 \mathrm{~m}$, respectively; Nyblade et al., 1990; Wheildon et al., 1994). The differences between the geothermal gradients observed in boreholes and corresponding predictions of the 3-D thermal model are shown in Fig. 8c. The overall range in the differences between modelled and measured gradients (with a mean of $-4 \mathrm{~K} \mathrm{~km}^{-1}$ ) suggests that the model neither significantly overestimates nor underestimates the heat arriving at the surface of the model. On the other hand, modelled geothermal gradients, which are too low compared to the measured values, are concentrated close to the Nyanza-Kenya rift junction, while overestimated geotherms are scattered across the entire study area.

The calculated maximum differential stress varying with depth is illustrated by YSEs for four locations along an across-rift profile (Fig. 9). In western Kenya (locations A and B), the basal crustal layer forms a weak domain between the upper crustal layer and the mantle ("jelly-sandwich model"; Hirth and Kohlstedt, 2013). Towards the east, the strength of the basal crustal layer tends to increase so that the YSE at point D is "saturated" showing that ductile deformation is restricted to the mantle ("crème-brûlée model"; Jackson, 2002).

According to our calculations, the total strength integrated over the full depth of the lithosphere shows a large variability of $\sigma_{\mathrm{L}}=12.3-13.8 \log _{10} \mathrm{Pam} \sigma_{\mathrm{L}}=10^{12.3}-10^{13.8} \mathrm{Pam}$ ) across the study area (Fig. 10a). Almost as large as this is the spatial variability in integrated crustal strength (Fig. 10b). Both distributions reveal the largest strengths in the southeastern parts of the study area and the smallest strengths in northern Kenya. The northern domains of crustal and lithospheric weakness correlate with the shallowest depths of the 

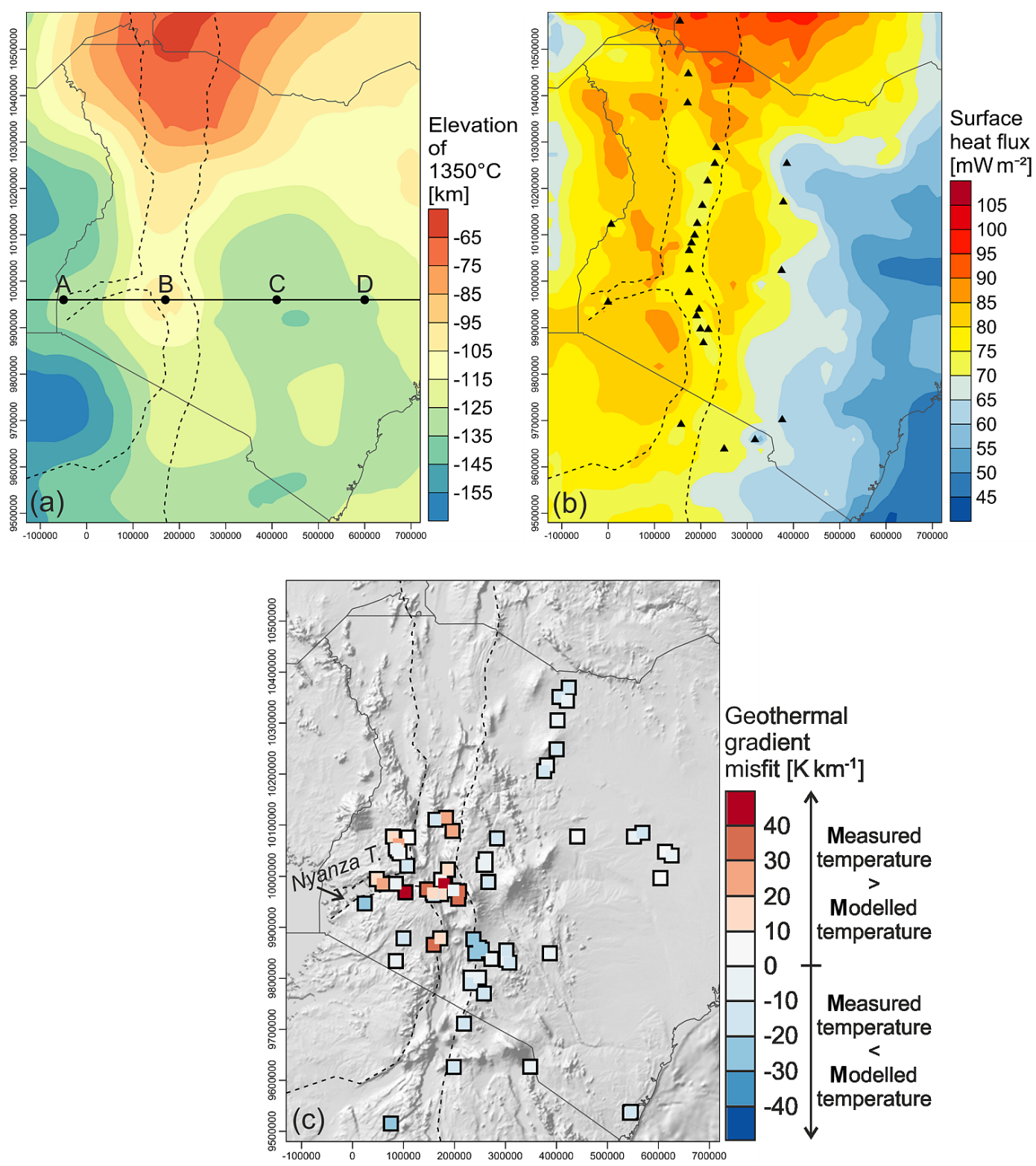

Figure 8. Modelled thermal field. (a) Depth of the $1350^{\circ} \mathrm{C}$ isotherm derived from $S$ wave velocity models (Fig. 5b) by following the approach of Priestley and McKenzie (2006) and utilised as the lower thermal boundary condition; black line and points A-D delineate the profile shown in Fig. 9. (b) Calculated surface heat-flux density derived from the 3-D thermal model; locations of volcanoes from the Global Volcanism Program, Department of Mineral Sciences, Smithsonian Institution, http://volcano.si.edu/. (c) Misfits in shallow geothermal gradients (measured minus modelled values). The measured geotherms are derived from shallow temperature data covering maximum depth ranges of $280 \mathrm{~m}$ (databases of Nyblade et al., 1990; Wheildon et al., 1994).

$1350^{\circ} \mathrm{C}$ isotherm (Fig. 8a) and the highest surface heat-flux densities (Fig. 8b). In these sectors, up to $99 \%$ of the calculated strength is associated with the crust (Fig. 10c). In contrast, the Turkana and northern rift region - where the Moho is situated at shallow depths (Fig. 3a) and the crust is thinned (Fig. 3b) - bears most of its strength (up to 93\%) within the lithospheric mantle. In the southern rift domain (including the Tanzania divergence), both lithospheric and crustal strengths are significantly reduced compared to the corresponding off-rift domains. 


\section{Discussion}

\subsection{Modelled density configuration of the crust}

\subsubsection{Model sensitivity and robustness}

For the mantle below $100 \mathrm{~km}$ depth, we have converted $S$ wave velocities into temperatures (following the empirical approach of Priestley and McKenzie, 2006) and densities assuming that the mantle is homogeneously composed of undepleted spinel peridotite (Mechie et al., 1994). It would be highly speculative to implement lateral heterogeneities in mantle composition to assess the related influence on the gravity field. Testing alternative uniform mantle compositions for model sensitivity, however, is a straightforward undertaking as it means averaging physical properties according to alternative relative portions of constituting minerals (see Table D1, Appendix D). Such a change in the model set-up results in an overall shift of the calculated densities. For example, while for the undepleted spinel peridotite a mean of $3325 \mathrm{~kg} \mathrm{~m}^{-3}$ is calculated, the mean density for a harzburgite composition (Irifune, 1987) is $3373 \mathrm{~kg} \mathrm{~m}^{-3}$ and for a pyrolite composition (Irifune and Ringwood, 1987) it is $3400 \mathrm{~kg} \mathrm{~m}^{-3}$. The spatial variances in density, however, turn out to be nearly identical $\left(\Delta \rho=498 \pm 2 \mathrm{~kg} \mathrm{~m}^{-3}\right)$ for the three compositions, as are the standard deviations ( $\left.\rho=22.1 \pm 0.2 \mathrm{~kg} \mathrm{~m}^{-3}\right)$ and the spatial distributions of density highs and lows. Most importantly, all of the temperaturecontrolled density variations tested result in negligible effects on the gravity field, i.e. only $\pm 2 \mathrm{mGal}$ compared to a homogeneous mean mantle density. The modelled deeper part of the mantle $(>100 \mathrm{~km})$ thus does not have any significant influence on the gravity-driven investigation of the density configuration of the crust.

For mantle depths between the Moho and $100 \mathrm{~km}$, we have applied the linear relationship proposed by Ravat et al. (1999) to derive densities from different $P$ wave velocity datasets. These datasets (Fig. 5a) are remarkably consistent in terms of the location and geometry of the LVA underneath the rift while differing in terms of velocity contrast between the rifted mantle domains and undisturbed surroundings. Our model here comprises a relatively large density contrast in accordance with the KRISP seismic velocities $\left(\Delta \rho \leq 25 \mathrm{~kg} \mathrm{~m}^{-3}\right.$; Fig. 5a). According to the tomographic studies (e.g. Achauer and Masson, 2002), the negative velocity anomaly with respect to PREM amounts to $\leq 12 \%$, which translates to $\Delta \rho<10 \mathrm{~kg} \mathrm{~m}^{-3}$. When decreasing the mantle-density difference between the rift and surroundings to $\Delta \rho=10 \mathrm{~kg} \mathrm{~m}^{-3}$, we find that the calculated gravity response changes by up to $50 \mathrm{mGal}$, which implies a strong impact on the assessment of crustal densities. We favour, however, the presented model with a larger density contrast since it involves crustal densities that are consistent with those also derived from the KRISP seismic velocities (Eq. 1; Fig. 4d, e).
The largest uncertainties concerning the modelled depth of the Moho exist in north-eastern Kenya where this information derives from a (non-unique) gravity-constrained 3D density model (Woldetinsae, 2005). The only alternative model is the global model LITHO1.0 (with a lower spatial resolution of $1^{\circ}$; Pasyanos et al., 2014). Aside from local depth differences $(\Delta z<5 \mathrm{~km}$ over regions spanning $<150 \mathrm{~km}$ ) that would correspond to differences in calculated gravity of $< \pm 30 \mathrm{mGal}$, the two models agree well in terms of regional Moho trends. Hence, no matter which of these two models we would have chosen, one of the main findings of this study would remain, namely that north-eastern Kenya is regionally underlain by a lower crust of high density $\left(\rho=3000 \mathrm{~kg} \mathrm{~m}^{-3}\right)$ with NW-SE-oriented thickness maxima (Fig. 7b).

Modelling the sedimentary and volcanic cover involves uncertainties related to assumptions on lithologies and porosities (Tables 1, 2; Appendix A). For western Kenya, the use of information on lithologies (e.g. Morley et al., 1992) and densities (e.g. Morley, 1999) complemented by the KRISP constraints on crustal and mantle densities directly results in a reliable fit between calculated and measured gravity (Fig. 6c). We attribute this also to the low volumes of sedimentary/volcanic rocks in western Kenya (Fig. 2b). In contrast, sediment thicknesses in the domain of the eastern basins are much larger, pointing also to larger porosity variations (due to differential states of compaction). Our model is consistent with the available information on porosity-controlled density increase in the Anza (Jose and Romanov, 2012) and Lamu basins (Yuan et al., 2012). Assuming an alternative scenario of a fully compacted sediment package in the eastern basins domain with a homogeneous bulk density of $2710 \mathrm{~kg} \mathrm{~m}^{-3}$, for instance, would increase the gravity response locally by up to $+80 \mathrm{mGal}$. To restore the gravity fit, however, this density increase would require a reduction of the average density of the underlying upper crustal layer by $<40 \mathrm{~kg} \mathrm{~m}^{-3}$. Hence, the general trend of eastward increasing densities in the entire crust (Fig. 7c) would still remain.

In our gravity modelling approach we consider one single degree of freedom, which is the density configuration of the crystalline crust. However, given the relationship between two differently dense crustal layers and the resulting gravity response, the solution to our problem requires to take into account an additional free parameter, which is the depth of the top of the basal crustal layer outlining the thickness variations of the two layers. For this purpose, we present the map of the obtained average crustal density (Fig. 7c) together with the thicknesses and densities of the two crustal bodies (Fig. 7a, b). While the average crystalline crustal density (as derived from the density and thickness configurations of the two crustal units) may be regarded as the more appropriate interpretation of the observed gravity anomalies across wide parts of the study area, it under interprets the structural constraints provided by the KRISP profiles in western Kenya. 
In the final 3-D model, as constrained via the conversion of $P$ wave velocities and by gravity modelling, lateral variations in the density configuration are more reliable than absolute density values. This is because of uncertainties inherent in the density structure considered as the starting model. The most important determined trend, however, in terms of density gradients between western and eastern Kenya (Fig. 7c), is consistently mapped by both an eastward increase in the thickness of the relatively denser basal crustal layer and by the lateral density variations of the two crustal units.

The quality of the final modelling results rely on the quality of the input data used to build up the starting 3-D density model. Uncertainties associated with each dataset are, however, partly unknown (such as for the basement depth; Beicip, 1987), different in type (similar to the data) and are also transferred in a different manner to the 3-D model (via interpolation, velocity-density conversion, etc.). All of this hampers a quantification of uncertainties. It is also worth noting that any gravity-guided manual adjustment to the density configuration is subject to the modeller's decision. Therefore, there is an inevitable degree of non-uniqueness in the way density variations are partitioned. Although we have carried out all modifications in a systematic way, the modelling approach does not permit any straightforward quantitative assessment of related uncertainties with respect to the final 3-D density configuration.

The five tectono-thermal domains that are proposed to represent surface expressions of a complex juxtaposition of interlocked crustal units (Fritz et al., 2013) have not been used as input for the 3-D modelling. Since most of the study area is covered by Mesozoic-Cenozoic sediments and volcanics, the spatial distributions of these five domains (Fig. 1b) and their geometrical continuation towards greater crustal depths have only been interpreted from scattered outcrop observations (including fault geometries; Fritz et al., 2013). Our seismic velocity- and gravity-guided 3-D density model for the first time provides the basis for a joint interpretation of deep geophysics and surface geological observations concerning the configuration of the crust across the entire study area (see Sect. 6.1.2).

To summarise, we present a 3-D density model that is not only consistent with the observed gravity field but also cross-checked with a wide spectrum of gravity-independent criteria and observations. The strength of our modelling approach thus stems from an efficient integration and usage of a large variety of different datasets. Furthermore, as already discussed above, the obtained trends in crustal density heterogeneities would have remained of the same order even if the density configurations of the sediments and mantle would have been implemented differently from what was done in this study, though still within the respective data constraints.

\subsubsection{Model interpretation}

\section{Upper crustal layer}

The 3-D model reveals that the strongest density contrast within the upper crustal layer largely correlates with the western margin of the microcontinent Azania as proposed by Fritz et al. (2013; Figs. 1b, 7a). Azania is inferred to be separated from tectonic blocks of the Mozambique Belt (Arabian-Nubian Shield and Eastern Granulites; Fig. 1b) by west-dipping thrust faults (Fritz et al., 2013). In correspondence with this tectonic model, we interpret the slight westward offset of the modelled density contrast with respect to the surface boundary (Fig. 7a) as being due to fault dips through which Azania's margin is located farther west towards greater depths.

In contrast to previous studies (e.g. Tesha et al., 1997; Simiyu and Keller, 1997) that proposed a major density difference in the upper crust between the Tanzania Craton $\left(\rho=2680 \mathrm{~kg} \mathrm{~m}^{-3}\right)$ and the Mozambique Belt $\left(\rho=2700 \mathrm{~kg} \mathrm{~m}^{-3}\right)$, our study does not provide arguments for a further separation of the upper crustal layer into major (density) domains (such as those of Fritz et al., 2013; Fig. 1b). Both, seismic velocity distribution (Fig. 4d) and residual gravity (Fig. 6c) only indicate lower-amplitude and, in particular, smaller-scale density variations inside each of the two (western and eastern) density domains (Fig. 7a). In contrast to Azania being predominantly composed of metaigneous rocks, the Precambrian domains of western Kenya comprise both meta-sedimentary and meta-igneous rocks (Table 3), which might explain the similarities of the western Kenyan domains in terms of their overall velocity and density structure. Hence, we conclude that the most important physical contrast within the upper crustal layer corresponds to the boundary between Azania and the Mozambique Belt (Fig. 1b).

\section{Basal crustal layer}

We have extended the basal crustal layer as constrained along the KRISP refraction seismic profiles all across the study area where, however, it shows variable densities and thicknesses (Fig. 7b). For the main rift domain (with densities of $\rho=2920 \mathrm{~kg} \mathrm{~m}^{-3}$ ), there is strong consensus that the high $P$ wave velocities reflect mafic to ultramafic rocks that intruded and/or underplated the lower crust during Cenozoic rifting, especially if the large volumes of differentiated volcanic rocks are taken into account (e.g. Lippard, 1973; Hay et al., 1995; Mechie et al., 1997; Thybo et al., 2000). Accordingly, the high-density crustal material is interpreted as a residue of magmatic differentiation after ponding of magma around the Moho, a process known from various continental rifts (e.g. Thybo and Artemieva, 2013). Compared to the remaining model units of the basal crustal layer, the proposed mafic rocks underlying the Kenya rift show relatively low 
velocities and densities (Figs. 4e, 7b), which might be due to elevated mantle and crustal temperatures (cf. Figs. 5c, 8a) and related thermal expansion of the rocks (see also, e.g., Maguire et al., 1994).

Underplating during Cenozoic rifting and variable mantle temperatures at the present-day, however, cannot explain the whole complexity of the modelled basal crustal layer. The largest thicknesses of this layer, for example, have been modelled east of the Cenozoic rift (Fig. 7b), i.e. in a NW-SEstriking band underlying the similarly oriented Anza Basin (cf. Fig. 2b). This configuration might therefore be indicative of a Cretaceous phase of extensional tectonics (Foster and Gleadow, 1996) and magmatic underplating related to the development of this (ultimately failed) rift. On the other hand, the basal crustal layer also shows considerable thicknesses beneath the Mandera and northern Lamu basins (Fig. 7b) as well as their continuations towards Somalia, where an "anomalous basement" with densities of $\rho=3015$ $3300 \mathrm{~kg} \mathrm{~m}^{-3}$ is described (Rapolla et al., 1995). Hence, it is also plausible that the high-density basal crustal layer underlying the eastern basins already had formed during the Jurassic rifting events that culminated in the formation of the Indian Ocean.

Finally, there are domains of large thickness within the basal crustal layer that do not spatially correlate with rifted Phanerozoic sedimentary basins. Alternative processes such as metamorphism of the hydrous crust due to pressurisation and heating (e.g. Semprich et al., 2010) also could have potentially produced such a high-density lower crust. One indication for different origins of the basal crustal layer in the southern rift domain is provided by line G in KRISP; the basal layer below the rift reveals a much stronger seismic reflectivity than domains outside the rift (Thybo et al., 2000). According to our model, this change in reflectivity is accompanied by an increase in density and thickness towards the SE (Figs. 4c, 7b).

Within the south-eastern domain of highest densities $\left(\rho=3050 \mathrm{~kg} \mathrm{~m}^{-3}\right.$; Fig. $\left.7 \mathrm{~b}\right)$, the largest thicknesses are attained around the proposed boundary between Azania and the Mozambique Belt (Eastern Granulites; see Fig. 1b; Fritz et al., 2013). In northern Tanzania, this subdomain includes the Masai Plateau, a tectonic block of Neoproterozoic (PanAfrican) meta-sedimentary rocks (Selby and Mudd, 1965; Fig. 7a, b) that Ebinger et al. (1997) interpreted as a discrete terrane based on both distinctive gravity and magnetic anomalies. Hence, the formation of high-density lower crust in this area might also be related to magmatic and/or metamorphic processes that accompanied the Precambrian amalgamation associated with the East African Orogeny.

\section{Residual gravity}

Even if a better fit between modelled and observed gravity could theoretically be achieved, we refrain from implementing additional contrasts into the 3-D density model because (i) the wavelengths and amplitudes of the residual gravity anomalies $(<200 \mathrm{~km},< \pm 30 \mathrm{mGal}$; Fig. $6 \mathrm{c})$ are beyond the scope of this study and (ii) the results would largely remain highly non-unique due to the scarcity of gravity-independent constraints on subsurface densities. Nevertheless, some implications on smaller-scale density heterogeneities can be derived from the residual gravity directly.

Given the half-wavelengths in the residual gravity anomalies that predominantly remain shorter than $150 \mathrm{~km}$, their causes must be located within the crust rather than deeper in the mantle. This corresponds well with local $P$ wave velocity anomalies as detected on some of the KRISP profiles. For instance, the residual gravity of our study reveals a positive anomaly (indicating a mass deficit in the 3-D density model) on the eastern margin of the Kenya rift north-east of the Nyanza-Kenya rift junction (point A; Fig. 6c). Line D in KRISP crosses this area and reveals a $50 \mathrm{~km}$ wide structure at $<10 \mathrm{~km}$ depth with velocities up to $v_{p}=0.2 \mathrm{~km} \mathrm{~s}^{-1}$ larger than the surroundings (e.g. Maguire et al., 1994; KRISP line D, Fig. 4a). Keller et al. (1994) interpreted this highvelocity structure as being caused by numerous mafic intrusions (dykes). Likewise, Prodehl et al. (1994) related a structure of high seismic velocity and reflectivity at the southeastern tip of line E in KRISP (point B; Fig. 6c) to gabbroic intrusions inferred to predate Cretaceous (Anza) and Cenozoic (Kenya) rifting.

The gravity high in the southern rift domain (point $\mathrm{C}$; Fig. 6c) has been reproduced by a modelled high-density body (with $20 \mathrm{~km}$ width, at $4 \mathrm{~km}$ depth) that is interpreted as a massive intrusion within the thick low-density tuff and ashes of the Neogene to recent rift (Simiyu and Keller, 2001). On the other hand, the gravity high located farther southeast (point D; Fig. 6c) spatially correlates with a shallow zone of low electrical conductivity (high resistivity; $<100 \mathrm{~km}$ wide, $<10 \mathrm{~km}$ deep), which is bordered to the SE and NW by conductive material (interpreted to contain deposits with hot saline fluids; Meju and Sakkas, 2007). Taken together, these observations consistently relate local gravity (residual) highs, i.e. mass deficits in the regional 3-D density model, with massive and impervious high-density intrusions.

The four locations referred to (points A-D) appear as residuals of $>30 \mathrm{mGal}$ (Fig. 6c). Interestingly, most of such significant mass-deficit locations in our model are situated in a narrow $\mathrm{N}-\mathrm{S}$-oriented band along the eastern margin of the rift and west of Azania's western margin. It is not clear whether these shallow crustal structures developed in response to Precambrian Azania-Mozambique Belt collisional processes or during Cenozoic extension. Prodehl et al. (1994), for instance, favoured the first scenario. In any case, the related physical contrasts observed at the presentday should be taken into account when investigating local deformation such as dyke emplacement. It is interesting, for example, that the active volcanoes of the study area appear to be offset from these inferred high-density bodies (Fig. 6c). 
The residual gravity also reveals areas of significant mass excess in the 3-D density model; i.e. areas in which the calculated gravity overestimates the observed values by $>30 \mathrm{mGal}$ (Fig. 6c). Most of these spots are concentrated in the northern Kenya rift and the Nyanza rift. Since there is no correlation between the geometries of the rift fill (Fig. 2b) and the location of the mass excess areas, we can exclude that a modification of sediment and volcanic densities would decisively improve the gravity fit. Sedimentary and volcanic rocks in the Nyanza rift, for instance, are less widely distributed (Fig. 2a; Beicip, 1987) than the significant observed gravity low (Fig. 6a) and the related mass excess in the model (Fig. 6c). The extent of the negative anomaly rather points to a source within the crystalline basement.

The presented model reveals mass excess (Fig. 6c) in places where the Moho is situated at relatively shallow depths (as constrained by the KRISP refraction seismic data; Fig. 3a), the crust is strongly thinned (Fig. 3b) and mantle temperatures are increased (Fig. 5c; as indicated by low shear-wave velocities). Still, the spots of modelled mass excess reflect smaller-wavelength anomalies compared to these major products of rifting, which overall points to intracrustal heterogeneities. These low-density domains might be a result of local thermal anomalies (that are not integrated in the 3-D model and) that induce local thermal expansion (as proposed for the basal crustal layer; e.g. Maguire et al., 1994) and even partial melting (as proposed for the mantle; Mechie et al., 1994). A causal relationship between crustal density and thermal perturbations is also indicated by the active volcanoes that are predominantly located in areas of modelled mass excess (i.e. in spots of low residuals along the Kenya rift; Fig. 6c). Interestingly, also the geothermal gradients, underestimated by the purely conductive thermal model, are indicative of increased (maybe advective, magma or water controlled) heat transfer around the Nyanza-Kenya rift junction (Fig. 8c; see also Wheildon et al., 1994).

An alternative explanation for low densities in the Nyanza rift crust, however, could be seen in compositional variations. This part of the rift is known for its exceptional Cenozoic volcanic assemblages containing large amounts of carbonatites (Jones and Lippard, 1979; Onuonga et al., 1997). A compositional rather than thermal effect would better explain the significant drop of $P$ wave velocity (from $v_{p} \approx 6.325$ to $6.150 \mathrm{~km} \mathrm{~s}^{-1}$ ) in the upper crustal layer at the eastern end of the Nyanza rift (KRISP line ABC; Fig. 4d).

\subsection{Modelled strength configuration}

\subsubsection{Model sensitivity and robustness}

The rheological configuration of the lithosphere is mainly controlled by its thermal state (Eq. 7a, b), which is assessed based on two strong assumptions: (i) heat is transported solely by thermal conduction and (ii) the modelled system is in thermal equilibrium (steady state). Previous studies have
Table 5. Modelled brittle-ductile transitions and observed depths of peak seismicity.

\begin{tabular}{llrr}
\hline $\begin{array}{l}\text { Locations } \\
\text { (Fig. 10a) }\end{array}$ & $\begin{array}{l}\text { Modelled depth of the top of } \\
\text { the brittle-ductile transition }\end{array}$ & $\begin{array}{r}\text { Depths of peak } \\
\text { seismicity* }\end{array}$ \\
\hline & $\begin{array}{l}\text { crust } \\
(\mathrm{km})\end{array}$ & $\begin{array}{r}\text { mantle } \\
(\mathrm{km})\end{array}$ & $(\mathrm{km})$ \\
\hline E, "Bogoria" & 11.4 & 36.1 & 10.0 \\
F, "Magadi north" & 12.2 & 39.1 & $3.8 ; 12.2$ \\
G, "Magadi south" & 12.9 & 39.4 & 20.0 \\
H, "Balangida" & 13.1 & 43.9 & $20.0 ; 40.0$ \\
\hline
\end{tabular}

* From Albaric et al. (2009).

shown that thermal diffusion is the dominant heat transport mechanism in the lithosphere and thus controls the longwavelength temperature pattern within the crust (e.g. Pollack et al., 1993; McKenzie et al., 2005; Scheck-Wenderoth et al., 2014). The Kenya rift, however, is well-known for its active magmatic and hydrothermal systems leading to locally perturbed surface heat flow (e.g. Nyblade et al., 1990; Ogola et al., 1994; Wheildon et al., 1994).

Furthermore, we have derived the lower thermal boundary condition $\left(1350^{\circ} \mathrm{C}\right.$ isotherm; Fig. 8 a) from mantle $S$ wave velocities using an empirical conversion approach (Priestley and McKenzie, 2006) and assuming that it is in equilibrium with the prescribed surface temperatures (upper boundary condition). Such modelled steady-state conditions do not account for the likelihood that the excess heat related to the mantle thermal anomaly emplaced some $45 \mathrm{Ma}$ ago has not yet been conducted to the surface due to the low thermal diffusivity of rocks (Appendix E; e.g. Wheildon et al., 1994). Consequently, it must be expected that the thermal model overestimates temperatures in the shallower parts of the lithosphere (i.e. where the thermal anomaly has not yet diffused to).

Indeed, we find modelled thermal gradients that are too high compared to measured values spread all across the study area (Fig. 8c). In contrast, however, the largest misfits are indicative of underestimated temperatures being concentrated in the Nyanza and Kenya rifts that are believed to be perturbed by hydrothermal activity (e.g. Wheildon et al., 1994). The misfits generally tend to decrease with increasing distance from the rift. Hence, deeper temperature measurements that are less prone to advective thermal perturbations would be a more useful basis to validate the 3-D thermal model than the shallow geothermal gradients. Given the lack of such data and our interest in the crustal and lithospheric-scale thermal and rheological state of the system, we nevertheless regard the conductive 3-D thermal model as an appropriate general approximation.

The calculated lithospheric strength configuration (Fig. 9, 10 ) is based on a spatially invariable strain rate (of $\dot{\varepsilon}=10^{-15} \mathrm{~s}^{-1}$ ). We are aware that estimations of the presentday strain-rate variations show a range of $\approx 10^{-15}-10^{-18} \mathrm{~s}^{-1}$ 


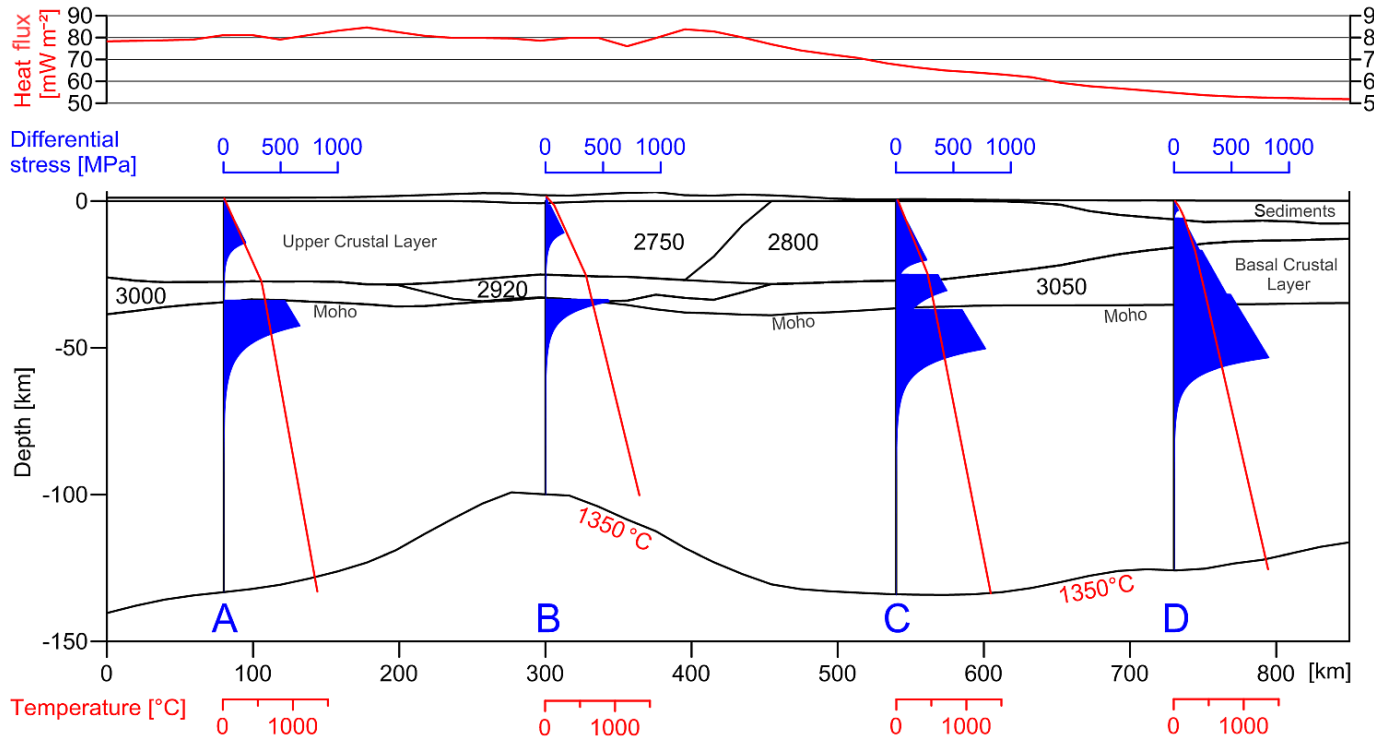

Figure 9. Across-rift profile through the 3-D structural model with yield-strength envelopes at four locations (A-D; locations in Figs. 8a and 10a); numbers in selected structural units indicate gravity-constrained density $\left(\mathrm{kg} \mathrm{m}^{-3}\right)$; also shown are the geothermal gradients for the four locations and the along-section heat-flux density.

for the EARS with significant strain localisation along its rifts (e.g. Stamps et al., 2014; Melnick et al., 2012). However, we do not intend to simulate present-day deformation with these calculations (which would require a dynamic instead of a steady-state approach). Using a spatially invariant strain rate, however, allows us to uncover rheological discontinuities inherent in the thermal state and the compositional heterogeneity of the system. Thus, we provide a model mimicking conditions that potentially have controlled the rift localisation process. The resulting pattern of strength variations thereby does not change significantly when applying alternative strain-rate values. For example, a strain rate of $\approx 10^{-16} \mathrm{~s}^{-1}$ would result in a range of lithospheric strength of $\sigma_{\mathrm{L}}=11.9-13.4 \log _{10} \mathrm{~Pa} \mathrm{~m}$ (compared to $\sigma_{\mathrm{L}}=12.0-13.5$ $\log _{10} \mathrm{Pam}$ for $\approx 10^{-15} \mathrm{~s}^{-1}$ ) while showing the same spatial trends.

The gravity-constrained 3-D structural model provides the basis and thus the spatial resolution for the thermal and rheological calculations. Each model unit is populated with homogeneous average rock properties according to its prevailing lithologies (Tables 1, 2, 3, 4). These lithologies, in turn, have been inferred from gravity-constrained densities in combination with seismic $P$ wave velocities (Christensen and Mooney, 1995). For the upper crustal layer this approach is confirmed relatively well by the consistency between the derived lithologies and geological outcrop data. A more detailed and thus more realistic differentiation of rheological heterogeneities in the lithosphere would require even more observations. At this stage of investigating the greater Kenya rift by means of the currently available data, however, we present only one scenario designed to reflect the main com- positional trends observed by correlating high (low) density with strong (weak) rheology.

A potential key to evaluate the uncertainties inherent in the overall rheological modelling approach is provided by local observations on seismicity. Assuming that shortterm deformation reflects the long-term mechanical properties of the lithosphere, the relative abundance of earthquakes is supposed to be related to the yield strength at depth (Ranalli, 1995, 1997). Albaric et al. (2009) presented the depth-frequency distribution of earthquakes for four localities in the southern rift domain including the Tanzania divergence (E-H; Table 5; Fig. 10a). At these points, the numbers of earthquakes strongly vary with depth, delineating one or more depth levels of increased seismicity. Albaric et al. (2009) interpreted these peak seismicity depths as indicating tops of brittle-ductile transitions (BDTs) and thus rheological discontinuities. For point $\mathrm{G}$ located in the southern rift (Fig. 10a), none of the modelled brittle-ductile transitions (neither in the crust nor in the mantle) fits with the observed peak seismicity depth (Table 5). In contrast, for points $\mathrm{E}$ and $\mathrm{F}$ certain peak seismicity depths correlate remarkably well with the tops of BDTs in the crust as predicted by our model. For point $\mathrm{H}$ in the Tanzania divergence it is the depth of the modelled mantle BDT that is similar to the observed peak seismicity depth in the mantle. Hence, despite the various model uncertainties we identify consistencies between the modelled rheological configuration of the lithosphere and first-order observations on seismicity. 

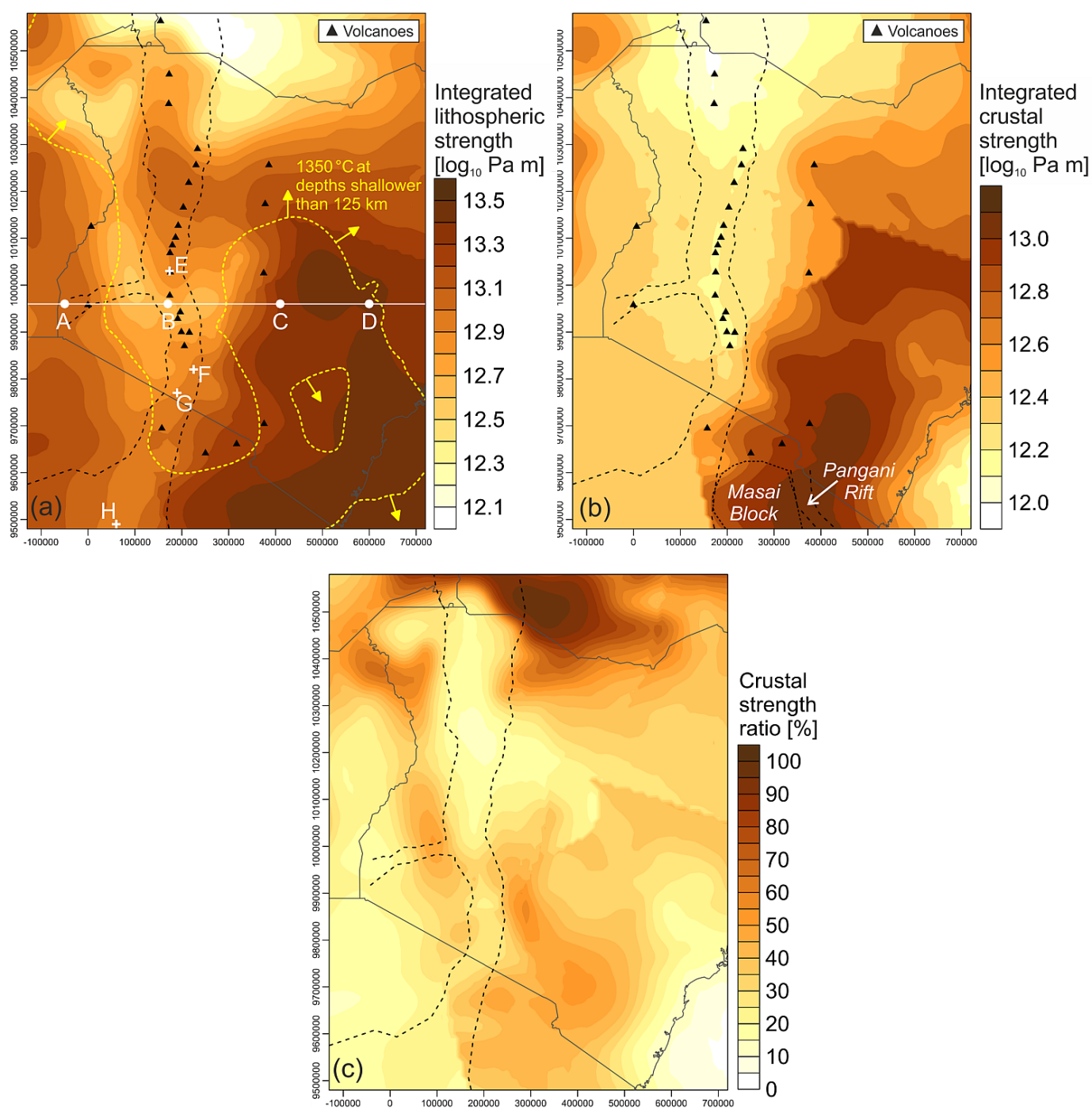

Figure 10. (a) Total depth-integrated strength of the lithosphere; locations of volcanoes from the Global Volcanism Program, Department of Mineral Sciences, Smithsonian Institution, http://volcano.si.edu/; white line and points A-D delineate the profile shown in Fig. 9, while points E-H mark the locations for which Albaric et al. (2009) have derived depths of peak seismicity (Table 5); yellow dashed line marks where the $1350{ }^{\circ} \mathrm{C}$ isotherm (Fig. 8a) is located at a depth of $125 \mathrm{~km}$ (see main text for comments). (b) Integrated strength of the crust; spatial extensions of the Masai block and the Pangani rift derived from Le Gall et al. (2008). (c) Ratio of crustal strength with respect to lithospheric strength.

\subsubsection{Model interpretation}

We find that the integrated strength of the lithosphere varies considerably across the study area $\left(\sigma_{\mathrm{L}}=12.0-13.5\right.$ $\log _{10}$ Pa m; Fig. 10a) showing almost the same range of orders of magnitude as lithospheric strength distributions calculated for global models (e.g. $\sigma_{\mathrm{L}}=12.3-14.1 \log _{10} \mathrm{~Pa} \mathrm{~m}$ under compression; Tesauro et al., 2012). Not surprisingly, this large variability in modelled strength is related to the mantle thermal anomaly: where the $1350{ }^{\circ} \mathrm{C}$ isotherm (Fig. 8a) is shallow, mechanical strength tends to be low, which is illustrated by plotting the $125 \mathrm{~km}$ contour of the $1350^{\circ} \mathrm{C}$ isotherm on the lithospheric strength map (Fig. 10a).
On the other hand, the crust contributes an important fraction to the total lithospheric strength (Fig. 10c) and boundaries between crustal domains with different densities (and strengths; Fig. 7a, b) can clearly be traced in the lithospheric strength distribution (Fig. 10a). Hence, according to our model, rheological differences within the crust are strongly controlled by crustal composition. Relative to the thermal impact, this inherited compositional effect on crustal strength has probably been even larger in the past when the diffusion process induced by the thermal anomaly was even less advanced.

As discussed above, the differences in crustal structure and composition between western and eastern Kenya can 
be ascribed to (i) the Precambrian amalgamation of eastern Kenya (i.e. mainly Azania) associated with the East African Orogeny and (ii) rifting-related upper crustal thinning and magmatic underplating in the Mesozoic. In line with the latter and based on seismicity-derived rheological models, Albaric et al. (2009) concluded that the lower crust in the south-eastern parts of the study area is generally enriched in magnesium and iron (mafic) and may be a product of magmatic events that repeatedly affected the crust since at least $\approx 2.5 \mathrm{Ga}$ (Halls et al., 1987; Ashwal and Burke, 1989). The western boundary of this proposed tectonic zone in SE Kenya is part of an overall NNE-SSW-oriented line that marks the most significant density contrast detected by our integrated 3D gravity modelling approach and runs parallel to Azania's western margin (Fig. 7c).

Variations in lithospheric strength west of this modelled boundary (i.e. in western Kenya; Fig. 10a, b) are mainly controlled by variable temperature (Fig. 8a) and differences in the thickness of the highly radiogenic (Table 4) upper crustal layer (Fig. 7a), while the basal crustal layer is weak (Fig. 9, points "A", "B"). Furthermore, according to the model, the upper crustal layer is compositionally homogeneous across western Kenya. This is consistent with small variabilities in bulk crustal Poisson's ratios ( $v=0.25-0.26$ for different Precambrian terranes of western Kenya) as derived from receiver function data (Tugume et al., 2013). These authors further propose that the different terranes due to their similar (felsic to intermediate) compositions have not exerted any major control on the localisation of Cenozoic rifting; instead, variations in the lithospheric mantle composition are put forward as a factor. This hypothesis contrasts with the results of previous studies that emphasise the spatial correlation of both the western and the eastern branches of the EARS with Proterozoic mobile belts surrounding the Archean Tanzania Craton. Accordingly, the localisation of the rift has been related to differences in crustal composition (e.g. McConnell, 1972), crustal composition and structure (e.g. Smith and Mosley, 1993; Hetzel and Strecker, 1994), crustal thickness (e.g. Tesha et al., 1997) or lithospheric rigidity (e.g. Nyblade and Brazier, 2002) between the Tanzania Craton and the Mozambique Belt.

Koptev et al. (2015) conceptually implemented the broad low-velocity anomaly observed in the deeper mantle beneath the Tanzania Craton (Nyblade et al., 2000; Adams et al., 2012) into thermo-mechanical forward numerical experiments that reproduce how the mantle plume beneath East Africa rises beneath the craton, is deflected by the cratonic keel and produces a magma-rich rift on its eastern boundary. Ashwal and Burke (1989) proposed that the lithospheric mantle beneath the craton is depleted, while the mantle beneath the rift is fertile (due to Precambrian collisional and post-collisional processes), which facilitated the extraction of magmas and the localisation of Cenozoic volcanism. The presented 3-D model is the first to jointly integrate the present-day mantle thermal anomaly, crustal composi- tion and related strength variations within the crust and lithospheric mantle. This opens the possibility for new hypotheses on plume-lithosphere interactions, i.e. on how dynamic mantle buoyancy forces contributed to tensional stresses in the lithosphere and how the latter responded. According to the 3-D model, the plume-related lithospheric thinning would have been taking place beneath a compositionally and rheologically heterogeneous crust (Fig. 7; Table 4) - even though its structural configuration and, above all, its thermal state have certainly not been the same in the past. Crustal thinning obviously focussed within the southward tapering ArabianNubian Shield (Fig. 1b) as the easternmost part of the rheologically weaker domain of western Kenya (Fig. 10a, b). At the same time, the configuration of eastern Kenya comprising Azania upper crust and remarkably thick, dense and stiff lower crustal rocks (Fig. 7) might have formed a strong barrier against crustal deformation. Hence, strain localisation (induced by mantle dynamics and related tensional stresses) would have been facilitated by pre-existing contrasts in rheological properties between western and eastern Kenya.

The model considering plume-craton interactions (Koptev et al., 2015) does not account for the observation that there is a mantle thermal anomaly with a larger $\mathrm{N}-\mathrm{S}$ extent, underlying all of East Africa (e.g. Hansen et al., 2012), producing hotspot tectonism in Ethiopia and Kenya (e.g. Nyblade, 2011; Bastow et al., 2011) and being responsible for the higher mantle temperatures in northern Kenya (e.g. Fig. 8a, b). New thermo-chronological data indicate that the northward movement of the African lithosphere with respect to the plume during the past $35 \mathrm{Ma}$ (e.g. Ebinger and Sleep, 1998; Moucha and Forte, 2011) was accompanied by an diachronous, spatially disparate and partly overlapping extension along the Kenya rift (Michon, 2015; Torres Acosta, 2015). In general, there is a prominent correlation between the N-S-striking $S$ wave velocity low in the mantle (Fig. 5b) and the N-S-striking Kenya rift (Figs. 2, 3b). In northern Tanzania, however, the rift changes direction to NNE-SSW, thus deviating from the $\mathrm{N}-\mathrm{S}$-oriented mantle anomaly. Furthermore, due to a thick high-density lower crust of maficgranulite composition, the rheological model predicts high crustal and lithospheric strengths for the south-eastern parts of the study area, just flanking the Tanzania divergence in the east (Fig. 10a, b). Hence, we conclude that a further southward propagation of the rift has been prevented by this crustal domain of increased strength leading to the observed southwestward turn (or "divergence") of the rift structures right into mechanically weaker parts of the mobile belt. This is consistent with the findings of Ebinger et al. (1997) and Le Gall et al. (2008), who interpret the relatively unfaulted and amagmatic Masai micro-block (Figs. 7a, b, 10b) to represent a cratonic fragment (beneath thin-skinned nappes) that formed a significant barrier to rifting. The Pangani rift, which is oriented NW-SE along the eastern border of the Masai block (Fig. 10b), cannot be correlated with a corresponding zone of lithospheric or crustal weakness predicted by our 3- 
D model. This tectonic zone differs from the Tanzania divergence also in the sense that it is older (2 Ma compared to ca. $1 \mathrm{Ma}$; Dawson, 1992) and in that it is seismically less active (Ebinger et al., 1997; Foster et al., 1997),

According to the model, active volcanoes within the Kenya rift are situated where the crustal strength is lowest (Fig. 10b), which correlates with locations of an extremely thinned upper crustal layer (Fig. 7a). In the central Kenya rift (i.e. just north of the Kenya rift-Nyanza trough junction; see Fig. 2a), this narrow zone of strongest crustal thinning and volcanism is locally offset from the rift centre towards the eastern boundary of the surface expression of the rift (Fig. 10b). This eastward shift of the volcanic chain, in turn, seems to be related to a local high in total lithospheric strength covering the rift centre (Fig. 10a). High lithospheric strength there is caused by mantle rocks that are situated at relatively shallow depths - as indicated by the corresponding Moho high (Fig. 3a) - and thus are colder and mechanically stronger than rocks in the surroundings.

The modelled strength configuration obviously provides explanations for the spatial distribution of in-rift volcanoes in the study area. For off-rift volcanism such relationships are not that straightforward, but it seems that these volcanoes occur where gradients in lithospheric strength are large (Fig. 10a, b). Further, they obviously flank the region that is most strongly affected by the mantle thermal anomaly (Fig. 8a) and hence most severely weakened. Previous models explaining off-rift volcanism alongside the Kenya rift involve the mechanical loading of homogeneous crust, such as the model of Ellis and King (1991), involving dilatational strain at the base of the crust of rift flanking footwall blocks as a flexural response to normal faulting or the model of Maccaferri et al. (2014) that relates the deflection of ascending magma-filled dykes to changes in the stress field as imposed by rifting-related crustal unloading. In contrast to these models, the presented data-driven 3-D model includes rheological heterogeneities within the crust and thus reveals another potential controlling factor for localised dyke propagation.

\section{Summary and conclusions}

We determined a density configuration for the crystalline crust of the greater Kenya rift region by integrating (i) lithology-constrained densities for the sedimentary and volcanic deposits, (ii) densities derived from $P$ wave velocity models for the mantle down to $100 \mathrm{~km}$ depth, (iii) densities derived from $S$ wave velocity models for the mantle at $100-200 \mathrm{~km}$ and (iv) in particular the gravity field. This 3-D density model is consistent with the main trends in crustal $P$ wave velocities revealed by the KRISP refraction seismic profiles. Furthermore, we find that

- mantle density variations below $100 \mathrm{~km}$ depth (derived from $S$ wave velocity models) do not decisively affect the distribution of gravity anomalies;
- the plume-related lateral variability in mantle density between the Moho and $100 \mathrm{~km}$ depth amounts to $\Delta \rho \approx 20 \mathrm{~kg} \mathrm{~m}^{-3}$ (which corresponds to a temperature difference of $\approx 200^{\circ} \mathrm{C}$ according to Eq. B2);

- there is an overall trend of increasing mean crustal densities from mainly $<2880$ in western Kenya to $>2880 \mathrm{~kg} \mathrm{~m}^{-3}$ in eastern Kenya, which is likely due to compositional differences;

- measured gravity anomalies larger than $100 \mathrm{~km}$ (halfwavelength) can be reproduced by a model comprising a two-layered crust, with both layers being laterally differentiated into domains of different densities;

- the strongest density contrast modelled for the upper crustal layer corresponds with the Precambrian boundary between the Mozambique Belt in the west (known to be made up of meta-sedimentary and meta-igneous rocks) and the microcontinent Azania in the east (containing predominantly meta-igneous rocks);

- the basal crustal layer reveals largest thicknesses and densities (i) underneath the eastern basins domain (in particular the Anza Basin) where it might have formed through magmatic underplating during Mesozoic rifting phases and (ii) beneath the Eastern Granulites where it might derive from magmatic and/or metamorphic processes accompanying the Precambrian tectonic amalgamation associated with the East African Orogeny;

- there might be additional magnesium and iron-rich (mafic) intrusions in the crust that are not implemented in the model but indicated by local positive gravity residuals $(>+30 \mathrm{mGal}$ at half-wavelengths of $<100 \mathrm{~km})$;

- local areas of significant mass excess in the final density model (indicated by gravity residuals of $<-30 \mathrm{mGal}$ ) are concentrated in the northern Kenya rift and the Nyanza rift where they might be related to positive thermal anomalies within the crust involving partial melting and/or rock expansion.

Having assessed the 3-D density configuration of the lithosphere, we have gone further and derived potential implications for its thermal and rheological state. The 3-D distribution of rock types inferred from geological and geophysical observations thereby has provided the basis to parameterise model units with rock physical properties. The lower thermal boundary condition has been defined as the $1350{ }^{\circ} \mathrm{C}$ isotherm as derived from $S$ wave velocity models.

Although the model only accounts for conductive heat transport and despite uncertainties in the assigned thermal properties, measured near-surface geothermal gradients are largely reproduced with a misfit of $< \pm 10 \mathrm{~K} \mathrm{~km}^{-1}$ for sites spread all over Kenya and northern Tanzania. 
The overall dominance $(65 \%)$ of sites with overestimated thermal gradients, however, might be related to the modelled steady-state conditions not taking into account that the mantle thermal anomaly most likely has not yet fully propagated from the mantle up to the Earth's surface.

Around the Kenya-Nyanza rift junction, the purely conductive thermal model significantly underestimates observed geothermal gradients pointing to advective (water and/or magmatism controlled) heat transport.

By integrating the modelled thermal field and type rheologies consistent with lithological interpretations for the modelled units, we have calculated the lithospheric yield-strength configuration (as a multi-1-D approach for steady-state conditions). We have assumed that the higher the seismic velocity and density of a model unit, the stiffer it is.

First-order observations on seismicity (i.e. depths of peak seismicity) in western Kenya and northern Tanzania are consistent with the modelled strength configuration (i.e. tops of the brittle-ductile transitions).

The model predicts smaller depth-integrated strengths for western Kenya (including the rift) than for eastern Kenya on both crustal and lithospheric scales.

Since the most significant strength contrast correlates with the western margin of Azania (upper crustal layer) and a strong thickness increase of the basal crustal layer, we conclude that the present-day rheological configuration traces back to (i) the Precambrian amalgamation associated with the East African Orogeny and (ii) magmatic processes (probably underplating) affecting eastern Kenya during Mesozoic rifting phases.

In northern Kenya the mantle thermal anomaly strongly weakens the lithosphere, while this thermal effect decreases towards the south due to a narrowing of the plume beneath the rift proper.

According to the 3-D model, plume-related lithospheric thinning has been taking place beneath a compositionally heterogeneous crust and crustal thinning concentrated within the southward tapering Arabian-Nubian Shield located adjacent to the rheologically stronger domains of eastern Kenya.

The influence of crustal heterogeneities on rift localisation during Paleogene times has probably been even stronger relative to thermal effects, since the utilised steady-state thermal model seems to overestimate the thermal anomaly in the crust.
Despite an overall N-S-oriented mantle thermal anomaly, the western rifts of the Tanzania divergence strike NNESSW, which can be explained by a domain of increased crustal strength in SE Kenya due to which the localisation of extension was deflected into a weaker domain farther west.

The spatial correlations of in-rift volcanoes with lowest crustal strengths and off-rift volcanoes with large gradients in lithospheric strength provide new starting points for investigating volcano tectonics and dyke emplacement in the region.

The steady-state rheological model provides a framework for future studies on dynamic processes such as rift localisation and propagation in the region.

\section{Data availability}

The key input data for the development of the presented models are (1) the KRISP (Kenya rift International Seismic Project) refraction seismic data (Khan et al., 1999) made available through Table S1 in the Supplement and (2) the EIGEN-6C4 gravity data (Förste et al., 2015) that can be downloaded from http://icgem.gfz-potsdam.de/ICGEM/. For the availability of the remaining input datasets, the reader is referred to the respective scientific publications as provided in the main text (e.g., for temperature data to the tables in Nyblade et al., 1990, and Wheildon et al., 1994). By performing integrated 3-D structural, gravity, thermal and rheological modelling while using different software packages (see main text), we have generated a set of numerical models with different contents and formats, with related data being available upon request (please contact the corresponding author, sippel@gfz-potsdam.de). 
Appendix A: Lithology-driven modelling of the density configuration of the sedimentary and volcanic rocks

\section{A1 Eastern Kenya}

Deposits of the Lamu Basin are lithologically described as a repetitive sequence of mainly siliciclastic rocks (sandstones, siltstones, shales) and intercalated limestones (Nyagah, 1995; Table 1). Direct evidence on the density configuration of the basin infill is provided by the study of Yuan et al. (2012), who jointly investigated reflection seismic and gravity data from the central Lamu Basin. According to these observations, density increases with depth and age of the depositional sequences (the main ones of which are of Cenozoic, Cretaceous, Jurassic and Permian/Triassic ages).

Except for some Permo-Triassic evaporitic series in the Mandera Basin (e.g. Ali Kassim et al., 2002) and Miocene to Quaternary volcanics in the north-western Anza Basin (e.g. Class et al., 1994), these two basins also primarily contain siliciclastic rocks and limestones (Table 1). Due to this similarity in lithological trends and a lack of more detailed information on the spatial configuration of lithologies and densities, we have modelled the Mandera, Lamu and Anza basins as one consistent domain, referred to as the eastern basins domain (Fig. 2b).

The downward density increase observed in the Lamu Basin obviously results from compaction and related porosity loss with increasing burial depth and time (Yuan et al., 2012). Similar depth-dependent porosity and density trends can be assumed to characterise the sequences of the Mandera and Anza basins that also show considerable maximum burial depths of $>9 \mathrm{~km}$ (Fig. 2a). One commonly used relationship (Athy, 1930) to empirically describe porosity $\phi_{z}$ as a function of hydrostatic depth $z$ reads as

$\phi_{z}=\phi_{0} \times e^{-c z}$,

where values for the surface (respectively depositional) porosity $\phi_{0}$ and the compaction coefficient $c$ vary with lithology (e.g. Hantschel and Kauerauf, 2009; Allen and Allen, 2013). We use the resulting depth-dependent porosity $\phi_{z}$ together with the density of the pore-filling fluid $\left(\rho_{\text {por }}=1030 \mathrm{~kg} \mathrm{~m}^{-3}\right)$ and the lithology-dependent matrix density $\rho_{\text {mat }}$, to calculate the bulk rock density $\rho_{\text {bulk }}$ configuration in the eastern basins domain:

$\rho_{\text {bulk }}=(1-\phi) \rho_{\text {mat }}+\phi \rho_{\text {por }}$

For setting up the starting density model we have chosen parameter values (i.e. $c=0.4 \mathrm{~km}^{-1} ; \phi_{0}=0.4$; $\rho_{\text {mat }}=2720 \mathrm{~kg} \mathrm{~m}^{-3}$ ) that are representative of a mixture of siliciclastic rocks and limestones and, as shown by Meeßen (2015), reasonably well reproduce the observed density increase in the Lamu Basin (Yuan et al., 2012). For the lithospheric-scale 3-D gravity modelling, we have used a simplified representation of the modelled continuous density increase with depth: we have subdivided the infill of the eastern basins into a vertical succession of six layers (Table 2; Fig. 7d) each of which is representative of a depth interval of up to $2 \mathrm{~km}$ thickness (levels A-F) and characterised by a constant average density (between 2270 and $2710 \mathrm{~kg} \mathrm{~m}^{-3}$ ).

\section{A2 Western Kenya}

In western Kenya, as a result of spatially and temporally varying depositional environments and types of volcanism, a large variety of rock types is observed in the different rift segments. Hence, the 3-D density model differentiates six domains (Table 1; Fig. 2b): the Lotikipi Plain domain in NW Kenya, three domains along the main Cenozoic rift and two domains encompassing major volcanic edifices of the region.

The lithology of the deepest successions in the Lotikipi Plain domain is poorly constrained, but Tiercelin et al. (2012) suggested that sandstones equivalent to the Late Cretaceous Turkana Grits plus lacustrine deposits form a layer of $\leq 700 \mathrm{~m}$. These sedimentary rocks are overlain by a volcanic layer of Oligocene basalts (with interbedded tuffaceous sediments) and Miocene to Lower Pliocene rhyolitic flows (Morley, 1999). The shallowest strata are formed by Upper Pliocene to recent volcanic-derived fluvial and lacustrine sediments with a thickness of about $1000 \mathrm{~m}$ (Tiercelin et al., 2012; Morley, 1999). According to the generalised stratigraphy and gravity-constrained density proposed by Morley (1999), we have differentiated two layers for the Lotikipi Plain, each with a homogeneous density in the starting model (Table 2). The upper layer represents $1000 \mathrm{~m}$ of predominantly volcanic-derived sediments with an average density of $2350 \mathrm{~kg} \mathrm{~m}^{-3}$. The remaining space down to the basement (with $<2600 \mathrm{~m}$ thickness) is modelled with a density of $2550 \mathrm{~kg} \mathrm{~m}^{-3}$ representing a mixed layer of volcanics and clastic sediments.

The Turkana rift domain encompasses the Turkana, Lokichar and North Kerio basins (Fig. 2a). The deeper infill of these basins is dominated by a variety of siliciclastic rocks (conglomerates, shales and partly arkosic sandstones; e.g. Feibel, 2011). Hence, we have used the same approach as applied to the eastern basins domain, i.e. approximating depthdependent porosity and density with a vertical succession of model layers (levels B-D; Table 2). For the model layer representing the uppermost $2 \mathrm{~km}$ (level A), however, a slightly higher average density of $2400 \mathrm{~kg} \mathrm{~m}^{-3}$ has been chosen because of the abundance of massive Miocene volcanics at these depths (e.g. Morley et al., 1992).

The northern rift domain is segmented into the Suguta trough, the South Kerio trough and the Baringo Basin (Fig. 2a, b). The sedimentary and volcanic basin infill shows a maximum thicknesses of $>4000 \mathrm{~m}$ in the Baringo Basin. Siliciclastic sediments and mafic to intermediate volcanics are the dominating lithologies (Table 1). Combined seismic and gravity studies provide indications on the density configuration of the Baringo Basin infill, which is given as 
a range from $2460-2600$ by Swain et al. (1981) to 2460 $2750 \mathrm{~kg} \mathrm{~m}^{-3}$ by Maguire et al. (1994). For the shallower South Kerio Basin, Mugisha et al. (1997) estimated densities of $2000-2450 \mathrm{~kg} \mathrm{~m}^{-3}$. For the starting density model, the northern rift domain is represented by one continuous model unit with an average density of $2550 \mathrm{~kg} \mathrm{~m}^{-3}$.

We have combined the Nyanza, central and Magadi troughs together with the Tanzania divergence into the southern rift domain (Fig. 2a, b). In this domain, the thickness of sedimentary and volcanic rocks does not exceed $4200 \mathrm{~m}$. The basins are mainly filled by mafic to intermediate volcanics deposited as tuff and intercalated with volcanic-derived sediments (Table 1). Due to the high porosity of these tuff and sediments, we followed the approach of Simiyu and Keller (2001) and modelled this domain as a continuous unit with a density of $2400 \mathrm{~kg} \mathrm{~m}^{-3}$.

The stratovolcanoes Mt. Elgon, Mt. Kenya and Kilimanjaro overlie the pre-Mesozoic basement (e.g. Beicip, 1987) and are differentiated in the model as the volcanics domain (Fig. 2b). These volcanic edifices are composed of variable lithologies (Table 1). However, since they are entirely positioned above sea level and we model "Bouguer" anomalies induced only by densities below sea level (Sect. 3.4), their variable densities do not affect our gravity calculations. Further, although these density heterogeneities existing above sea level have transferred inaccuracies to the Bouguer reduction of the gravity data (which is based on a constant Bouguer plate density of $2670 \mathrm{~kg} \mathrm{~m}^{-3}$ ), neglecting the volcanic edifices in our modelling is not an obstacle to uncovering deep crustal density anomalies due to the limited spatial extents of the edifices compared to the first-order gravity anomalies.

\section{Appendix B: KRISP refraction seismic profiles (e.g. Khan et al., 1999)}

Major constraints for the 3-D gravity modelling performed in this study have been derived from the refraction seismic profiles of the KRISP (Kenya rift International Seismic Project) experiments (Fig. B1). Note that the original models in the form of velocity-depth functions every $10 \mathrm{~km}$ along the various profiles are presented as Table S1 in the Supplement.

\section{Appendix C: Comment on the usage of a modification of Birch's (1961, 1964) law}

We have modified the widely used Birch's empirical law (Birch, 1961, 1964) for crustal velocity-density relations to Eq. (1) by changing the added term from a value of 252 to $350 \mathrm{~kg} \mathrm{~m}^{-3}$. The reason for this modification can be illustrated by comparing the different densities resulting from the two equations. For a velocity of $v_{p}=6.33 \mathrm{~km} \mathrm{~s}^{-1}$, i.e. an average for the upper crustal layer in the $\mathrm{W}$, the corresponding densities would be $\rho_{\mathrm{c}}=2650$ for Birch's law and $\rho_{\mathrm{c}}=2750 \mathrm{~kg} \mathrm{~m}^{-3}$ for its modification (Eq. 1). We prefer the
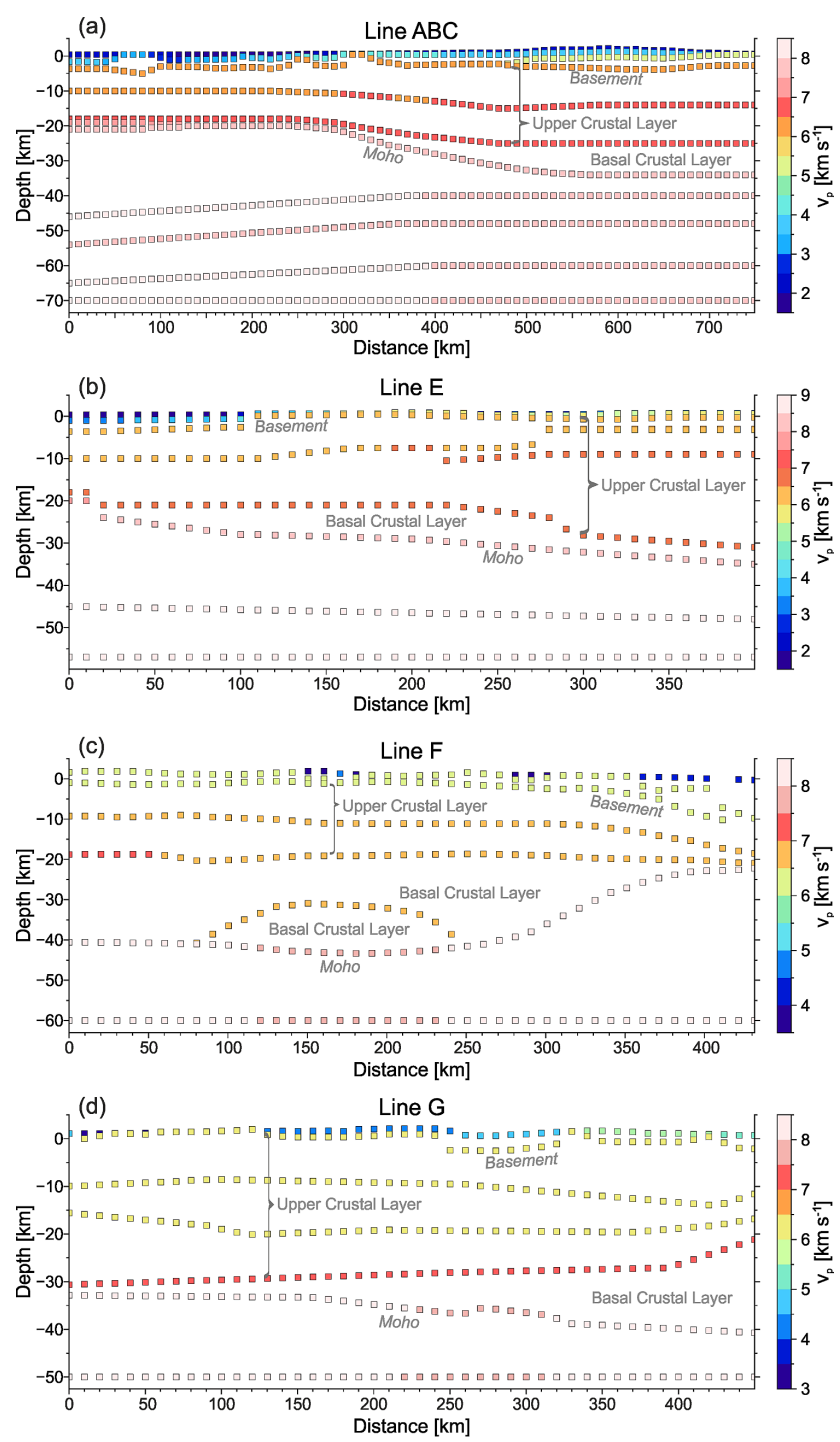

Figure B1. $P$ wave velocity structure along the KRISP refraction seismic profiles (e.g. Khan et al., 1999); the plotted velocities represent mean values for the depth interval below the respective vertex; for locations of the profiles refer to Figs. $1 \mathrm{~b}$ and 4; (a) profile $\mathrm{ABC}$; (b) profile E; (c) profile F; (d) profile G.

latter result since it is closer to the densities expected from the exposed (widely metamorphic) basement rock types (Table 3). 


\section{Appendix D: Conversion of $S$ wave velocity-derived temperatures to density}

To account for the gravity effects of the mantle, we have analysed $S$ wave velocity data (Adams et al., 2012; Fiswick, 2010) and, in a first step, converted them into temperatures by using the empirical approach of Priestley and McKenzie (2006). In a second step, we have assessed the mantle density configuration by using the relationship between the density of a mineral $\left(\rho_{i, 0}\left[\mathrm{~kg} \mathrm{~m}^{-3}\right]\right)$ at standard temperature and pressure conditions $\left(T_{0}[\mathrm{~K}] ; P_{0}[\mathrm{GPa}]\right)$, its thermal expansion coefficient $\left(\alpha\left[\mathrm{K}^{-1}\right]\right)$ and bulk modulus ( $\left.K[\mathrm{GPa}]\right)$ as well as its density at in situ temperature $(T[\mathrm{~K}])$ and pressure $(P[\mathrm{GPa}])$ :

$\rho_{i}(P, T)=\rho_{i, 0}\left[1-\alpha_{i}\left(T-T_{0}\right)+\frac{P-P_{0}}{K_{i}}\right]$

(e.g. Goes et al., 2000).

The mineral properties $\left(\rho_{i, 0}, \alpha_{i}\right.$ and $\left.K_{i}\right)$ are derived from compiled laboratory measurements (Table D1). To account for the composite mineralogy of the mantle, we have averaged the in situ densities of different minerals to obtain the bulk density $\rho_{\text {bulk }}$ :

$\rho_{\text {bulk }}=\sum x_{i} \rho_{i}$

where $x_{i}$ is the volumetric proportion of the mineral $i$.

Mechie et al. (1994) proposed a mantle composition for the Kenya rift and its eastern flank based on the combined analysis of $P$ and $S$ wave seismic velocities and compositions of mantle xenoliths brought up by Quaternary volcanics (Henjes-Kunst and Altherr, 1992). Accordingly, we assume that the study area is underlain by a compositionally homogeneous mantle representing undepleted spinel peridotite (Table D1).
The in situ pressure (vertical load $P_{\text {lith }}$; Eq. C3) has been assessed by integrating the density $(\rho)$-controlled linear relationship between pressure and depth (below topography, $z$ ), while considering the acceleration due to gravity $\left(g=9.81 \mathrm{~m} \mathrm{~s}^{-2}\right)$ :

$P_{\text {lith }}=g \int_{0}^{z} \rho(z) \mathrm{d} z$.

Without knowing crust and mantle densities a priori, we have approximated in situ pressure conditions for the mantle by taking into account the Moho depth (Fig. 3a) as well as average densities for the crust $\left(2810 \mathrm{~kg} \mathrm{~m}^{-3}\right.$ as derived from KRISP) and the mantle ( $3300 \mathrm{~kg} \mathrm{~m}^{-3}$; according to Ravat et al., 1999).

The involved inaccuracy of the pressure calculation (Eq. C3) related to the utilisation of constant average densities for the mantle and the crust does not significantly affect the density calculation (Eq. C1), which can be shown by a simple scenario; not considering a lateral variability in mantle density of $100 \mathrm{~kg} \mathrm{~m}^{-3}$ (representing, for example, a lateral change from 3250 to $3350 \mathrm{~kg} \mathrm{~m}^{-3}$ ) for the depth interval of $100-200 \mathrm{~km}$ would mean imposing an error of $\approx 0.1 \mathrm{GPa}$ in the calculated pressure (vertical load; $P_{\text {lith }}$; Eq. C3). Since typically $K>100 \mathrm{GPa}$ (Table D1), the uncertainty in the pressure term of Eq. (C3) related to an error of $\approx 0.1 \mathrm{GPa}$ would thus be $<0.1 \%$. For this reason, we regard spatial density variations occurring in the mantle and the crust as negligible for the pressure and final density calculations.

Table D1. Volumetric proportions of minerals and physical properties assumed to form mantle rock in the study area.

\begin{tabular}{lrrrr}
\hline & $\begin{array}{r}\text { Volumetric } \\
\text { proportion }\end{array}$ & $\begin{array}{r}\text { Density at standard } \\
\text { conditions for } \\
P \text { and } T\end{array}$ & $\begin{array}{r}\text { Thermal } \\
\text { expansion } \\
\text { coefficient }\end{array}$ & $\begin{array}{r}\text { Bulk } \\
\text { modulus }\end{array}$ \\
& $\begin{array}{r}\rho_{0} \\
{[\%]}\end{array}$ & {$\left[\mathrm{kg} \mathrm{m}^{-3}\right]$} & $\begin{array}{r}\alpha \\
{\left[10^{-5} \mathrm{~K}^{-1}\right]}\end{array}$ & $\mathrm{K}$ \\
& {$[\mathrm{GPa}]$}
\end{tabular}

Iron content: $X_{\mathrm{Fe}}=\mathrm{Fe} /(\mathrm{Fe}+\mathrm{Mg})=0.1$. Mineral properties as compiled in Goes et al. (2000) and Cammarano et al. (2003). 
Appendix E: Comment on the characteristic timescale of thermal diffusion

The 1-D instantaneous cooling of a semi-infinite half-space (with no internal heating) is approximated by an error function

$T_{t}=T_{0} \cdot \operatorname{erf}\left(\frac{z}{2 \sqrt{\kappa t}}\right)$,

where $T_{t}$ is the temperature at time $t$ and depth $z, \kappa$ is the thermal diffusivity of the rocks $\left[\mathrm{m}^{2} \mathrm{~s}^{-1}\right]$ and $T_{0}$ is the initial temperature (e.g. Turcotte and Schubert, 2014). Accordingly, the amount of time $t$ necessary for a change in $T$ to propagate a distance $l$ reads as

$t=\frac{l^{2}}{\kappa}$.

The minimum depth of the $1350^{\circ} \mathrm{C}$ isotherm in the study area (at the present-day) is $\approx 63 \mathrm{~km}$ (Fig. 8a). Given a thermal diffusivity of $\kappa=10^{-6} \mathrm{~m}^{2}, \mathrm{~s}^{-1}$ (which is a typical average value for the lithosphere), a change of temperature at a depth of $63 \mathrm{~km}$ would take $\approx 129$ Ma to reach the Earth's surface. For this reason, it is very likely that the mantle thermal anomaly emplaced below the Kenya rift $\approx 45 \mathrm{Ma}$ ago is not yet in thermal equilibrium with near-surface temperatures. 


\section{The Supplement related to this article is available online at doi:10.5194/se-8-45-2017-supplement.}

Competing interests. The authors declare that they have no conflict of interest.

Acknowledgement. We want to thank Girma Woldetinsae for providing us with a numerical 3-D density model of Ethiopia and northern Kenya that was developed in the frame of a study funded by the Katholischer Akademischer Ausländer-Dienst (KAAD). We also would like to acknowledge the comments and advice of Geoffrey Kimbell and an anonymous reviewer as well as from the editor Gwenn Peron-Pinvidic, who all helped to improve the quality of this manuscript.

The article processing charges for this open-access publication were covered by a Research

Centre of the Helmholtz Association.

Edited by: G. Peron-Pinvidic

Reviewed by: G. Kimbell and one anonymous referee

\section{References}

Achauer, U.: A Study of the Kenya Rift Using Delay-Time Tomography Analysis and Gravity Modeling, Tectonophysics, 209, 197-207, doi:10.1016/0040-1951(92)90023-Y, 1992.

Achauer, U. and Masson, F.: Seismic tomography of continental rifts revisited: From relative to absolute heterogeneities, Tectonophysics, 358, 17-37, doi:10.1016/S00401951(02)00415-8, 2002.

Adams, A., Nyblade, A., and Weeraratne, D.: Upper mantle shear wave velocity structure beneath the East African plateau: Evidence for a deep, plateauwide low velocity anomaly, Geophys. J. Int., 189, 123-142, doi:10.1111/j.1365-246X.2012.05373.x, 2012.

Albaric, J., Deverchere, J., Petit, C., Perrot, J., and Le Gall, B.: Crustal rheology and depth distribution of earthquakes: Insights from the central and southern East African Rift System, Tectonophysics, 468, 28-41, doi:10.1016/j.tecto.2008.05.021, 2009.

Ali Kassim, M., Carmignani, L., Conti, P., and Fantozzi, P. L.: Geology of the Mesozoic-Tertiary sedimentary basins in southwestern Somalia, J. Afr. Earth Sci., 34, 3-20, doi:10.1016/S08995362(01)00102-6, 2002.

Allen, P. A. and Allen, J. R.: Basin Analysis: Principles and Applications, Wiley-Blackwell, 2013.

Amante, C. and Eakins, B. W.: ETOPO1 1 Arc-Minute Global Relief Model, NOAA Technical Memorandum NESDIS NGDC, https://www.ngdc.noaa.gov/docucomp/page?xml= NOAA/NESDIS/NGDC/MGG/DEM/iso/xml/316.xml\&view= getDataView\&header=none, 24, 19-19, 2009.

Ashwal, L. D. and Burke, K.: African lithospheric structure, volcanism, and topography, Earth Planet. Sc. Lett., 96, 8-14, doi:10.1016/0012-821X(89)90119-2, 1989.
Athy, L. F.: Density, porosity and compaction of sedimentary rocks, AAPG Bulletin, 14, 1-24, 1930.

Bagley, B. and Nyblade, A. A.: Seismic anisotropy in eastern Africa, mantle flow, and the African superplume, Geophys. Res. Lett., 40, 1500-1505, doi:10.1002/grl.50315, 2013.

Baker, B. H.: Outline of the petrology of the Kenya rift alkaline province, Geological Society, London, Special Publications, 30, 293-311, doi:10.1144/GSL.SP.1987.030.01.14, 1987.

Baker, B. H. and Mitchell, J. G.: Volcanic stratigraphy and geochronology of the Kedong-Olorgesailie area and the evolution of the South Kenya rift valley, J. Geol. Soc., 132, 467-484, doi:10.1144/gsjgs.132.5.0467, 1976.

Baker, B. H., Mohr, P. A., and Williams, L. A. J.: Geology of the Eastern Rift System of Africa, Geological Society of America Special Papers, 136, 1-68, doi:10.1130/SPE136-p1, 1972.

Baker, B. H., Williams, L. A. J., Miller, J. A., and Fitch, F. J.: Sequence and geochronology of the Kenya rift volcanics, Tectonophysics, 11, 191-215, doi:10.1016/00401951(71)90030-8, 1971.

Bastow, I. D., Keir, D., and Daly, E.: The Ethiopia Afar Geoscientific Lithospheric Experiment (EAGLE): Probing the transition from continental rifting to incipient seafloor spreading, Geological Society of America Special Papers, 478, 51-76, doi:10.1130/2011.2478(04), 2011.

Beicip: Geological Map of Kenya with Structural Contours, $1: 1000000$, Ministry of Energy and Regional Development of Kenya, Nairobi, 1987.

Birch, F.: Density and composition of mantle and core, J. Geophys. Res., 69, 4377-4388, doi:10.1029/JZ069i020p04377, 1964.

Birch, F.: The velocity of compressional waves in rocks to 10 kilobars: 2, J. Geophys. Res., 66, 2199-2224, doi:10.1029/JZ066i007p02199, 1961.

Bosworth, W. and Maurin, A.: Structure, Geochronology and Tectonic Significance of the Northern Suguta Valley (Gregory Rift), Kenya, J. Geol. Soc., 150, 751-762, doi:10.1144/gsjgs.150.4.0751, 1993.

Bosworth, W. and Morley, C. K.: Structural and Stratigraphic Evolution of the Anza Rift, Kenya, Tectonophysics, 236, 93-115, doi:10.1016/0040-1951(94)90171-6, 1994.

Bosworth, W. and Strecker, M. R.: Stress field changes in the Afro-Arabian rift system during the Miocene to Recent period, Tectonophysics, 278, 47-62, doi:10.1016/S00401951(97)00094-2, 1997.

Braile, L. W., Wang, B., Daudt, C. R., Keller, G. R., and Patel, J. P.: Modeling the 2-D Seismic Velocity Structure across the Kenya Rift, Tectonophysics, 236, 251-269, doi:10.1016/00401951(94)90179-1, 1994.

Burke, K.: The African Plate, South African J. Geol., 99, 341-409, 1996.

Burov, E., Jaupart, C., and Mareschal, J. C.: Large-scale crustal heterogeneities and lithospheric strength in cratons, Earth Planet. Sc. Lett., 164, 205-219, doi:10.1016/S0012-821X(98)00205-2, 1998.

Burov, E. B.: Rheology and strength of the lithosphere, Mar. Petrol. Geol., 28, 1402-1443, doi:10.1016/j.marpetgeo.2011.05.008, 2011.

Byerlee, J.: Friction of rocks, pure and applied geophysics, 116, 116, 615-626, doi:10.1007/bf00876528, 1978. 
Cacace, M., Kaiser, B. R. O., Lewerenz, B. R., and ScheckWenderoth, M.: Geothermal energy in sedimentary basins: What we can learn from regional numerical models, Chemie der Erde - Geochemistry, 70, 33-46, doi:10.1016/j.chemer.2010.05.017, 2010.

Cacace, M. and Scheck-Wenderoth, M.: Why intracontinental basins subside longer: 3-D feedback effects of lithospheric cooling and sedimentation on the flexural strength of the lithosphere, J. Geophys. Res.-Sol. Ea., 121, 3742-3761, doi:10.1002/2015JB012682, 2016.

Cammarano, F., Goes, S., Vacher, P., and Giardini, D.: Inferring upper-mantle temperatures from seismic velocities, Phys. Earth Planet. Int., 138, 197-222, doi:10.1016/S0031-9201(03)00156$0,2003$.

Carter, N. L. and Tsenn, M. C.: Flow Properties of Continental Lithosphere, Tectonophysics, 136, 27-63, doi:10.1016/00401951(87)90333-7, 1987.

Catuneanu, O., Wopfner, H., Eriksson, P. G., Cairncross, B., Rubidge, B. S., Smith, R. M. H., and Hancox, P. J.: The Karoo basins of south-central Africa, J. Afr. Earth Sci., 43, 211-253, doi:10.1016/j.jafrearsci.2005.07.007, 2005.

Cermak, V. and Rybach, L.: Thermal conductivity and specific heat of minerals and rocks, edited by: Angenheister, G., Springer, New York, 1982.

Chapman, G. R., Lippard, S. J., and Martyn, J. E.: The stratigraphy and structure of the Kamasia Range, Kenya Rift Valley, J. Geol. Soc., 135, 265-281, doi:10.1144/gsjgs.135.3.0265, 1978.

Chorowicz, J.: The East African rift system, J. Afr. Earth Sci., 43, 379-410, doi:10.1016/j.jafrearsci.2005.07.019, 2005.

Christensen, N. I. and Mooney, W. D.: Seismic Velocity Structure and Composition of the Continental-Crust - a Global View, J. Geophys. Res.-Sol. Ea., 100, 9761-9788, doi:10.1029/95jb00259, 1995.

Class, C., Altherr, R., Volker, F., Eberz, G., and Mcculloch, M. T.: Geochemistry of Pliocene to Quaternary Alkali Basalts from the Huri Hills, Northern Kenya, Chem. Geol., 113, 1-22, doi:10.1016/0009-2541(94)90002-7, 1994.

Clifford, T. N.: The structural framework of Africa, edited by: Clifford, T. N. and Gass, I., Oliver and Boyd, Edinburgh, 1970.

Collins, A. S. and Pisarevsky, S. A.: Amalgamating eastern Gondwana: The evolution of the Circum-Indian Orogens, Earth-Sci. Rev., 71, 229-270, doi:10.1016/j.earscirev.2005.02.004, 2005.

Cox, K. G.: Karoo igneous activity, and the early stages of the break-up of Gondwanaland, Geological Society, London, Special Publications, 68, 137-148, doi:10.1144/GSL.SP.1992.068.01.09, 1992.

Crossley, R.: The Cenozoic stratigraphy and structure of the western part of the Rift Valley in southern Kenya, J. Geol. Soc., 136, 393405, doi:10.1144/gsjgs.136.4.0393, 1979.

Cutten, H., Johnson, Simon P., and Waele, Bert D.: Protolith Ages and Timing of Metasomatism Related to the Formation of Whiteschists at Mautia Hill, Tanzania: Implications for the Assembly of Gondwana, J. Geol., 114, 683-698, doi:10.1086/507614, 2006.

Dawson, J. B.: Neogene tectonics and volcanicity in the North Tanzania sector of the Gregory Rift Valley: contrasts with the Kenya sector, Tectonophysics, 204, 81-92, doi:10.1016/00401951(92)90271-7, 1992.
Dziewonski, A. M. and Anderson, D. L.: Preliminary reference Earth model, Phys. Earth Planet. Int., 25, 297-356, doi:10.1016/0031-9201(81)90046-7, 1981.

Ebinger, C., Djomani, Y. P., Mbede, E., Foster, A., and Dawson, J. B.: Rifting Archaean lithosphere: the Eyasi-ManyaraNatron rifts, East Africa, J. Geol. Soc., 154, 947-960, doi:10.1144/gsjgs.154.6.0947, 1997.

Ebinger, C. and Scholz, C. A.: Continental Rift Basins: The East African Perspective, in: Tectonics of Sedimentary Basins, John Wiley \& Sons, Ltd, doi:10.1002/9781444347166.ch9, 2011.

Ebinger, C. J. and Ibrahim, A.: Multiple episodes of rifting in Central and East Africa: A re-evaluation of gravity data, Geol. Rundsch., 83, 689-702, doi:10.1007/bf00251068, 1994.

Ebinger, C. J. and Sleep, N. H.: Cenozoic magmatism throughout east Africa resulting from impact of a single plume, Nature, 395, 788-791, 1998.

Ebinger, C. J., Yemane, T., Harding, D. J., Tesfaye, S., Kelley, S., and Rex, D. C.: Rift deflection, migration, and propagation: Linkage of the Ethiopian and Eastern rifts, Africa, Geol. Soc. Am. B., 112, 163-176, doi:10.1130/0016-7606(2000)112< 0163:Rdmapl> 2.3.Co;2, 2000.

Ellis, M. and King, G.: Structural control of flank volcanism in continental rifts, Science, 254, 839-842, doi:10.1126/science.254.5033.839, 1991.

Exxon Production Research: Tectonic Map of the World, Tulsa, OK, USA, 1985.

Feibel, C. S.: A Geological History of the Turkana Basin, Evol. Anthropol., 20, 206-216, doi:10.1002/evan.20331, 2011.

Fishwick, S.: Surface wave tomography: Imaging of the lithosphere-asthenosphere boundary beneath central and southern Africa?, Lithos, 120, 63-73, doi:10.1016/j.lithos.2010.05.011, 2010.

Fitch, F. J., Hooker, P. J., Miller, J. A., Mitchell, J. G., and Watkins, R. T.: Reconnaissance potassium-argon geochronology of the Suregei-Asille district, northern Kenya, Geol. Mag., 122, 609622, doi:10.1017/S0016756800032027, 1985.

Förste, C., Bruinsma, S. L., Abrikosov, O., Lemoine, J. M., Schaller, T., Götze, H. J., J, E., Marty, J. C., Flechtner, F., Balmino, G., and Biancale, R.: EIGEN-6C4 - The latest combined global gravity field model including GOCE data up to degree and order 2190 of GFZ Potsdam and GRGS Toulouse, 5th GOCE User Workshop 25-28 November 2014, Paris, 29-29, 2015.

Foster, A., Ebinger, C., Mbede, E., and Rex, D.: Tectonic development of the northern Tanzanian sector of the east African rift system, J. Geol. Soc., 154, 689-700, doi:10.1144/gsjgs.154.4.0689, 1997.

Foster, D. A. and Gleadow, A. J. W.: Structural framework and denudation history of the flanks of the Kenya and Anza Rifts, East Africa, Tectonics, 15, 258-271, doi:10.1029/95tc02744, 1996.

Fritz, H., Tenczer, V., Hauzenberger, C. A., Wallbrecher, E., Hoinkes, G., Muhongo, S., and Mogessie, A.: Central Tanzanian tectonic map: A step forward to decipher proterozoic structural events in the East African Orogen, Tectonics, 24, Tc6013, doi:10.1029/2005TC001796, 2005.

Fritz, H., Tenczer, V., Hauzenberger, C., Wallbrecher, E., and Muhongo, S.: Hot granulite nappes - Tectonic styles and thermal evolution of the Proterozoic granulite belts in East Africa, Tectonophysics, 477, 160-173, doi:10.1016/j.tecto.2009.01.021, 2009. 
Fritz, H., Abdelsalam, M., Ali, K. A., Bingen, B., Collins, A. S., Fowler, A. R., Ghebreab, W., Hauzenberger, C. A., Johnson, P. R., Kusky, T. M., Macey, P., Muhongo, S., Stern, R. J., and Viola, G.: Orogen styles in the East African Orogen: A review of the Neoproterozoic to Cambrian tectonic evolution, J. Afr. Earth Sci., 86, 65-106, doi:10.1016/j.jafrearsci.2013.06.004, 2013.

Fuchs, S., Schutz, F., Forster, H. J., and Forster, A.: Evaluation of common mixing models for calculating bulk thermal conductivity of sedimentary rocks: Correction charts and new conversion equations, Geothermics, 47, 40-52, doi:10.1016/j.geothermics.2013.02.002, 2013.

Gac, S., Klitzke, P., Minakov, A., Faleide, J. I., and ScheckWenderoth, M.: Lithospheric strength and elastic thickness of the Barents Sea and Kara Sea region, Tectonophysics, 691, 120-132, doi:10.1016/j.tecto.2016.04.028, 2015.

Goes, S., Govers, R., and Vacher, P.: Shallow mantle temperatures under Europe from P and S wave tomography, J. Geophys. Res.Sol. Ea., 105, 11153-11169, doi:10.1029/1999jb900300, 2000.

Goetze, C. and Evans, B.: Stress and temperature in the bending lithosphere as constrained by experimental rock mechanics, Geophys. J. Int., 59, 463-478, doi:10.1111/j.1365246X.1979.tb02567.x, 1979.

Goetze, C. and Poirier, J. P.: The Mechanisms of Creep in Olivine [and Discussion], Philos. T. R. Soc. A, 288, 99-119, doi:10.1098/rsta.1978.0008, 1978.

Guiraud, R., Bosworth, W., Thierry, J., and Delplanque, A.: Phanerozoic geological evolution of Northern and Central Africa: An overview, J. Afr. Earth Sci., 43, 83-143, doi:10.1016/j.jafrearsci.2005.07.017, 2005.

Halldõrsson, S. A., Hilton, D. R., Scarsi, P., Abebe, T., and Hopp, J.: A common mantle plume source beneath the entire East African Rift System revealed by coupled helium-neon systematics, Geophys. Res. Lett., 41, 2304-2311, doi:10.1002/2014GL059424, 2014.

Halls, H. C., Burns, K. G., Bullock, S. J., and Batterham, P. M.: Mafic dyke swarms of Tanzania interpreted from aeromagnetic data, in: Geological Society of Canada, edited by: Swarms, M. D., Halls, H. C., and Fahrig, W. F., Special Papers, 1987.

Hansen, S. E., Nyblade, A. A., and Benoit, M. H.: Mantle structure beneath Africa and Arabia from adaptively parameterized $P$ wave tomography: Implications for the origin of Cenozoic Afro-Arabian tectonism, Earth Planet. Sc. Lett., 319, 23-34, doi:10.1016/j.epsl.2011.12.023, 2012.

Hantschel, T. and Kauerauf, A. I.: Fundamentals of Basin and Petroleum Systems Modeling, Springer-Verlag Berlin Heidelberg, 2009.

Hautot, S., Tarits, P., Whaler, K., Le Gall, B., Tiercelin, J.-J., and Le Turdu, C.: Deep structure of the Baringo Rift Basin (central Kenya) from three-dimensional magnetotelluric imaging: Implications for rift evolution, J. Geophys. Res.-Sol. Ea., 105, 2349323518, doi:10.1029/2000JB900213, 2000.

Hay, D. E., Wendlandt, R. F., and Keller, G. R.: The origin of Kenya Rift Plateau-type flood phonolites: Integrated petrologic and geophysical constraints on the evolution of the crust and upper mantle beneath the Kenya Rift, J. Geophys. Res.-Sol. Ea., 100, 10549-10557, doi:10.1029/94jb03036, 1995.

Heine, C., Zoethout, J., and Müller, R. D.: Kinematics of the South Atlantic rift, Solid Earth, 4, 215-253, doi:10.5194/se-4215-2013, 2013.
Henjes-Kunst, F. and Altherr, R.: Metamorphic Petrology of Xenoliths from Kenya and Northern Tanzania and Implications for Geotherms and Lithospheric Structures, J. Petrol., 33, 11251156, doi:10.1093/petrology/33.5.1125, 1992.

Hetzel, R. and Strecker, M. R.: Late Mozambique Belt Structures in Western Kenya and Their Influence on the Evolution of the Cenozoic Kenya Rift, J. Struct. Geol., 16, 189-201, doi:10.1016/01918141(94)90104-X, 1994.

Hirth, G. and Kohlstedt, D.: Rheology of the Upper Mantle and the Mantle Wedge: A View from the Experimentalists, in: Inside the Subduction Factory, Am. Geophys. Union, doi:10.1029/138GM06, 2013.

Holmes, A.: The sequence of Precambrian orogenic belts in south and central Africa, 18th International Geological Congress, London, 254-269, 1951.

Huismans, R. S., Buiter, S. J. H., and Beaumont, C.: Effect of plastic-viscous layering and strain softening on mode selection during lithospheric extension, J. Geophys. Res.-Sol. Ea., 110, 117, doi:10.1029/2004JB003114, 2005.

Irifune, T.: An experimental investigation of the pyroxene-garnet transformation in a pyrolite composition and its bearing on the constitution of the mantle, Phys. Earth Planet. Int., 45, 324-336, doi:10.1016/0031-9201(87)90040-9, 1987.

Irifune, T. and Ringwood, A. E.: Phase transformations in a harzburgite composition to $26 \mathrm{GPa}$ : implications for dynamical behaviour of the subducting slab, Earth Planet. Sc. Lett., 86, 365376, doi:10.1016/0012-821X(87)90233-0, 1987.

Jackson, J.: Strength of the lithosphere:time to abandon the jelly sandwich?, GSA Today, 2, 1-11, doi:10.1130/10525173(2002)012<0004:SOTCLT> 2.0.CO;2, 2002.

Jones, P. D., New, M., Parker, D. E., Martin, S., and Rigor, I. G.: Surface air temperature and its changes over the past 150 years, Rev. Geophys., 37, 173-199, doi:10.1029/1999rg900002, 1999.

Jones, W. B. and Lippard, S. J.: New age determinations and the geology of the Kenya Rift-Kavirondo Rift junction, W Kenya, J. Geol. Soc., 136, 693-704, doi:10.1144/gsjgs.136.6.0693, 1979.

Jose, B. F. and Romanov, A.: Resource assessment of certain P and $\mathrm{G}$ holdings of Simba Energy inc. in the Mandera-Lugh Basin (block 2a) area of Kenya (as of 31 May 2012), Sproule, 2012.

Karato, S. and $\mathrm{Wu}, \mathrm{P} .:$ Rheology of the upper mantle: a synthesis, Science, 260, 771-778, doi:10.1126/science.260.5109.771, 1993.

Keller, G. R., Prodehl, C., Mechie, J., Fuchs, K., Khan, M. A., Maguire, P. K. H., Mooney, W. D., Achauer, U., Davis, P. M., Meyer, R. P., Braile, L. W., Nyambok, I. O., and Thompson, G. A.: The East-African Rift System in the Light of Krisp-90, Tectonophysics, 236, 465-483, doi:10.1016/00401951(94)90190-2, 1994.

Kerr, J. M., Mackeith, N. J., Nyagah, K., and Ngenoh, D. K.: The hydrocarbon potential of the basins of Kenya, Sedimentary Events, Hydrocarbon Systems - CSPG-SEPM Joint Convention 1997: Program with Abstracts, Calgary, 153-153, 2010.

Khan, M. A., Mechie, J., Birt, C., Byrne, G., Gaciri, S., Jacob, B., Keller, G. R., Maguire, P. K. H., Novak, O., Nyambok, I. O., Patel, J. P., Prodehl, C., Riaroh, D., Simiyu, S., and Thybo, H.: The lithospheric structure of the Kenya Rift as revealed by wide-angle seismic measurements, Geological Society, London, Special Publications, 164, 257-269, doi:10.1144/gsl.sp.1999.164.01.13, 1999. 
Koptev, A., Calais, E., Burov, E., Leroy, S., and Gerya, T.: Dual continental rift systems generated by plume-lithosphere interaction, Nat. Geosci., 8, 388-392, doi:10.1038/Ngeo2401, 2015.

Le Gall, B., Nonnotte, P., Rolet, J., Benoit, M., Guillou, H., Mousseau-Nonnotte, M., Albaric, J., and Deverchère, J.: Rift propagation at craton margin. Distribution of faulting and volcanism in the North Tanzanian Divergence (East Africa) during Neogene times, Tectonophysics, 448, 1-19, doi:10.1016/j.tecto.2007.11.005, 2008.

Lippard, S. J.: The petrology of phonolites from the Kenya Rift, Lithos, 6, 217-234, doi:10.1016/0024-4937(73)90083-2, 1973.

Maboko, M. A. H.: Neodymium Isotopic Constraints on the Protolith Ages of Rocks Involved in Pan-African Tectonism in the Mozambique Belt of Tanzania, J. Geol. Soc., 152, 911-916, 1995.

Maboko, M. A. H. and Nakamura, E.: Isotopic dating of Neoproterozoic crustal growth in the Usambara Mountains of northeastern Tanzania: Evidence for coeval crust formation in the Mozambique Belt and the Arabian-Nubian Shield, Precambrian Res., 113, 227-242, doi:10.1016/S0301-9268(01)00213-3, 2002.

Maccaferri, F., Rivalta, E., Keir, D., and Acocella, V.: Off-rift volcanism in rift zones determined by crustal unloading, Nat. Geosci., 7, 297-300, doi:10.1038/ngeo2110, 2014.

Maguire, P. K. H., Swain, C. J., Masotti, R., and Khan, M. A.: A Crustal and Uppermost Mantle Cross-Sectional Model of the Kenya Rift Derived from Seismic and Gravity-Data, Tectonophysics, 236, 217-249, doi:10.1016/0040-1951(94)90178-3, 1994.

Mariita, N. O. and Keller, G. R.: An integrated geophysical study of the northern Kenya rift, J. Afr. Earth Sci., 48, 80-94, doi:10.1016/j.jafrearsci.2006.05.008, 2007.

Mbede, E.: Tectonic setting and uplift analysis of the Pangani rift basin in northern Tanzania using apatite fission track thermochronology, Tanzania J. Sci., 27, 23-38, 2001.

McConnell, R. B.: Geological Development of the Rift System of Eastern Africa, Geol. Soc. Am. B., 83, 2549-2572, doi:10.1130/0016-7606(1972)83[2549:gdotrs]2.0.co;2, 1972.

McKenzie, D., Jackson, J., and Priestley, K.: Thermal structure of oceanic and continental lithosphere, Earth Planet. Sc. Lett., 233, 337-349, doi:10.1016/j.eps1.2005.02.005, 2005.

Mechie, J., Keller, G. R., Prodehl, C., Gaciri, S., Braile, L. W., Mooney, W. D., Gajewski, D., and Sandmeier, K. J.: Crustal Structure beneath the Kenya Rift from Axial Profile Data, Tectonophysics, 236, 179-200, doi:10.1016/00401951(94)90176-7, 1994.

Mechie, J., Keller, G. R., Prodehl, C., Khan, M. A., and Gaciri, S. J.: A model for the structure, composition and evolution of the Kenya rift, Tectonophysics, 278, 95-119, doi:10.1016/S00401951(97)00097-8, 1997.

Meeßen, C.: Lithosphere-scale 3-D density model of the Kenya Rift System, 103-103, 2015.

Meju, M. A. and Sakkas, V.: Heterogeneous crust and upper mantle across southern Kenya and the relationship to surface deformation as inferred from magnetotelluric imaging, J. Geophys. Res.Sol. Ea., 112, B04103-B04103, doi:10.1029/2005JB004028, 2007.

Melnick, D., Garcin, Y., Quinteros, J., Strecker, M. R., Olago, D., and Tiercelin, J. J.: Steady rifting in northern Kenya inferred from deformed Holocene lake shorelines of the Suguta and Turkana basins, Earth Planet. Sc. Lett., 331-332, 335-346, doi:10.1016/j.eps1.2012.03.007, 2012.

Michon, L.: What the volcanism of the East African Rift tells us on its evolution and dynamics: a reappraisal, EGU, Vienna, Austria 2015.

Midttømme, K. and Roaldset, E.: Thermal conductivity of sedimentary rocks: uncertainties in measurement and modelling, Geological Society, London, Special Publications, 158, 45-60, doi:10.1144/GSL.SP.1999.158.01.04, 1999.

Milesi, J. P., Frizon de Lamotte, D., de Kock, G., and Toteu, F.: Tectonic Map of Africa at $1: 10 \mathrm{M}$ scale, Commission for the Geological Map of the World, Paris, 2010.

Möller, A., Mezger, K., and Schenk, V.: Crustal age domains and the evolution of the continental crust in the Mozambique Belt of Tanzania: Combined $\mathrm{Sm}-\mathrm{Nd}, \mathrm{Rb}-\mathrm{Sr}$, and $\mathrm{Pb}-\mathrm{Pb}$ isotopic evidence, J. Petrol., 39, 749-783, doi:10.1093/petrology/39.4.749, 1998.

Morley, C. K.: Geoscience of Rift Systems: Evolution of East Africa, American Association of Petroleum Geologists, ISBN: 9780891810513, 1999.

Morley, C. K., Wescott, W. A., Stone, D. M., Harper, R. M., Wigger, S. T., and Karanja, F. M.: Tectonic evolution of the northern Kenyan Rift, J. Geol. Soc., 149, 333-348, doi:10.1144/gsjgs.149.3.0333, 1992.

Mosley, P. N.: Geological Evolution of the Late Proterozoic Mozambique Belt of Kenya, Tectonophysics, 221, 223-250, doi:10.1016/0040-1951(93)90334-G, 1993.

Moucha, R. and Forte, A. M.: Changes in African topography driven by mantle convection, Nat. Geosci., 4, 707-712, doi:10.1038/ngeo1235, 2011.

Mugisha, F., Ebinger, C. J., Strecker, M., and Pope, D.: Two-stage rifting in the Kenya rift: implications for halfgraben models, Tectonophysics, 278, 63-81, doi:10.1016/S00401951(97)00095-4, 1997.

Mulibo, G. D. and Nyblade, A. A.: The P and S wave velocity structure of the mantle beneath eastern Africa and the African superplume anomaly, Geochem. Geophy. Geosy., 14, 2696-2715, doi:10.1002/ggge.20150, 2013.

Müller, R. D., Sdrolias, M., Gaina, C., and Roest, W. R.: Age, spreading rates, and spreading asymmetry of the world's ocean crust, Geochem. Geophy. Geosy., 9, Q04006, doi:10.1029/2007gc001743, 2008.

Noble, W. P., Foster, D. A., and Gleadow, A. J. W.: The postPan-African thermal and extensional history of crystalline basement rocks in eastern Tanzania, Tectonophysics, 275, 331-350, doi:10.1016/S0040-1951(97)00026-7, 1997.

Nyagah, K.: Stratigraphy, Depositional History and Environments of Deposition of Cretaceous through Tertiary Strata in the Lamu Basin, Southeast Kenya and Implications for Reservoirs for Hydrocarbon Exploration, Sediment. Geol., 96, 43-71, doi:10.1016/0037-0738(94)00126-F, 1995.

Nyblade, A.: The upper-mantle low-velocity anomaly beneath Ethiopia, Kenya, and Tanzania: Constraints on the origin of the African superswell in eastern Africa and plate versus plume models of mantle dynamics, edited by: Beccaluva, L., Bianchini, G., and Wilson, M., The Geological Society of America, Special Paper, doi:10.1130/2011.2478(03), 2011.

Nyblade, A. A. and Brazier, R. A.: Precambrian lithospheric controls on the development of the East African rift sys- 
tem, Geology, 30, 755-758, doi:10.1130/0091-7613(2002)030< 0755:PLCOTD> 2.0.CO;2, 2002.

Nyblade, A. A., Owens, T. J., Gurrola, H., Ritsema, J., and Langston, C. A.: Seismic evidence for a deep upper mantle thermal anomaly beneath east Africa, Geology, 28, 599-602, doi:10.1130/0091-7613(2000)28<599:sefadu> 2.0.co;2, 2000.

Nyblade, A. A., Pollack, H. N., Jones, D. L., Podmore, F., and Mushayandebvu, M.: Terrestrial Heat Flow in East and Southern Africa, J. Geophys. Res.-Sol. Ea., 95, 17371-17384, doi:10.1029/JB095iB11p17371, 1990.

Ogola, J. S., Behr, H. J., and Van den Kerkhof, A. M.: Fluid Inclusion and Cathodoluminescence Studies on Fluorite from the Kerio Valley, Kenya, J. Afr. Earth Sci., 18, 309-323, doi:10.1016/0899-5362(94)90070-1, 1994.

Onuonga, I. O., Fallick, A. E., and Bowden, P.: The recognition of meteoric-hydrothermal and supergene processes in volcanic carbonatites, Nyanza Rift, western Kenya, using carbon and oxygen isotopes, J. Afr. Earth Sci., 25, 103-113, doi:10.1016/S08995362(97)00064-X, 1997.

Pasyanos, M. E., Masters, T. G., Laske, G., and Ma, Z.: LITHO1.0: An updated crust and lithospheric model of the Earth, J. Geophys. Res.-Sol. Ea., 2153-2173, doi:10.1002/2013JB010626, 2014.

Pickford, M.: The tectonics, volcanics and sediments of the Nyanza Rift Valley, Kenya, Z. Geomorphol., 42, 1-33, 1982.

Pollack, H. N., Hurter, S. J., and Johnson, J. R.: Heat flow from the Earth's interior: Analysis of the global data set, Rev. Geophys., 31, 267-280, doi:10.1029/93RG01249, 1993.

Price, R. C., Johnson, R. W., Gray, C. M., and Frey, F. A.: Geochemistry of phonolites and trachytes from the summit region of Mt. Kenya, Contrib. Mineral. Petrol., 89, 394-409, doi:10.1007/BF00381560, 1985.

Priestley, K. and McKenzie, D.: The thermal structure of the lithosphere from shear wave velocities, Earth Planet. Sc. Lett., 244, 285-301, doi:10.1016/j.eps1.2006.01.008, 2006.

Prodehl, C., Jacob, A. W. B., Thybo, H., Dindi, E., and Stangl, R.: Crustal Structure on the Northeastern Flank of the Kenya Rift, Tectonophysics, 236, 271-290, doi:10.1016/00401951(94)90180-5, 1994.

Ranalli, G.: Rheology and deep tectonics, Annali di Geofisica XL, 671-681, 1997.

Ranalli, G.: Rheology of the Earth, Chapman and Hall, London, 1995.

Randriamamonjy, F.: Contribution à la mise à jour de la Base De Données du SIGAfrique, 2006.

Rapolla, A., Cella, F., and Dorre, A. S.: Gravity Study of the Crustal Structures of Somalia Along International Lithosphere Program Geotransects, J. Afr. Earth Sci., 20, 263-274, doi:10.1016/08995362(95)00053-V, 1995.

Ravat, D., Lu, Z., and Braile, L. W.: Velocity-density relationships and modeling the lithospheric density variations of the Kenya Rift, Tectonophysics, 302, 225-240, doi:10.1016/S00401951(98)00283-2, 1999.

Reeves, C. V., Sahu, B. K., and De Wit, M.: A re-examination of the paleo-position of Africa's eastern neighbours in Gondwana, J. Afr. Earth Sci., 34, 101-108, doi:10.1016/S08995362(02)00011-8, 2002.

Ring, U., Schwartz, H. L., Bromage, T. G., and Sanaane, C.: Kinematic and sedimentological evolution of the Manyara Rift in northern Tanzania, East Africa, Geol. Mag., 142, 355-355, doi:10.1017/S0016756805000841, 2005.

Scheck-Wenderoth, M., Cacace, M., Maystrenko, Y. P., Cherubini, Y., Noack, V., Kaiser, B. O., Sippel, J., and Björn, L.: Models of heat transport in the Central European Basin System: Effective mechanisms at different scales, Mar. Petrol. Geol., 55, 315-331, doi:10.1016/j.marpetgeo.2014.03.009, 2014.

Schmidt, S., Plonka, C., Götze, H. J., and Lahmeyer, B.: Hybrid modelling of gravity, gravity gradients and magnetic fields, Geophys. Prospect., 59, 1046-1051, doi:10.1111/j.13652478.2011.00999.x, 2011.

Seipold, U.: Depth dependence of thermal transport properties for typical crustal rocks, Phys. Earth Planet. Int., 69, 299-303, doi:10.1016/0031-9201(92)90149-P, 1992.

Selby, J. and Mudd, G. C.: Kondoa, 1 : 250000 map sheet, Dodoma, Tanzania, 1965.

Semprich, J., Simon, N. S. C., and Podladchikov, Y. Y.: Density variations in the thickened crust as a function of pressure, temperature, and composition, Int. J. Earth Sci., 99, 1487-1510, doi:10.1007/s00531-010-0557-7, 2010.

Seton, M., Müller, R. D., Zahirovic, S., Gaina, C., Torsvik, T. H., Shephard, G., Talsma, A., Gurnis, M., Turner, M., Maus, S., and Chandler, M.: Global continental and ocean basin reconstructions since $200 \mathrm{Ma}$, Earth-Sci. Rev., 113, 212-270, doi:10.1016/j.earscirev.2012.03.002, 2012.

Simiyu, S. M. and Keller, G. R.: An integrated analysis of lithospheric structure across the East African plateau based on gravity anomalies and recent seismic studies, Tectonophysics, 278, 291-313, doi:10.1016/S0040-1951(97)00109-1, 1997.

Simiyu, S. M. and Keller, G. R.: An integrated geophysical analysis of the upper crust of the southern Kenya rift, Geophys. J. Int., 147, 543-561, doi:10.1046/j.0956-540x.2001.01542.x, 2001.

Slack, P., Davis, P., Dahlheim, H., Glahn, A., Ritter, J., Green, W., Maguire, P., and Meyer, R.: Attenuation and Velocity of $P$ Waves in the Mantle Beneath the East-African Rift, Kenya, Tectonophysics, 236, 331-358, doi:10.1016/0040-1951(94)90183-X, 1994.

Smith, M.: Stratigraphic and Structural Constraints on Mechanisms of Active Rifting in the Gregory Rift, Kenya, Tectonophysics, 236, 3-22, doi:10.1016/0040-1951(94)90166-X, 1994.

Smith, M. and Mosley, P.: Crustal heterogeneity and basement influence on the development of the Kenya Rift, East Africa, Tectonics, 12, 591-606, doi:10.1029/92TC01710, 1993.

Sonder, L. J. and England, P.: Vertical Averages of Rheology of the Continental Lithosphere - Relation to Thin Sheet Parameters, Earth Planet. Sc. Lett., 77, 81-90, doi:10.1016/0012821x(86)90134-2, 1986.

Stamps, D. S., Calais, E., Saria, E., Hartnady, C., Nocquet, J.M., Ebinger, C. J., and Fernandes, R. M.: A kinematic model for the East African Rift, Geophys. Res. Lett., 35, L05304, doi:10.1029/2007GL032781, 2008.

Stamps, D. S., Flesch, L. M., Calais, E., and Ghosh, A.: Current kinematics and dynamics of Africa and the East, J. Geophys. Res.-Sol. Ea., 119, 5161-5186, doi:10.1002/2013jb010717, 2014.

Swain, C. J., Khan, M. A., Wilton, T. J., Maguire, P. K. H., and Griffiths, D. H.: Seismic and gravity surveys in the Lake BaringoTugen Hills area, Kenya Rift Valley, J. Geol. Soc., 138, 93-101, doi:10.1144/gsjgs.138.1.0093, 1981. 
Talbot, M. R., Morley, C. K., Tiercelin, J. J., Le Hérissé, A., Potdevin, J. L., and Le Gall, B.: Hydrocarbon potential of the Meso-Cenozoic Turkana Depression, northern Kenya, II. Source rocks: Quality, maturation, depositional environments and structural control, Mar. Petrol. Geol., 21, 63-78, doi:10.1016/j.marpetgeo.2003.11.008, 2004.

Tenczer, V., Hauzenberger, C. A., Fritz, H., Whitehouse, M. J., Mogessie, A., Wallbrecher, E., Muhongo, S., and Hoinkes, G.: Anorthosites in the Eastern Granulites of Tanzania-New SIMS zircon U-Pb age data, petrography and geochemistry, Precambrian Res., 148, 85-114, doi:10.1016/j.precamres.2006.03.004, 2006.

Tesauro, M., Audet, P., Kaban, M. K., Brgmann, R., and Cloetingh, S.: The effective elastic thickness of the continental lithosphere: Comparison between rheological and inverse approaches, Geochem. Geophy. Geosy., 13, 1-18, doi:10.1029/2012GC004162, 2012.

Tesauro, M., Kaban, M. K., and Cloetingh, S. A. P. L.: Global model for the lithospheric strength and effective elastic thickness, Tectonophysics, 602, 78-86, doi:10.1016/j.tecto.2013.01.006, 2013.

Tesha, A. L., Nyblade, A. A., Keller, G. R., and Doser, D. I.: Rift localization in suture-thickened crust: evidence from Bouguer gravity anomalies in northeastern Tanzania, East Africa, Tectonophysics, 278, 315-328, doi:10.1016/S00401951(97)00110-8, 1997.

Thybo, H. and Artemieva, I. M.: Moho and magmatic underplating in continental lithosphere, Tectonophysics, 609, 605-619, doi:10.1016/j.tecto.2013.05.032, 2013.

Thybo, H., Maguire, P. K. H., Birt, C., and Perchuć, E.: Seismic reflectivity and magmatic underplating beneath the Kenya Rift, Geophys. Res. Lett., 27, 2745-2748, doi:10.1029/1999GL011294, 2000.

Tiercelin, J., Nalpas, T., Thuo, P., and Potdevin, J.: Hydrocarbon Prospectivity in Mesozoic and Early-Middle Cenozoic Rift Basins of Central and Northern Kenya, Eastern Africa, Tectonics and sedimentation: Implications for petroleum systems - AAPG Memoir, 100, 179-207, doi:10.1306/13351553M1001742, 2012.

Tiercelin, J. J., Potdevin, J. L., Morley, C. K., Talbot, M. R., Bellon, H., Rio, A., Le Gall, B., and Vétel, W.: Hydrocarbon potential of the Meso-Cenozoic Turkana Depression, northern Kenya. I. Reservoirs: Depositional environments, diagenetic characteristics, and source rock-reservoir relationships, Mar. Petrol. Geol., 21, 41-62, doi:10.1016/j.marpetgeo.2003.11.007, 2004.

Torres Acosta, V., Bande, A., Sobel, E. R., Parra, M., Schildgen, T. F., Stuart, F., and Strecker, M. R.: Cenozoic extension in the Kenya Rift from low-temperature thermochronology: Links to diachronous spatiotemporal evolution of rifting in East Africa, Tectonics, 2367-2386, doi:10.1002/2015TC003949, 2015.

Tugume, F., Nyblade, A., and Julia, J.: Moho depths and Poisson's ratios of Precambrian crust in East Africa: Evidence for similarities in Archean and Proterozoic crustal structure, Earth Planet. Sc. Lett., 355, 73-81, doi:10.1016/j.epsl.2012.08.041, 2012.

Tugume, F., Nyblade, A., Julia, J., and van der Meijde, M.: Precambrian crustal structure in Africa and Arabia: Evidence lacking for secular variation, Tectonophysics, 609, 250-266, doi:10.1016/j.tecto.2013.04.027, 2013.
Turcotte, D. L. and Emerman, S. H.: Mechanisms of active and passive rifting, Tectonophysics, 94, 39-50, doi:10.1016/00401951(83)90008-2, 1983.

Turcotte, D. L. and Schubert, G.: Geodynamics, Cambridge University Press, 2014

USGS: World Geologic Maps, http://energy.usgs.gov/ OilGas/AssessmentsData/WorldPetroleumAssessment/ WorldGeologicMaps.aspx, 2012.

Vilà, M., Fernández, M., and Jiménez-Munt, I.: Radiogenic heat production variability of some common lithological groups and its significance to lithospheric thermal modeling, Tectonophysics, 490, 152-164, doi:10.1016/j.tecto.2010.05.003, 2010.

Watts, A. B. and Burov, E. B.: Lithospheric strength and its relationship to the elastic and seismogenic layer thickness, Earth Planet. Sc. Lett., 213, 113-131, doi:10.1016/S0012-821X(03)00289-9, 2003.

Wescott, W. A., Stone, D. M., and Wigger, S. T.: Geological and geophysical reconnaissance of the Lotikipi plain of northwestern Kenya and its relationship to the northern Kenya Rift, J. Afr. Earth Sci., 21, 241-251, doi:10.1016/0899-5362(95)000766, 1995.

Wessel, P., Smith, W. H. F., Scharroo, R., Luis, J., and Wobbe, F.: Generic mapping tools: Improved version released, Eos Trans. Am. Geophys. Union, 94, 409-410, doi:10.1002/2013EO450001, 2013

Wheildon, J., Morgan, P., Williamson, K. H., Evans, T. R., and Swanberg, C. A.: Heat-Flow in the Kenya Rift-Zone, Tectonophysics, 236, 131-149, doi:10.1016/0040-1951(94)90173-2, 1994.

Wichura, H., Jacobs, L. L., Lin, A., Polcyn, M. J., Manthi, F. K., Winkler, D. A., Strecker, M. R., and Clemens, M.: A 17My-old whale constrains onset of uplift and climate change in east Africa, P. Natl. Acad. Sci. USA, 112, 3910-3915, doi:10.1073/pnas.1421502112, 2015.

Wilks, K. R. and Carter, N. L.: Rheology of some continental lower crustal rocks, Tectonophysics, 182, 57-77, doi:10.1016/00401951(90)90342-6, 1990.

Williams, L. A. J.: Geochemistry and petrogenesis of the Kilimanjaro volcanic rocks of the Amboseli area, Kenya, B. Volcanol., 33, 862-888, doi:10.1007/BF02596754, 1969.

Winn, R. D., Steinmetz, J. C., and Kerekgyarto, W. L.: Stratigraphy and Rifting History of the Mesozoic-Cenozoic Anza Rift, Kenya, Aapg Bull, 77, 1989-2005, 1993.

Woldetinsae, G.: The Lithosphere of the East African Rift and Plateau (Afar-Ethiopia-Turkana): Insights from Integrated 3D Density Modelling, $\mathrm{PhD}$, Christian-Albrechts-Universität zu Kiel, 2005.

Yuan, B., Xie, W., Liu, G., and Zhang, C.: Gravity field and tectonic features of Block L2 in the Lamu basin, Kenya, Geophys. Prospect., 60, 161-178, doi:10.1111/j.1365-2478.2011.00961.x, 2012.

Zeyen, H., Volker, F., Wehrle, V., Fuchs, K., Sobolev, S. V., and Altherr, R.: Styles of continental rifting: crust-mantle detachment and mantle plumes, Tectonophysics, 278, 329-352, doi:10.1016/S0040-1951(97)00111-X, 1997. 